
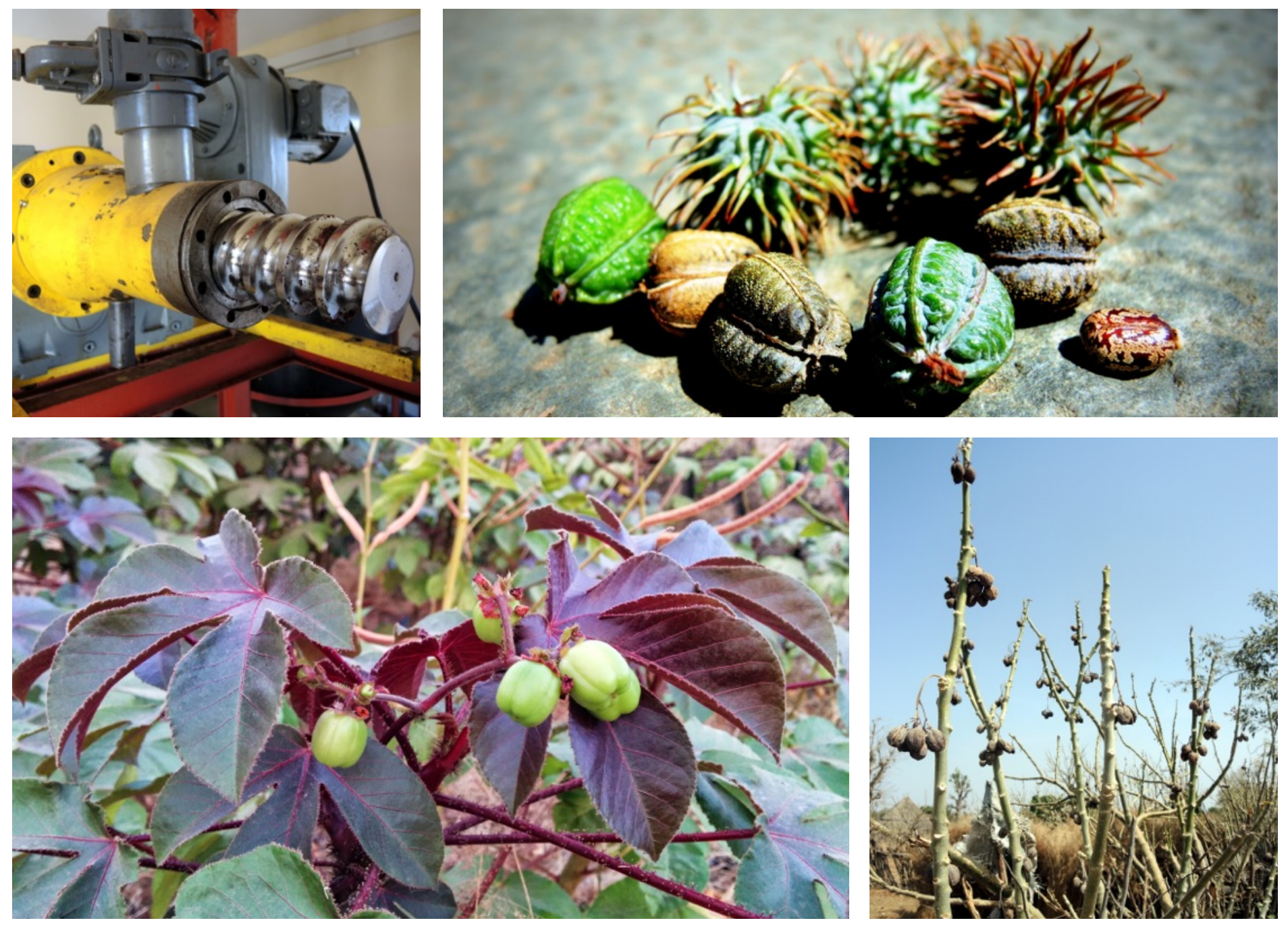

Hope or Hype?

A critical assessment of Jatropha curcas for domestic biofuel production in Senegal
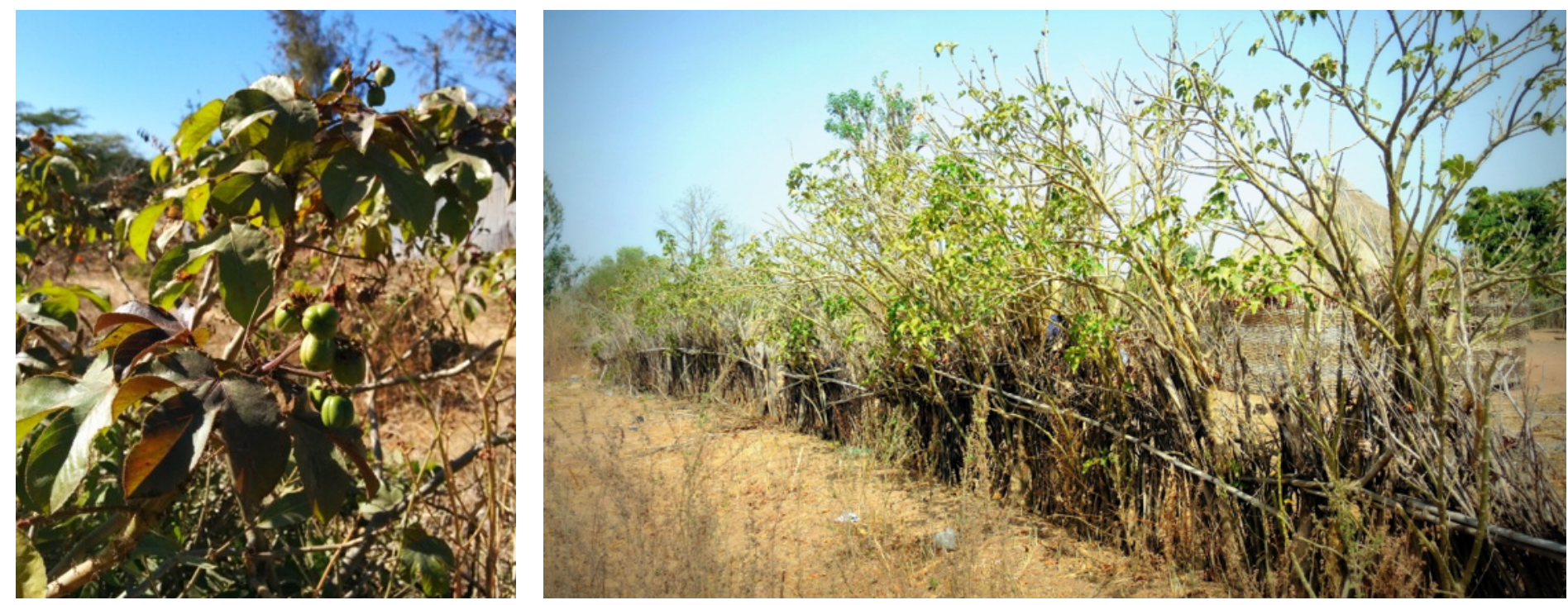


\title{
HOPE OR HYPE: A CRITICAL ASSESSMENT OF JATROPHA CURCAS FOR DOMESTIC BIOFUEL PRODUCTION IN SENEGAL
}

\author{
BY \\ DAVID CAMPBELL
}

\author{
A thesis \\ submitted to Victoria University of Wellington \\ in fulfillment of the requirements for the degree of \\ Master of Environmental Studies
}

Victoria University of Wellington 2014 


\section{Abstract}

This thesis was designed to critically test the suitability of Jatropha curcas as a plant feedstock for liquid biofuel production in Senegal. Many countries around the globe have attempted to incorporate bioenergy into their broader energy supply mix, and liquid biofuels are a key component of a low-carbon economy to replace fossil fuels for transport and electrical generation. The Senegalese government instituted a national biofuel plan between 2007 and 2012 to achieve energy independence through biofuels with an annual production target of more than a billion liters of oil. The plan was intended to reduce problems with energy scarcity and price fluctuations, contribute to local economic growth, and expand agricultural production to degraded or otherwise fallow land. The project was largely unsuccessful, and to date there has been no significant oil production from Jatropha curcas for the national energy supply.

This research study was developed to understand the key barriers to the success of this program and mitigate the mistakes of future project developers and policymakers. Preliminary literature reviews and examples from similar endeavors in other countries suggested three main barriers that would be primary determinants of success or failure: the agronomic suitability, and therefore production and yield capacity, of Jatropha curcas to the Senegalese climate; the socio-economic challenges of integrating a broad national plan with smallholder farmers and assuring that the economics are fair for both growers and buyers; and the policy framework developed by government agencies, development organizations, and commercial interests to support an emergent biofuel industry. A mixed-method research design including document reviews, interviews and surveys, and case studies was employed to answer the key questions of why and how the Senegalese biofuel program has failed to achieve its intended goals.

Results from this study indicate that Jatropha curcas is unsuitable as a plant feedstock for liquid biofuels in Senegal at this time, due to significant shortcomings in all three key categories examined. The plant is vastly underproductive and requires considerable investment in scientific improvement of yield, pest tolerance and seed oil content; the economic gain is neither adequate to justify smallholder farmers to adopt it as an alternative to existing crops nor for project developers to generate income from fuel on the open market; and supporting policy has not been consistent or favorable enough to carry this emergent industry from nascence to maturity. There are, however, encouraging signs of resilience in two particular case studies that provide insight into how future programs could be structured, most notably in the Sine-Saloum Delta region. Further research should be devoted to specific economic schemes and innovative financing options for community focused biofuel programs.

Key Words: Jatropha curcas; Senegal National Biofuel Program; Socio-economics; Agronomy; Biofuel policy 


\section{Acknowledgements}

First and foremost I would like to thank the Rotary Foundation for supporting my first year of study at Victoria University and giving me the opportunity to pursue this degree. Without their support, it is highly unlikely that this thesis would have ever been produced. I would likewise thank the Fulbright Foundation for supporting the research component of this thesis in Senegal and ensuring the completion of this degree.

My advisor, Associate Professor Ralph Chapman, has been most helpful at providing guidance from afar, and ensured that this thesis could be completed on time despite both of us being at a distance for most of the year. J'espère que nous aurons l'occasion de travailler ensemble à l'avenir.

There are many people who facilitated my research in Senegal and ensured that it will remain an influential experience in my personal and professional life, most importantly the Senegalese people. Bruno Legendre, thank you for being a wise counsel and paramount example of dedication to your principles, you inspire me to continue pursuing meaningful work. Dany Bode, I have little doubt that we will continue to cross paths in the future, and aspire to achieve your level of generosity and sense of duty to community based development. Saliou Kante, na karamoho le ti, n'se I dimbaya khonton. Lun do, n'se baro ke la le Kedougou dala. Nin sege, nin che, mbe wo tumo.

My family has without question been the greatest pillar of support, and despite the many years and long distances that have defined the journey toward this thesis, they have remained steadfastly supportive and patient. They have always pushed me to expect more from myself, and I will be forever grateful to have been gifted with so many positive influences. Thank you. 


\section{Table Of Contents}

$\begin{array}{lr}\text { Abstract } & \text { i } \\ \text { Acknowledgments } & \text { ii } \\ \text { Table of Contents } & \text { ii } \\ \text { Table of Figures } & \text { iv } \\ \text { Terms and Definitions } & \text { v }\end{array}$

Chapter 1 - Introduction, Aims and Objectives $\quad 1$

1.1 Introduction 1

1.2 Bioenergy Potential and Limitations 2

1.3 The Senegal National Biofuel Program $\quad 4$

$\begin{array}{ll}1.4 \text { Thesis Goals } & 5\end{array}$

1.5 Rationale for Research $\quad 6$

$\begin{array}{ll}1.6 \text { Thesis Overview } & 7\end{array}$

Chapter 2 - Research Design 9

2.1 Introduction $\quad 9$

2.2 Methodology $\quad 9$

2.2.1 Mixed Method 9

2.2.2 Literature Review $\quad 10$

2.2.3 Farmer Survey \& Questionnaire $\quad 10$

2.2.4 Semi-Structured Interviews

2.2.5 Case Study 11

2.3 Choice of Setting $\quad 12$

2.3.1 Personal Background $\quad 12$

2.3.2 Senegal Country Profile $\quad 13$

2.3.3 Regional Case Study Profiles $\quad 15$

$\begin{array}{ll}2.4 \text { Choice of Participants } & 16\end{array}$

2.5 Data Analysis $\quad 17$

$\begin{array}{lr}2.6 \text { Ethical Considerations } & 18\end{array}$

$\begin{array}{ll}2.6 .1 \text { Positionality } & 18\end{array}$

2.6.2 Victoria University Ethical Approval $\quad 18$

2.6.3 Confidentiality 19

2.7 Limitations $\quad 19$

$\begin{array}{ll}2.8 \text { Conclusion } & 19\end{array}$ 
Chapter 3 - Literature Review and Research Context

3.1 Introduction

3.2 International Energy Demands $\quad 22$

3.3 Bioenergy and Liquid Biofuels 23

3.4 Senegal National Energy Requirements $\quad 25$

3.5 Senegal National Energy Generation Options 26

3.6 Foundations of the Senegal National Biofuel Program 28

3.7 West African Comparisons $\quad 29$

3.8 Social and Environmental Considerations 31

3.9 Conclusion $\quad 32$

Chapter 4 - Agronomic Limitations 33

4.1 Introduction $\quad 33$

4.2 Provenance and Regional Adaptability 34

4.3 Seed Source and Yield Variability 36

4.4 Agricultural Inputs and Physical Infrastructure 39

$\begin{array}{ll}4.5 \text { Pests } & 41\end{array}$

4.6 Improved Seed Varieties $\quad 43$

4.7 Environmental Impact and Land Use Change 46

$\begin{array}{ll}4.8 \text { Conclusion } & 48\end{array}$

Chapter 5 - Socio-economic Limitations $\quad 51$

5.1 Introduction $\quad 51$

5.2 Different Approaches and Models $\quad 52$

5.2.1 Agro-Industrial vs. Permaculture-Local $\quad 52$

5.2.2 Domestic Production vs. Export Production $\quad 54$

5.3 Economic Constraints of Jatropha Oil Production 55

5.4 Social Considerations for Smallholder Farmers $\quad 58$

5.5 Alternative Value Streams for Jatropha Production 59

5.5.1 External Financing Tools $\quad 59$

$\begin{array}{ll}\text { 5.5.2 Oil Production Byproducts } & 61\end{array}$

5.6 Case Study Economics $\quad 62$

5.5.1 Case Study 1: Fatick - Technologies for Human Development (THD) 63

5.5.2 Case Study 2: Kaffrine - Africa National Oil Corporation (ANOC) 67

5.5.3 Case Study 3: Kedougou-Trees for the Future (TFF) 71

$\begin{array}{ll}5.7 \text { Conclusion } & 75\end{array}$ 
$\begin{array}{ll}\text { 6.1 Introduction } & 77\end{array}$

6.2 Underpinnings of the Senegal National Biofuel Program $\quad 78$

6.3 West African Comparisons and Collaboration $\quad 80$

6.4 Supporting Policy Structures $\quad 83$

6.5 Non-Governmental Policy $\quad 87$

$\begin{array}{ll}6.6 \text { Conclusion } & 89\end{array}$

Chapter 7 - Discussion, Recommendations \& Conclusion 91

$\begin{array}{ll}7.1 \text { Introduction } & 91\end{array}$

$\begin{array}{ll}7.2 \text { General Conclusions } & 91\end{array}$

$\begin{array}{ll}\text { 7.2.1 Central Limitations } & 92\end{array}$

A. Agronomic $\quad 92$

B. Socio-economic 93

$\begin{array}{ll}\text { C. Policy } & 94\end{array}$

7.2.2 The Importance of Data 96

7.3 Status of the Senegal National Biofuel Program 96

7.4 Food Competition and Land Use Change 97

7.5 Arguments for a Mixed-Method Interim 98

7.6 Arguments for Innovative Support Structures 99

7.7 General Recommendations 100

$\begin{array}{ll}7.8 \text { Areas of Further Study } & 101\end{array}$

$\begin{array}{ll}7.7 \text { Final Remarks } & 102\end{array}$

$\begin{array}{ll}\text { References } & 103\end{array}$

$\begin{array}{ll}\text { Appendices } & 110\end{array}$

A. Senegal National Biofuel Program $\quad 110$

B. Participant Information Sheet 116

C. Participant Consent Form 118

D. Semi-structured Interviews $\quad 119$

E. Farmer Survey and Questionnaire $\quad 121$

F. Human Ethics Committee Clearance 124 


\section{Table Of Figures}

\section{Chapter 2}

Figure 2.1: Senegal, administrative divisions 14

Figure 2.2: Fatick region $\quad 15$

Figure 2.3: Kaffrine region $\quad 15$

Figure 2.4: Kedougou region $\quad 15$

\section{Chapter 3}

Figure 3.1: World Energy Consumption 1990-2040 22

Figure 3.2: World Energy Consumption by Fuel Type 1990-2040 22

Figure 3.3: European Commission classification of first and second generation biofuels 24

Figure 3.4: Senegal national energy sources by type, 2006

Figure 3.5: National fuel expenditures, 2000-2008 25

Figure 3.6: Senegal liquid fuel requirements by fuel type, $2007 \quad 26$

Figure 3.7: Senegal electric production and transmission network 27

\section{Chapter 4}

Figure 4.1: Global Distribution of Jatropha curcas and Oil Palm, 1986 - 2007

Figure 4.2: Senegal rainfall patterns 35

Figure 4.3: Soil Types in Senegal

Figure 4.4: Jatropha projects in Senegal, 2008

Figure 4.5: Phase one agricultural inputs for Jatropha cultivation 40

Figure 4.6: Farmer outlays for Jatopha production in Senegal, years one through five $\quad 40$

Figure 4.7: Comparison of expected and actual yields in Bokhol, Northern Senegal 41

Figure 4.8: Attack by cochineal insects at a THD test plot 42

Figure 4.9: Termite attack on mature plants at an ANOC plantation in central Senegal 43

Figure 4.10: Seeds from the Africa New Oil Corporation (ANOC) plantation in Gossas 44

Figure 4.11: High performance local plants in Kafori, southeastern Senegal 45 


\section{Chapter 5}

Figure 5.1: Economic development models of Jatropha producers in Senegal 53

Figure 5.2: Economic Assumptions of the SNBP

Figure 5.3: Observed Jatropha biofuel activity in Senegal 56

Figure 5.4: Pump price for diesel fuel (US dollar per liter) in Senegal, 1992 - 2013

Figure 5.5: Projected and actual seed prices, with corresponding market oil prices 57

Figure 5.6: International ETS price trends 2010-13 60

Figure 5.7: Sales revenue from Jatropha and associated byproducts 61

Figure 5.8: Technologies for Human Development (THD) pressing facility in Fatick Region 64

Figure 5.9: THD oil press, an AXIA 4 KW model with 50,000 1/yr capacity 64

Figure 5.10: Seed and press cake storage at the THD pressing facility 65

Figure 5.11: THD oil decantation and storage tanks 66

Figure 5.12: Africa National Oil Corporation seedling nursery, Kaffrine 68

Figure 5.13: ANOC full-field plantation with $2 \mathrm{~m} \times 2 \mathrm{~m}$ spacing, year one 68

$\begin{array}{ll}\text { Figure 5.14: ANOC headquarters in Gossas } & 69\end{array}$

Figure 5.15: ANOC full-field plantation in year five $\quad 70$

Figure 5.16: Above average Jatropha agronomic performance, Kedougou 72

Figure 5.17: Unharvested Jatropha seed in the village of Kafori, Kedougou 72

Figure 5.18 : Jatropha being used as a live fence in the village of Kafori, Kedougou 73

Figure 5.19: Trees for the Future extension agent Karamba Diakhabi and farmers in Kafori 74

\section{Chapter 6}

Figure 6.1: Jatropha industry support network maturity in Benin, Burkina Faso, Mali and $\quad 80$ Senegal, measured by 6 categories: Extraction Tools, Processing Equipment, Post-press conditioning, Quaility control and standardization, Economic maturity, and Intellectual Property Exchanges

Figure 6.2: Jatropha cultivation and production in the JatroREF network, West Africa 81

Figure 6.3: West African biofuel programs and expected fuel production outcomes 82

Figure 6.4: Combination framework of policy incentives as a function of technical maturity 84

Figure 6.5: Fuel price structure in Mali and Burkina Faso for DDO (straight vegetable oil) 86 and Gasoil (diesel); prices in FCFA. 


\section{Terms and Definitions}

ANCAR: National Rural and Agricultural Advisory Agency

ANOC: Africa National Oil Corporation

CRES: Consortium for Economic and Social Research

ENDA: Environment and Development Action

Feedstock: raw material to supply or fuel a machine or industrial process. Jatropha is the primary biodiesel feedstock under consideration in this report.

ISRA: Senegalese Institute for Agricultural Research

MOA: Ministry of Agriculture

MFP: Multi-Function Platform

OECD: Organization for Economic Cooperation and Development

RDRD: Regional Department for Rural Development

SNBP: Senegal National Biofuel Program

TFF: Trees for the Future

Transesterification: The reaction of an ester with an alcohol in order to replace the alkoxy group;

it is used in the synthesis of polyesters and in the production of biodiesel

THD: Technologies for Human Development

UNDP: United Nations Development Program

WHO: World Health Organization 


\section{Chapter 1 - Introduction, Aims and Objectives}

\subsection{Introduction:}

As we move into the 21st century, both emerging and industrialized nations face a difficult proposition: maintain economic growth and increase standards of living without driving irreversible and potentially catastrophic climate change. As economic activity increases, so does the rate of consumption, and by proxy, energy use. This in itself does not have negative consequences; rather it is the source of our energy that can cause unmitigated climate change. Our modern industrialized society has been built primarily with energy derived from fossil fuels, the combustion of which releases carbon dioxide and other greenhouse gases into the atmosphere, which the scientific community has now conclusively agreed is the major driving force behind current global warming trends (IPCC, 2013). It remains to be seen how damaging these changes will be, as there is still a degree of uncertainty in climate sensitivity and the associated effects (Ackerman, F., Stanton, E., DeCanio, S., et al, 2009; Rahmstorf, 2008; Weitzman, 2011). However, it is now more certain than ever that anthropogenic greenhouse gases will be the major driving force in these changes, and this provides a strong incentive to divest ourselves of the carbon-intense activities associated with our modern world.

There are a number of alternatives for generating energy to replace the current fossil fuels - namely coal, oil and natural gas - that are projected to constitute the majority of global energy supply through 2035 (IEA, 2011). Generating energy for consumption on local and international electrical power grids can be performed by an increasingly cost competitive blend of renewable sources including solar, wind, hydro, geothermal and in some cases nuclear. Studies have quantitatively illustrated how individual nations and groups of nations could supply the entirety of their electrical power needs from renewable energy sources alone (IPCC, 2011; Sims et al, 2011; Nordel, 2008; IEA, 2010; Strauss, 2009). Liquid fuels for transport, heating and a myriad of commercial and industrial uses cannot be generated from the aforementioned sources without major conversion losses, and thus a renewable source for liquid fuels must be developed to mitigate the large carbon emissions from this sector. The developed economies of the world have an impetus to improve energy efficiency measures and replace existing power generating capacity with clean alternatives, but developing nations have an opportunity to bypass carbonintensive fuels and transition directly to renewable sources of energy - not only improving their domestic supply and hedging against volatility in international energy markets, but moving towards a standard of renewable energy for base load use. Climate change will have the most direct effect on developing nations, therefore carbon emissions reduction is in their best interest. 


\subsection{Bioenergy Potential and Limitations}

Biomass is currently the largest renewable energy contributor to the global primary energy supply and greatly eclipses the other renewable energy sources being implemented (Chum et al., 2011; IEA Bioenergy, 2009). Primarily used for cooking and heating in developing nations, there is a growing proportion allocated to electricity production and combined heat and power functions in advanced economies as well. Modern procurement of biofuel in the form of ethanol and biodiesel offers the potential for liquid fuels for transport, but the transformation of farmland for fuel crops has been a matter of significant controversy (Keyzer et al, 2008; Harvey \& Pilgrim, 2011). Cellulosic and high-oil content feedstocks such as prairie grasses and rapeseed offer particular promise, but much research and development is still required before they can be considered viable contributors (Laser et al., 2009; IATA, 2009). A particular advantage of biofuels is that feedstocks are extremely varied and found across the globe, encompassing animal waste and fat, sugar and starch crops, sewage and sludge, microalgae and bacteria, as well as wood, straw and certain streams of municipal solid waste. The opportunities for innovation are also vast, with potential for the conversion of bioenergy through direct combustion, fermentation, gasification and pyrolysis, or anaerobic digestion, among others.

Potential for further development of bioenergy is difficult to evaluate because of several factors that could limit its expansion, such as water availability, soil degradation, land management and competition with food crops (Berndes et al., 2003; Berndes, 2002; Molden, 2007; De Fraiture et al., 2008). The availability of water is an especially important factor that is guiding research towards highly resilient, drought tolerant, yet energy rich feedstocks that could be produced on marginal land not in competition with existing farmland (UN Water, 2007). This ambition to find and develop locally appropriate plant feedstocks for biofuel led to the commercial cultivation of Jatropha curcas, despite it being a wild plant. Efforts to develop feedstocks out of products currently considered waste offer significant opportunities as well. The effects of climate change will further complicate bioenergy production, as shifts in rainfall patterns and regional climatic changes render some agricultural areas unproductive. Bioenergy has the distinction of being the most readily available renewable energy source, yet fuels derived using modern techniques, such as ethanol and biodiesel, require greater expertise, research and development before they can contribute significantly to the world's energy supply.

Jatropha curcas, a bushy plant belonging to the Euphorbiaceae family native to Central America, has been identified as a potential contributor to primary energy supply because of its oil-rich seeds and resilient growth characteristics. It has been promoted due to its ability to grow

in challenging climatic zones and poor soils, often planted for the purpose of erosion control and later to produce seeds for liquid biofuels (Gübitz et al, 1999; Heller, 1996). Its spread around the world was encouraged due to its usefulness as a natural hedge for agriculture and the insecticidal 
and fungicidal properties of its oil. It can now be found throughout the tropical zone, from Central America to Africa, Asia and the South Pacific (Openshaw, 2000). The oil contained within its seeds has unique chemical properties that make it valuable for many applications including as a traditional medicine and homemade soap substrate. It has been used as a replacement for kerosene and diesel, blended with other fuels and used as a substitute for other biomass fuels such as firewood (Gübitz, 1997). Over the past decade or so there has been a rapidly expanding incidence of Jatropha being exploited for large scale plantations, often on tracts of wasteland, and promoted to smallholder farmers as a lucrative cash crop (Francis, 2005; Sharma et al, 1997; Foidl, 1997). Despite these developments, the results of widespread Jatropha cultivation have been less than favorable, and there is considerable debate as to whether or not these projects can be successful, and more importantly, whether they are a responsible proposition for farmers in poor nations.

Many studies have cast doubt on the initial promise of Jatropha for large scale energy production, claiming that its actual performance is far below the expected levels promoted by early adopters and encouraging further testing and analysis before calling for expanded use. Early enthusiasm for the crop can be seen in the rhetoric of academics who were eager to promote its use as an energy feedstock, as exemplified by Joachim Heller (1996), who summarized that "the only real limitation of this crop is that the seeds are toxic and the press cake cannot be used as a fodder." However, a comprehensive scientific and economic analysis of Jatropha by Keith Openshaw (2000) a few years later was far more critical, concluding that, "if the full potential of the plant is to be realized, much more research is required into the growing and management of Jatropha curcas and more information is needed on the actual and potential markets for all its products." Despite the caution urged by some academics who were not convinced of the full potential of this plant feedstock, national governments, development agencies, private foundations and independent entrepreneurs were ready to devote significant resources to exploit Jatropha curcas for domestic energy production. 


\subsection{The Senegal National Biofuel Program}

The principal objective of the Senegal National Biofuel Program (SNBP), coordinated under the Ministry of Agriculture and the Senegalese Institute for Agricultural Research (ISRA), was to achieve national self sufficiency in biodiesel over the course of five years, with a target annual production of 1,190,000,000 liters of crude Jatopha oil, translating to roughly 1 billion liters of refined biodiesel for transport and stationary power generation. Launched in 2007, the program was designed to evolve in three distinct phases: (1) intensive seed production, (2) transformation to oil, and (3) national distribution; reaching full production capacity in 2012.1

The SNBP was designed by evaluating the current and projected energy needs of the country in 2007, and setting production targets to meet these thresholds, rather than evaluating the technical capacity of the assigned agencies to orchestrate the program or the ability of the communities responsible for the production to achieve the expected results. For this reason, many of the goals outlined in the project plan are very broad, with little consideration paid to the vast differences in the rural communities that would supply the Jatropha feedstock for the national energy supply. To elucidate this point, the plan calls for a cultivated area of 321,000 hectares to meet the biodiesel requirements of the country. To achieve this goal, each rural community ${ }^{2}$ in the country was expected to put 1,000 hectares of Jatropha under cultivation, regardless of their location and growing potential, socio economic preconditions or the support structures necessary to guarantee success. This approach assumed that all areas of the country would be equally capable, and have the resources required, to rapidly expand agricultural production in addition to their traditional activities for subsistence and commercial gain.

The finer points of the Senegal National Biofuel Program will be covered in greater detail in subsequent sections of this report; however it must be clear from the outset that the design and expected outcomes of the plan all rely on best case scenarios in terms of implementation, propagation and performance of Jatropha curcas, despite warnings from academic sources and similar projects in other countries which did not validate these expectations. The program posted broad and ambitious goals in agricultural, social and economic terms that would have profound effects on the Senegalese economy. The key expected outcomes are highlighted below:

- One billion Jatropha curcas plants will be grown in vitro, in nurseries and with cuttings

- 321,000 hectares will be cultivated (1,000 per rural community)

\footnotetext{
1 The complete edition (in French) of the Senegal National Biofuel Program can be found in Appendix A. Elements included in this report have been translated and in some cases paraphrased from the original.

${ }^{2}$ Communautés rurales are the fourth tier administrative designation in Senegal, behind communes, departments and regions. In 2007, there were 321 rural communities in the country.
} 
- Representatives of the local districts will be trained in cultivation techniques and long term care techniques for the first 18 months after planting

- One billion one hundred and ninety million $(1,190,000,000)$ liters of Jatropha oil will be be produced to meet national biodiesel requirements

- Bioelectricity will be produced in local refining facilities

- The Senegalese national energy bill will be reduced

- Household energy bills will be significantly reduced, realized due to the comparatively low cost of biodiesel relative to fuels available on the market

- 100,000 jobs will be directly created from the project

- The technical and organizational capacity of local districts will be reinforced

- Agro-industrial centers will be established in each administrative region

- Agricultural income will be increased and diversified from the bioenergy sector

- Improved living conditions for rural populations and a significant reduction in the incidence of poverty

- A reduction of the national debt from an improved trade balance in energy.

- Guaranteed seed prices for farmers to ensure stability of production

- Secured prices for biodiesel sales to State institutions

- Farmer assistance through the provision of agricultural inputs and technical expertise

- Guarantee of domestic oil processing and production.

\subsection{Thesis Goals}

The central goal of this study was to test the suitability of Jatropha curcas as a biofuel feedstock in Senegal, in the context of the Senegal National Biofuel Program. In particular, this research project focused on the three areas - agronomic, socio-economic and policy limitations - that were consistently problematic in related projects. To date, no final report or summarizing publication has been produced to evaluate the success of the SNBP, slated to be fully operational in 2012. Various intermediate reports have been produced by consultants and independent evaluating bodies highlighting areas of concern (ENDA, 2010; Simpson, 2009; IPAR, 2012), but little is known about the status of the major goals highlighted in the previous section. Without a critical performance assessment of this bold national plan, it is difficult to measure the areas of success that should be seized upon and developed or replicated, just as it is impossible to judge the failures that could be improved upon. 
The body of knowledge concerning Jatropha curcas as a biofuel feedstock is still relatively narrow, and this thesis seeks to contribute to the field and provide a basis for future project planners and policymakers drawing from real experiences. The most critical questions that this thesis aims to address are the how and the why concerning the results of the SNBP, and particular attention will be paid to case studies from within Senegal that could provide important insight for best practices. By gathering and examining information from a wide spectrum of sources, from top level policy makers, academics and program directors to regional technical advisors and individual farmers working to incorporate Jatropha into their landholdings, this study hopes to produce a holistic synthesis of the program's results.

\subsection{Rationale for Research}

Senegal is not the sole country to have experimented with bioenergy to contribute to its national energy supply goals. Ambitious projects have been implemented in the Americas, Europe and Asia with mixed results. In fact, there are many African countries that preceded Senegal in pursuing Jatropha curcas as a major energy feedstock for biodiesel, but there were already many signs that it would not prove to be a successful endeavor even as the SNBP was conceived. A highly critical assessment of the national bioenergy program in Kenya by the German Technical Cooperation ${ }^{3}$ completely discredited promoting Jatropha for smallholder farmers, and used extensive farmer surveys to illustrate that its promotion was actually damaging to farmers in the long run (GTZ, 2009). In light of this and similar reports, it is unclear why the Senegalese government decided to move ahead with the SNBP without further advanced study or consideration of other potential crop feedstocks. In addition to the central questions regarding agronomy, socio economics and policy, the present study will address the following points:

- Why was the Senegalese National Biofuel Program constructed as it was, even as the viability of Jatropha curcas as an oilseed crop was being called into question elsewhere?

- Why was Jatropha pursued in preference to other alternatives?

- Where were the targets for the National Program derived from, and could there have been greater success if they had been set differently?

- Has the National Bioenergy Policy been sufficient and adaptive?

- What lessons can be learnt for future projects?

${ }^{3}$ Jatropha Reality Check, produced by the German Technical Cooperation in partnership with Endelevu Energy, the World Agroforestry Center and the Kenya Forest Research Institute, examined Jatropha curcas,, Castor and Croton for their socioeconomic suitability as oilseed crops, and found all three deficient under current market conditions. 


\subsection{Thesis Overview}

Chapter Two introduces the research design for the thesis. It explains the mixed methodology employed and the choice of Senegal as a field site for this study. It discusses the choice of participants, the ethical considerations and matters of confidentiality that are important features of the research. The limitations and scope of the study are also delineated.

Chapter Three provides an overview of the relevant literature and provides context for the analysis of biofuels in Senegal. It begins by highlighting international examples of biofuel initiatives and the rationale behind the existence of such programs. This is followed by a brief discussion of the Senegalese energy generation landscape and the renewable energy options at its disposition, as well as several West African examples. Social and cultural considerations relevant to the research are also discussed.

Chapter Four addresses the first of the three primary areas of focus in this thesis: the agronomic limitations of Jatropha cultivation in Senegal. Using a combination of primary and secondary data, this chapter provides an in-depth examination of the potential of Jatropha in agronomic terms. The background and provenance of Jatropha are discussed in greater detail, as well as the important conditions that have influenced the crop's performance in Senegal. The environmental impact of a national biofuel program and the implications this has on the debate over food versus fuel are also examined.

Chapter Five addresses the most important factor under examination in the thesis: the socio economic limitations of Jatropha cultivation in Senegal. It covers the different economic models proposed and tested during the implementation of the National Program, comparing local vs. commercial production and domestic supply vs. export supply. An economic analysis of the Jatropha value chain is presented, with examples from literature, farmer surveys and interviews with project developers. Three case studies are presented to shed light on the only remaining Jatropha projects in the country to understand the conditions that led to their success. Their advantages and disadvantages are presented at length, and the socio economic repercussions of these choices examined.

Chapter Six addresss the final area of focus in this thesis: the policy limitations of Jatropha cultivation in Senegal. Here the report discusses the policy that was established to support the Senegal National Biofuel Program, and other political structures that were developed to nurture it. Using supporting literature and interviews with key policymakers, the adequacy of the policy is discussed. The policies of private Jatropha project developers and non-governmental actors 
are also addressed. Finally, the roles and implications of carbon credits and national fuel taxes are presented.

Chapter Seven presents relevant discussion and conclusions concerning the Senegal National Biofuel Program. This chapter assesses the most important points from the research project and provides a frank evaluation of Jatropha curcas as an oilseed biofuel feedstock. The agronomic, socio economic and policy limitations of Jatropha cultivation in Senegal are reviewed, followed by final remarks concerning the strengths and limitations of the study.

Chapter Eight offers recommendations and alternatives in light of important conclusions from this research. A primary goal of this study was to provide guidance to future project planners and policymakers so as to help them avoid replicating mistakes in kind. It takes into consideration alternative energy crops that could have been substituted for Jatropha, as well as other renewable energy sources that could suit the Senegalese climate and context.

Recommendations on how to adapt to current project limitations and proceed with the Senegal National Biofuel Program are offered as a final word. 


\section{Chapter 2 - Research Design}

\subsection{Introduction}

This chapter provides an overview of the research design of the study. It begins with a discussion of the methodology employed and the choice of research tools used to test the suitability of Jatropha curcas for the Senegal National Biofuel Program. A justification for the choice of setting is presented, and a preliminary profile of Senegal offered to orient the reader for the remainder of the report. This study had several ethical considerations, as well as confidentiality issues regarding sensitive economic data, both of which are discussed in this section. Finally, the scope and limitations of the study are explained as a conclusion.

\subsection{Methodology}

The methodology for this study was adapted and developed from an extensive literature review and based upon the best practices of several prior research projects conducted on Jatropha curcas in East and West Africa. In many cases, studies that were either too heavily quantitative or qualitative failed to capture the most salient issues, and it was therefore determined that a mixed method approach was most appropriate to capture the concrete and nuanced elements of this research.

\subsubsection{Mixed Method}

Mixed methods research can be formally defined as the class of research where the researcher mixes or combines quantitative and qualitative research techniques, methods, approaches, concepts or language into a single study (Johnson, 2004). This methodology is expansive, inclusive and pluralistic, and allows the researcher a measure of pragmatism when determining the best approach for answering questions that may not be easily addressed through a single method. This research design gives a researcher the latitude to incorporate the particular strengths of both quantitative research, such as deduction, confirmation, thesis testing and standardized data collection; as well as qualitative strengths, such as inductive reasoning, discovery and exploration, theoretical construction and nuanced interpretation. According to what Turner (2003) calls the fundamental principle of mixed research, one should collect data using different strategies, approaches, and methods in such a way that the resulting mixture or combination is likely to result in complementary strengths and a superior result. 
A mixed methodology was the most appropriate approach to understanding the key questions of this study. There were important points that needed to be validated through data; such as yield, seed oil content and the incidence of water sources and farm implements, and others that were impossible to ascertain through quantitative data collection alone; such as political persuasions, the cultural acceptance of fuel crops or the impact of fluctuations in annual market forces that became major determinants in the project. Both forms of data collection were performed concurrently, which makes sense when time limitations prevent a linear or ordered research structure (Johnson \& Christenson, 2004; Tashakkori \& Teddlie, 1998). The study progressed in three distinct phases: identifying the research objective; data collection, both qualitative and quantitative; and synthesis/analysis.

\subsubsection{Literature Review}

Successive literature reviews were an important component of this research, and contributed to the content of the farmer surveys and the semi-structured interviews that would constitute the primary data for analysis. When performing research in developing countries it is sometimes very difficult to find a comprehensive body of work from a distance, and therefore it was challenging to perform a thorough literature review outside of Senegal in advance of the research period. Much of the literature that lent the most insight into the data collection phase was not listed in online journals or available from traditional scholarly archives, and was in the form of copy reports obtained from government agencies and non-governmental organizations. In addition, sensitive economic evaluations and reports were provided by several private project developers, providing evidence on the economic challenges inherent to the cultivation of Jatropha in West Africa. Literature was used in the data analysis to give perspective on the study's findings that had regional or international dimensions.

\subsubsection{Farmer Survey \& Questionnaire}

A farmer survey was developed to create the primary basis for qualitative analysis in the sections of the report concerning agronomic and socio-economic limitations of Jatopha curcas in Senegal. A questionnaire was added to the survey to allow for more open-ended responses that would add further weight to the quantitative findings. This survey was built using similar multivariable studies conducted in East and West Africa (GTZ, 2009; Coulibaly, 2013) and using input from the literature review. The farmer survey was intended to shed light on the basic socioeconomic situation in the field sites where Jatropha was being cultivated, and collect information on crop performance, yield, and economic activity. A preliminary section concerns the farmer's general demographic information, followed by sections regarding land use, traditional agricultural activity, and finally any biofuels activity both predating and following the Senegal National Biofuel Program. A full copy of the survey can be found in Appendix E. 
The farmer survey was constructed to take approximately 30 minutes, and was therefore unobtrusive enough to be performed in the farmer's fields, at their house, or in an organized setting. Because this research was designed to be conducted along the entire breadth of the country, it was important that it be comprehensive yet concise, so as to allow a single researcher to quickly move from one site to the next while capturing the most salient information. Because of this time constraint, certain questions had to be omitted from the farmer survey. A future study that could track more longitudinal information would clearly provide a more complete perspective on the issues addressed.

\subsubsection{Semi-Structured Interviews}

The semi-structured interviews employed for this research were built from an extensive literature review, and were designed to elicit important qualitative data most critical for the sections regarding the socio-economic and policy limitations of Jatropha curcas in Senegal. These interviews were conducted with academics who have been working in the field of bioenergy and renewable energy in the national and regional context at Cheikh Anta Diop University in Dakar; with policy experts who drafted the original National Biofuel Program; with project developers, financiers and entrepreneurs who were formerly or presently active in the biofuel economy; and with governmental officials attached to or affiliated with agencies that currently or formerly managed the structure of the program. These interviews were designed to delve into the complex political, organizational, legal and technical elements of the program and provide qualitative support for the quantitative data derived from the farmer surveys.

The semi-structured nature of the interviews, designed to be conducted in approximately 30 minutes, allowed them to take their own course depending on the interviewee's area of expertise. Each started formally with generalized questions related to the biofuel industry and the interviewee's background to contextualize their answers, and eventually led to market related content and resource mobilization, concluding with comparisons to international indicators and influences. These interviews were conducted in tandem with the farmer survey over the course of several months and in no pre-set order. A particular challenge in delivering these interviews was simply guaranteeing the presence of the interviewee on the assigned date and time. A full copy of the interview questions can be found in Appendix $C$.

\subsubsection{Case Study}

Among the areas that were profiled for this report there were three cases that appeared to be particularly useful for the purposes of this study. They have been elaborated upon in more detail so as to provide additional clarity on the successes and failures of certain projects all operating under the Senegal National Biofuel Program. According to Yin (2003) a case study design should 
be considered when: (a) the focus of the study is to answer "how" and "why" questions; (b) the investigator cannot manipulate the behavior of those involved; (c) one wants to cover contextual conditions because it is believed they are relevant to the phenomenon under study (Baxter, 2008). For this study in particular, a multiple case study design was required to draw forth the similarities and differences from disparate parts of the country that were dealing with a combination of contextual issues. Doing so allowed critical analysis both within and across settings, but all within the broad underpinnings of the central thesis goals.

\subsection{Choice of Setting}

The decision to perform this research in Senegal was made for multiple reasons, both personal and practical. Senegal is a country that struggles with multiple grave environmental issues, from overpopulation and deforestation, to water and food shortages, environmental degradation and habitat loss, to energy generation and distribution. It is a country that is highly vulnerable to climate change and is actively pursuing new policies and practices to adapt to its many challenges. The projected completion of the Senegal National Biofuel Program in 2012 was a major determinant of this research study, as it provided the impetus to measure the results of such a far reaching project.

\subsubsection{Personal Background}

Senegal was particularly relevant to me as a researcher due to the fact that I had lived and worked in the country for 2 years between 2009 and 2011. Immersed in a rural community in southeastern Senegal, I had been exposed to the language and culture, the challenges associated with working in such different circumstances, and seen first hand the need for community-based economic opportunities. As a volunteer with the United States Peace Corps, I had worked with farmers and micro-finance organizations to provide advice and in some cases financing to promote grassroots projects in agriculture, small business creation, and simple irrigation. I was exposed to Jatropha curcas indirectly through other volunteers who were extending it as a live fencing material and for reforestation projects in the region. Its potential for biofuel was recognized but there were no support mechanisms in place to help farmers transform the seeds into oil and the oil into biodiesel, so it was used mainly as a hedge for traditional food crops.

When settling on a field site for this research, there were many options available to me, as Jatropha is cultivated and similar objectives are being pursued throughout the tropics. Using Senegal was an obvious choice as it allowed me to perform my research with a facility that would not have come so easily in a new setting. Cultural expectations are very important when working in these communities and performing interviews, and my ability to communicate in the 
local languages allowed far more access than I would have achieved had I chosen a site in, for example, Southeast Asia or the Pacific. Fluency in French allowed me to participate and engage in more formal settings, while a solid understanding of the Wolof, Pulaar and Malinke languages proved invaluable during field excursions ${ }^{4}$.

\subsubsection{Senegal Country Profile}

Senegal is the westernmost country in Africa, bounded by the Atlantic Ocean to the west, and bordering Mauritania, Mali, Guinea and Guinea Bissau to the North, East and South, respectively. It is a member state of the Economic Community of West African States (ECOWAS) and the African Union (AU). Senegal achieved independence from France in 1960, but still maintains close economic and political ties with its former colonizer. Senegal has been a republican democracy since its independence, and has remained uncommonly stable by West African standards, having never experienced hostile government takeovers through political or military coups. Senegal has a land area of nearly 197,000 square kilometers (76,000 sq mi), and an estimated population of 13 million. The population is increasingly concentrated in large urban areas in the west, most notably the capital city of Dakar, with an estimated population of 4 million inhabitants (ENDA, 2010). The climate is sub tropical with two seasons: the extended dry season and the short but intense rainy season.

Senegal lies squarely in the Sahel, the arid borderland between the Sahara desert to the north and the more tropical and forested countries to the south. There are three principal rivers, the Senegal, Gambia and Casamance, that provide opportunities for flood plain agriculture and irrigation, as well as the smaller Sine Saloum river system which opens into a wide delta in the center of the country. Outside of these areas the county is reliant on rainfall for agriculture, which is generally limited to the months between June and October. The difference in rainfall from the north of the country to the south is significant, with a range of as little as $250 \mathrm{~mm}$ on the northern border to $1500 \mathrm{~mm}$ in the far south (CIA, 2009; Dia, 2010).

This study was conducted in the principal agrarian zones conducive to the cultivation of Jatropha curcas, extending south from the capital city of Dakar. Although there were examples of Jatropha being grown using irrigation on the Senegal river in the north, these were met with significant challenges and no longer existed at the time of this research. The regions with the heaviest concentration of Jatropha plantation included Thies, Fatick, Kaolack, Tambacounda and Kedougou, which together span the center of the country from west to south-east.

\footnotetext{
${ }^{4}$ French is the Official language of Senegal, and is spoken and recorded for all official proceedings. Wolof is the National language of Senegal, and is the most common local language spoken across the country. There are several other dominant languages spoken in the regions more distant from the capital, including Pulaar, Pula Futa, Malinke, Mandinka, Sereer, and Jalonke.
} 

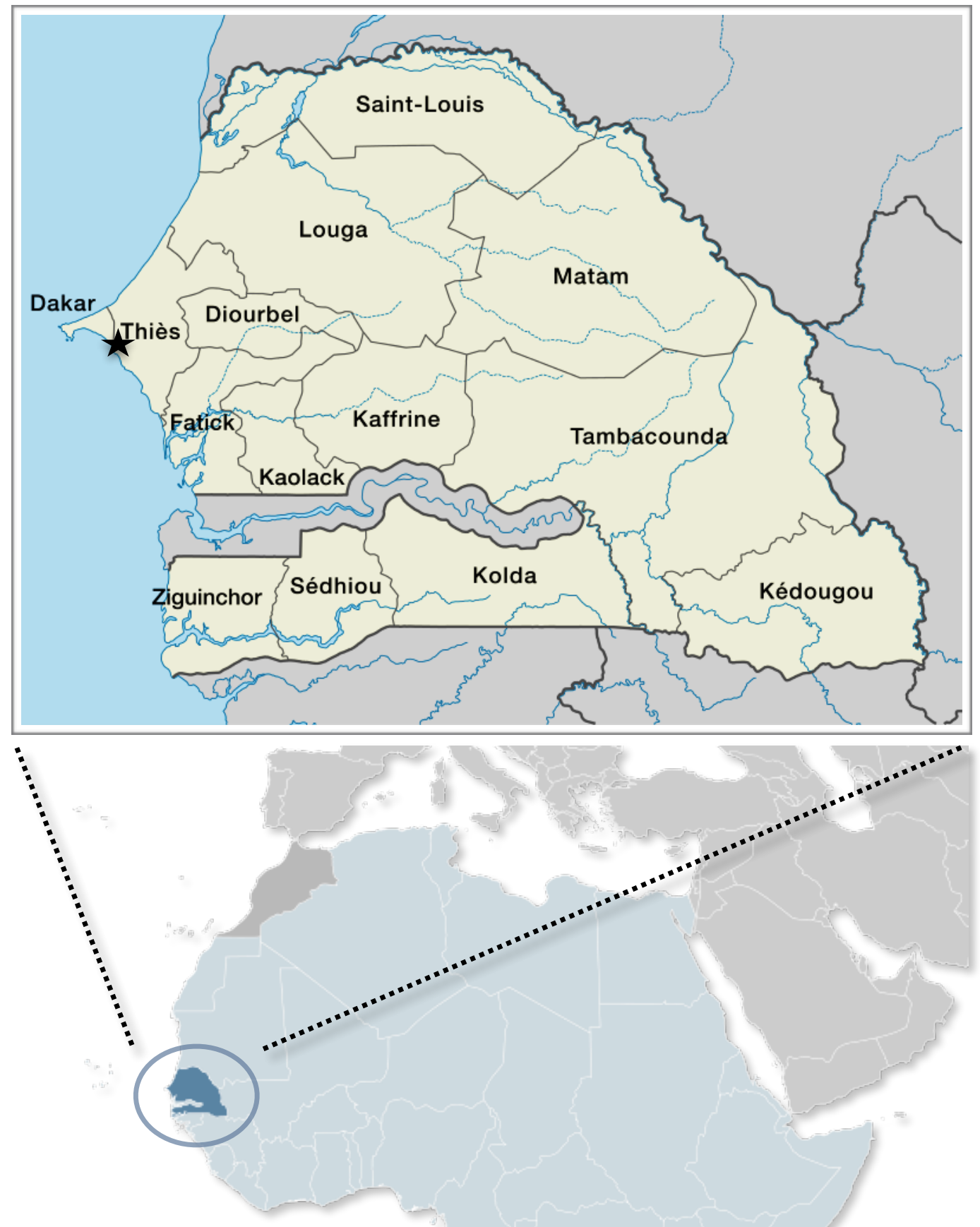

Figure 2.1: Senegal, administrative divisions.

Source: Agence National de la Statistique et de la Demographie Senegal. www.ansd.sn

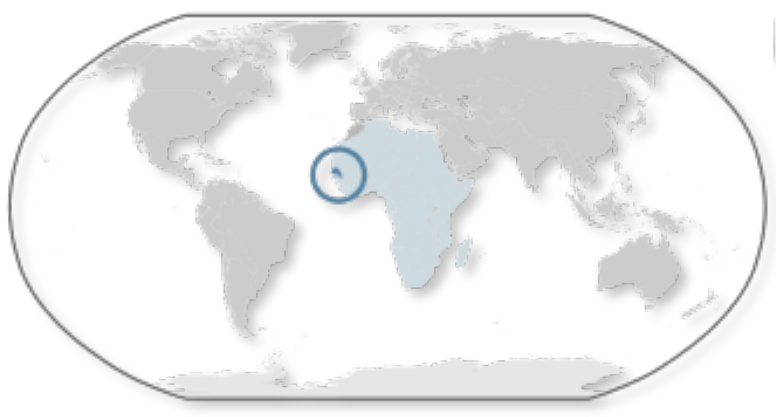




\subsubsection{Regional Case Study Profiles}

Three case studies are highlighted in this report, and were selected after extensive field sampling during the course of this research. The cases that are examined more closely come from three regions extending east from the capital, and are subject to a unique combination of advantageous and disadvantageous traits that have contributed to the overall success or failure of Jatropha propagation in those areas.

Fatick region, just east of the capital and the most densely populated, has the highest concentration of smallholder farmers active in the cultivation of Jatropha for biofuel. Its proximity to the capital provides more direct access to important energy markets, and the projects developed in this area have a strong focus on local population engagement.

Kaffrine, in the center of the country, has the most land area under cultivation, and is focused on a large scale plantation style reminiscent of the groundnut plantations that formerly occupied this area. It is close enough to the major population centers to be an energy supplier, but provisioning local water pumping stations is the central challenge.

Kedougou, the country's newest administrative region in the southeast, is the least densely populated, yet has a strong traditional understanding of Jatropha as a live fence. These three regions were not preselected for their suitability as case studies, but rather emerged as the best indicators of key success factors with regards to the Senegal National Biofuel Program during scheduled field visits.

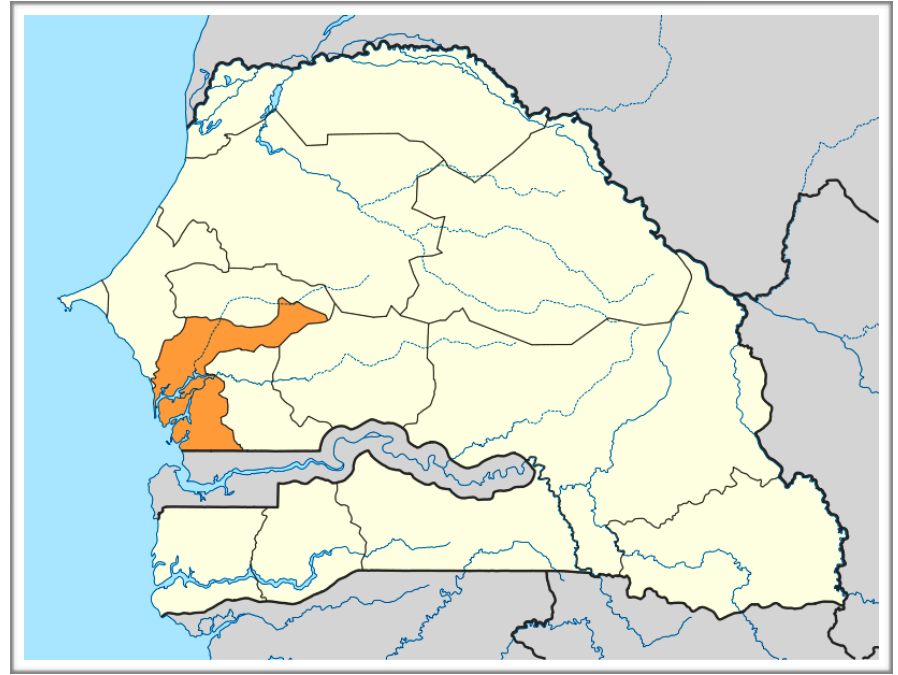

Figure 2.2: Fatick region

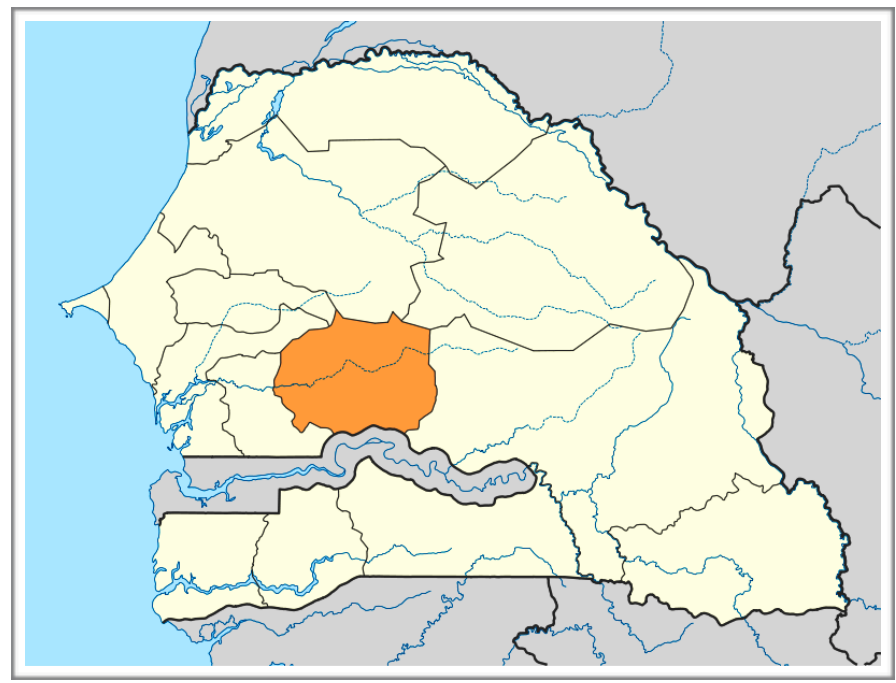

Figure 2.3: Kaffrine region

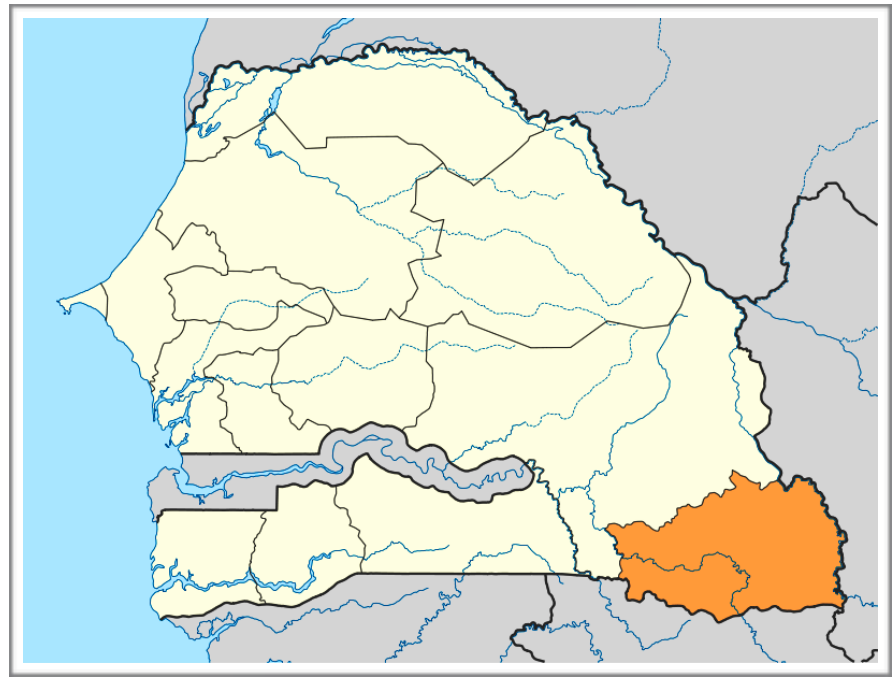

Figure 2.4: Kedougou region 


\subsection{Choice of Participants}

The selection of participants for this study was reflective of the need to collect a broad sample of qualitative and quantitative data from a variety of sources. To appropriately evaluate the Senegal National Biofuel Program and the performance of Jatopha curcas as a crop feedstock, it was important to incorporate perspectives from stakeholders that had been on both sides of its implementation. The key themes evaluated by this research study - the agronomic, socio economic, and policy limitations of Jatropha for the SNBP - were the major drivers behind selection of interview and survey participants.

In terms of the agronomic and policy limitations, feedback was sought from those who had been directly or indirectly involved in crafting the Senegal National Biofuel Program at the governmental and agency level, as well as the farmers and project leaders who were tasked with putting it into practice. Policy makers with the Ministry of Agriculture (MOA), the Senegalese Institute for Agricultural Research (ISRA), the National Rural and Agricultural Advisory Agency (ANCAR), and the Regional Department for Rural Development (RDRD) were central to the cultivation and distribution of seedlings in the project, and soliciting their feedback was a primary goal. The directorial offices for all of these agencies were located in the capital, Dakar, and interviews were conducted either on site or during inter-agency meetings and conferences. Affiliate agencies, such as Environment and Development Action (ENDA) and the Consortium for Economic and Social Research (CRES), who had performed independent reviews of the program were also engaged to ensure a balanced and unbiased set of responses. A significant contribution to this portion of the research came from the members of the professional working group JatroREF, a loosely affiliated network of experts from across West Africa with practical knowledge of Jatropha curcas.

The socio economic indicators required responses from a diverse set of respondents as well, and the surveys and interviews for this portion of the research were pulled from smallholder farmers, project developers, non-governmental organizations and financial organizations who were concerned with the development of Jatropha for economic activity. Interviews with project developers were conducted largely in the capital, Dakar, where their central offices were typically based, and they were sourced through local industry and professional contacts. The farmer survey participants were chosen using a quasi-random selection technique to reach a wide sample of socio economic conditions in different regions and within different villages in those regions. Participants were selected using a variety of methods, including scheduled interviews through farmer federations and working groups, surveys arranged with the help and consent of project coordinators, and surveys conducted at random with smallholder farmers at their family compounds and in their fields. 


\subsection{Data Analysis}

Thematic analysis is the most commonly implemented analysis tool for qualitative research and was chosen as an effective means of finding meaning in the results of this study. Thematic analysis provides a structure by which a researcher can identify, examine, emphasize and record patterns or themes within data. These themes create observable patterns within and across data sets that can provide insight into the phenomenon or thesis under examination (Muir-Cochrane \& Fereday, 2006; Guest et al., 2012). These common themes later become the basis for analysis. This analysis methodology often employs a standardized process of thematic coding to recognize meaningful patterns that might otherwise be difficult to recognize across a large body of information. Creswell (2012) discusses the many ways a researcher might develop the set of codes that could shed light on their data, including:

... look for code segments that can be used to describe information and develop themes. These codes can represent

- information that researchers expect to find before the study

- surprising information that the researcher did not expect to find; and

- information that is conceptually interesting or unusual to the researcher

Creswell's recommendations were followed for the purposes of theme selection, and laid the foundation for the primary tranche analysis of the agronomic, socio economic and policy limitations that are the focus of this report. There were indeed surprises in the data that were only identified in the process of coding and thematic identification. The data collected in this research study was analyzed according to the six phases outlined by Braun and Clarke (2006). These phases are: familiarization with data, generating initial codes, searching for themes among codes, reviewing themes, defining and naming themes, and producing the final report.

Data from the semi-structured interviews and farmer surveys was first transcribed and organized in a central database that could be easily referenced. In general, extensive notes were taken during the interview process and re-recorded and organized later in the day or the following day to make sense of the information. Quantitative data was organized in an Excel spreadsheet, where the most salient data points became clear immediately. Qualitative data was then coded over the course of the study, wherein the principal themes of the study became apparent and preliminary assumptions were validated or refuted. The final data analysis was not completed until all primary and secondary data had been collected. Due to the fact that important data from regional case studies was being collected over the course of several months, it was not possible to perform a conclusive analysis before all data were collected. 


\subsection{Ethical Considerations}

The primary goal of this study was to evaluate the suitability of Jatropha curcas for the Senegal National Biofuel Program, which in isolation does not pose any ethical challenges. However, there are often unintended ethical considerations when performing qualitative research and soliciting personal information, especially in an international setting. In order to obtain honest and straightforward responses from the respondents in the semi-structured interviews and the farmer surveys, it was vitally important that respondents were in no way compromised or exposed. Some of the interview responses included opinions on the handling of the program that could have led to personal and professional challenges, and every effort has been made to protect the identity of the participants in this study.

\subsubsection{Positionality}

As stated previously in this chapter, I spent two years as a volunteer with the United States Peace Corps in a small village in southeastern Senegal. This experience gave me a greater level of insight and preparedness for this research than a first-time visitor, but I was sensitive to the fact that it may have influenced my feelings towards the SNBP, which I had been exposed to during that time. During the course of this research, every effort was made to maintain neutrality and avoid pre-conceptions of the different socio economic models proposed for biofuel production. Although I have every desire to see successful production of biofuels in Senegal, I have treated the information and data collected in as unbiased a position as possible in the hope of delivering recommendations that would lead to development of a viable program, if feasible. My physical appearance as a white male may have unintentionally elicited responses from farmers that seemed more culturally appropriate or expected, and survey questions were carefully crafted so as not to lead respondents to particular answers. If, during the course of an interview, it became clear that qualitative answers were being provided in a deliberately skewed manner, their contents were discounted in the wider results of the study.

\subsubsection{Victoria University Ethical Approval}

Victoria University requires those students engaging in research with interviews or surveys with human subjects acquire ethical clearance 5 . Clearance was solicited and granted on March 13, 2014 for the research period. Participation in the interviews and surveys was entirely voluntary, and participants gave informed consent before engaging with the researcher. An information sheet detailing the purpose of the study and the confidentiality of the respondents was provided

\footnotetext{
${ }^{5}$ All materials required for ethical approval, including the participant information sheet, the informed consent form, and the memorandum of ethical clearance from the Victoria University Human Ethics Committee can be found in Appendices B, C \& F of this report.
} 
before all interviews, and signed consent was recorded for each of the participants. Any documentation containing sensitive responses or proprietary knowledge has been kept in a locked drawer and will be destroyed at the end of the research period.

\subsubsection{Confidentiality}

Participant confidentiality has been guaranteed for situations in which responses might cause harm to the respondent or in which sensitive economic data would compromise the business interests of the organization or entity involved. Certain individuals' names have been changed or their positions kept confidential to mitigate the risk of professional or political reprisal, although there is a risk that close associates or those intimately familiar with the programs in question could ascertain the identity of the respondent. Every effort has been made to protect the identity of the study participants. Sensitive electronic data provided to give context and detail for the socio economic case studies has been maintained in a password protected database available only to the researcher and his advisor, and will be destroyed after a period of two years.

\subsection{Limitations}

This study was limited in scope so as to be achievable by a single researcher in a short period of time. The interviews and surveys were both designed to catch the indicators that had been identified as the central points of success or failure in previous Jatropha programs, and a more thorough set of questions may have illuminated areas of concern or possibility that were not uncovered in this study. More time would have allowed for a greater set of respondents and a more refined set of quantitative results; however the results found are reasonably representative of the country as a whole. Although alternative biofuel feedstock crops are grown in Senegal, this study did not attempt to evaluate them in great depth for fear of diluting the core questions of the study. Areas in which the study could be expanded will be covered in Chapter 8 .

\subsection{Conclusion}

This study employs a mixed methodology to test the suitability of Jatropha curcas for the Senegal National Biofuel Program. A diverse set of tools, including intensive literature analysis, interviews and surveys, and case studies was developed to ensure a broad assessment of the elements under examination. Data was evaluated using thematic coding, and careful attention was paid to maintaining the confidentiality of the respondents who contributed to this work. The scope of the study was limited to three regions of Senegal for reasons of time and clarity. 


\section{Chapter 3 - Literature Review and Research Context}

\subsection{Introduction}

Jatropha curcas and the Senegal National Biofuel Program fall within a much larger and complex global context of energy shortages, anthropogenically induced climate change and the search for renewable energy pathways for a more sustainable future. The challenge posed by transitioning away from fossil fuel based energy sources responsible for global climate change is immense, and will require structural, economic and social changes. Emissions must be curtailed and energy efficiency improved, achieved through both government policy and organizational and individual behavior change. Furthermore, there is no single energy source or technology that will provide a comprehensive solution, and the future of renewable energy generation will have to include significant contributions from all of the major sources currently under development, including solar, wind, hydro, ocean, geothermal, and bioenergy.

At $10 \%$ of primary energy production, biomass is currently the largest renewable energy contributor to the global primary energy supply (Chum et al., 2011; IEA, 2009). Advanced procurement of biofuel from plant-based ethanol and biodiesel offer the potential for liquid fuels for transport, and traditional biomass plays a significant role in heating and power generation. Second-generation biofuels, including cellulosic prairie grasses, rapeseed, algae and other highoil content feedstocks offer particular promise, but much research and development is still required before they can be considered viable contributors to the world's energy supply (Laser et al., 2009; IATA, 2009). A particular advantage of biofuels is that feedstocks are extremely varied and readily available across the globe, and the opportunities for innovation are vast, with potential for the conversion of bioenergy through multiple processes.

There are many nations pursuing biofuels to contribute to their domestic energy requirements, and Senegal is but one country in a long list that have experimented with Jatropha plantations and schemes with similar results (Ewing and Msangi, 2009). These programs must typically take many issues into consideration, including their current and projected energy requirements, the renewable energy options that are available to them based on environmental factors, the land use changes that might be associated with different energy pathways, and the social and cultural limitations to developing these sources of energy, among many others. Several developed economies in the Americas and Europe have invested heavily in biofuel programs on a national level, and their example has been followed by many developing nations in Africa and Asia. This chapter examines some of the most significant contributors to the Senegalese National Biofuel Program as a basis for the following sections regarding the program itself. 


\subsection{International Energy Demands}

Projections for international energy demands over the next several decades vary from an increase of $50 \%$ to a near doubling of current energy use by the year 2050, and despite the wide margin of uncertainty in these estimates, it is clear that the demand for primary energy will only rise as an inevitable consequence of global population growth, urbanization, economic growth and the expansion of associated energy services (IEA, 2013; WEC, 2013; EIA, 2013). The vast majority of this demand will come from developing nations which currently exhibit

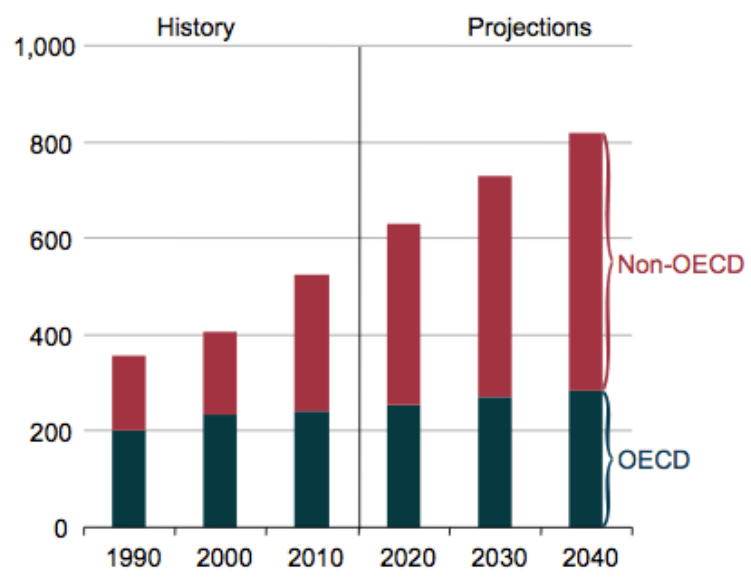

Figure 3.1: World Energy Consumption 1990-2040 Source: US Energy Information Administration the fastest economic growth rates, and developed nations will continue growing their energy requirements but at a much lower rate. There is a clear distinction between the energy growth projections for nations within the Organization for Economic Cooperation and Development (OECD) and those that are nonmembers ${ }^{6}$. OECD countries have generally stable, and in some cases contracting, populations, having moved through the most pronounced economic expansion phase into a more mature market condition. Access to reliable energy is an important component of sustainable development and has become a priority for many development agencies (UNDP \& WHO, 2009).

Non- OECD countries will exert the greatest pressure on international energy markets through 2050, and barring unforeseen economic downturns or significant changes in national policies, their demands will increase by $90 \%$ (EIA, 2013; IMF; 2008). Although renewable energy sources are among the fastest growing components of the global supply, cheap and ample resources of fossil fuels will still

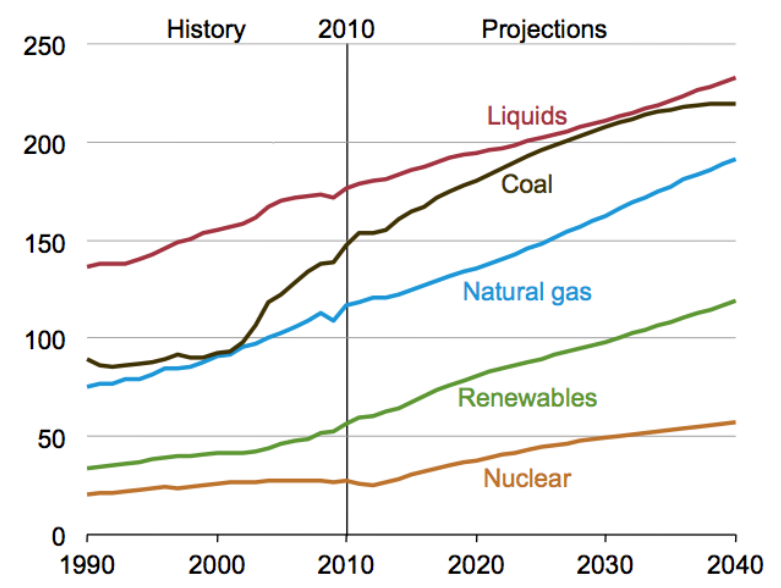

Figure 3.2: World Energy Consumption by Fuel Type 1990-2040

Source: US Energy Information Administration contribute $80 \%$ of total supply in 2040 unless

\footnotetext{
${ }^{6}$ OECD member countries as of June 2014, are the United States, Canada, Mexico, Austria, Belgium, Chile, Czech Republic, Denmark, Estonia, Finland, France, Germany, Greece, Hungary, Iceland, Ireland, Israel, Italy, Luxembourg, the Netherlands, Norway, Poland, Portugal, Slovakia, Slovenia, Spain, Sweden, Switzerland, Turkey, the United Kingdom, Japan, South Korea, Australia, and New Zealand.
} 
substantial and meaningful policy is agreed upon and enacted. Some academics argue that the impact from non-OECD countries is understated, and that the energy requirements from these countries could actually be much higher than current projections due to "dramatic increases in demand associated with poverty reduction" (Wolfram et al., 2012). In countries where there is very little access to energy there is great potential to provide these services without relying on fossil fuels and contributing to climate change. This is especially apparent on the African continent, where Christensen (2012) has noted that over 500 million inhabitants have no access to electricity, but could be reached through a combination of off-grid and local mini-grid installations. Evaluative tools have been developed to allow governments and development organizations to assess the costs of national grid extensions versus isolated mini-grids (Szabo et al., 2011), and in many cases it is more cost-effective to build entirely independent systems that do not rely on outdated fossil fuel electrical generation.

\subsection{Bioenergy and Liquid Biofuels}

Bioenergy represents the largest contribution of renewable energy to the global supply, largely through biomass for cooking and heating in developing nations. Production of heat through direct biomass combustion is generally cost competitive with fossil fuels, and therefore is the leading bioenergy application in the world (Goldemberg \& Teixeira Coelho, 2004). As one might expect, the proportion of biomass use is much higher in non-OECD nations, nearly double the rate of OECD member states. This ranges from residential heating to commercial scale electrical production using combined heat and power (CHP) systems. Although more widely used by commercial and industrial consumers, biomass refining techniques, such as wood pelletisation, will make this end-use more accessible and efficient for smaller users. There is a considerable level of research going into centralized electricity generation using biomass sources, including advanced CHP systems, anaerobic digestion facilities for liquid wastes and municipal solid waste combustion plants (Dong et al, 2009; Chynoweth et al, 2001; Tsai \& Chou, 2006). Arguably the most important role that bioenergy will play in the transition from fossil fuels to renewable energy will be in providing liquid fuels for transportation. Developed nations see this new source of energy as a way to reduce their carbon footprint, and developing nations see additional benefits through stimulated rural development, job creation, and an improved trade balance (Kojima \& Johnson, 2005).

Biofuels, although less efficient in terms of direct energy transformation than centralized biomass conversion to electricity, offer a real alternative to fossil fuels in the transport sector, and can be blended with existing hydrocarbons. Fuels in the transport sector can be differentiated as first and second generation biofuels, both being actively developed for commercial implementation (Naik, 2010; Antizar-Ladislao \& Turrion-Gomez 2008). First generation biofuels 
already enjoy a certain level of adoption in many countries but social and environmental constraints to wider expansion remain. Bioethanol, produced from sugar producing crops and starchy plants, and biodiesel, produced from oil plants and waste fats, are the two principal biofuels in use today. The greenhouse gas emission reductions, especially for biodiesel, can be considerable. "Ethanol yields $25 \%$ more energy than the energy invested in its production, whereas biodiesel yields $93 \%$ more. Relative to the fossil fuels they displace, greenhouse gas emissions are reduced $12 \%$ by the production and combustion of ethanol and $41 \%$ by biodiesel" (Hill et al, 2006).

Competition with food crops is seen as a major limitation of future development and is an important land use consideration. As Havlik (2011) explains, first or second generation biofuel feedstocks need to be carefully selected according to the impact on the land, for if a forest is cleared to produce ethanol from a monocrop corn plantation, the greenhouse gas emissions from the cleared area could take upwards of thirty years to recoup. Second generation biofuels overcome this problem by using non-food feedstocks that have a lower impact socially and environmentally, and their ability to grow on marginal land produces less climate impact in terms of land use change (Eisentraut, 2010). Feedstocks that show promise in this area include lignocellulosic plants, organic waste from forestry operations, high yield grasses and oil plants such as Miscanthus and Jatropha.
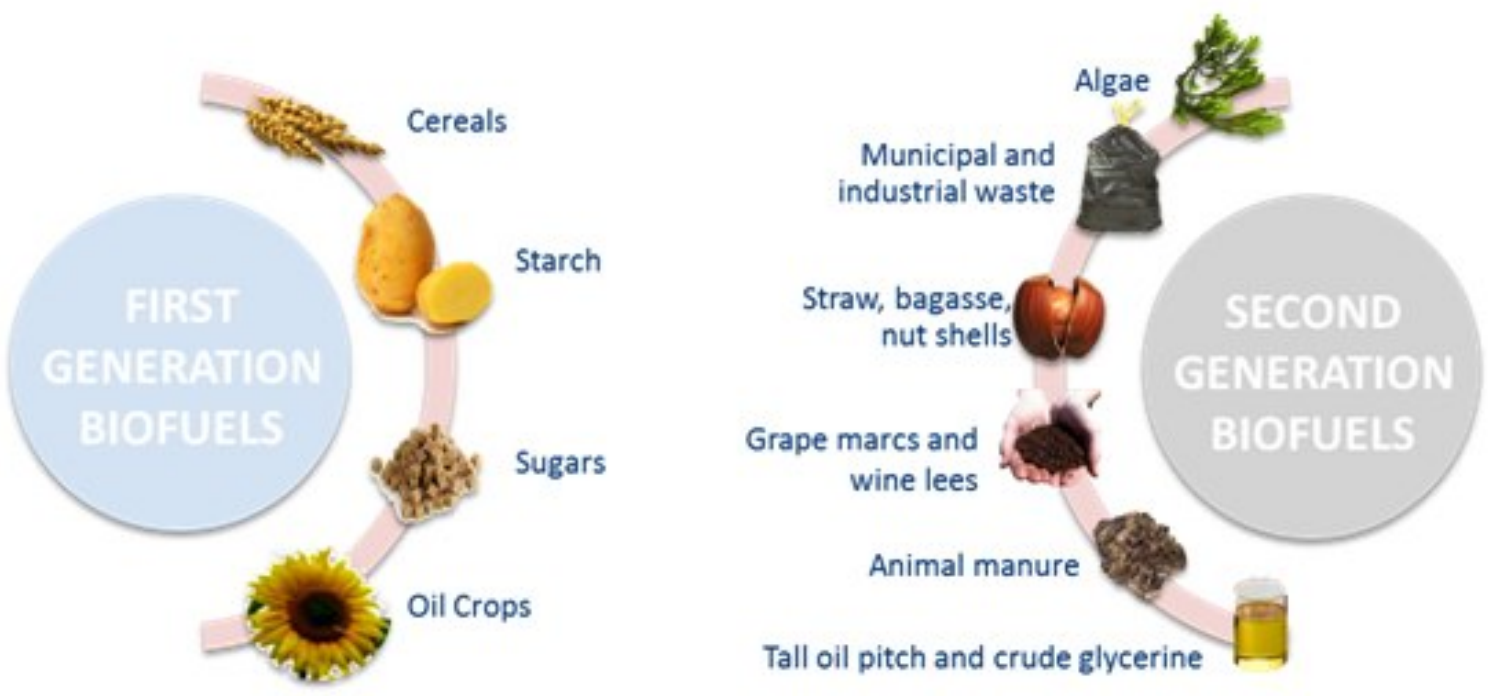

Figure 3.3: European Commission classification of first and second generation biofuels Source: MSL Group Brussels

Jatropha curcas is considered a second generation biofuel feedstock. It has numerous characteristics that make it an attractive option as an energy crop in developing nations, and its ability to grow on marginal land means that it will not necessarily compete with food crops in highly productive areas. The physiochemical properties of the oil and its suitability as an 
independent liquid fuel or additive have been examined exhaustively (Banerji et al., 1985; Kandpal and Madan, 1995; Kumar et al., 2003; Pramanik, 2003; Akintayo, 2004; Shah et al., 2004), and there is much evidence to illustrate that it is an attractive oil for multiple end uses, including energy. The uncertainty lies in its ability to be grown commercially so as to contribute meaningfully to the international energy market and in a way that will not be environmentally damaging.

\subsection{Senegal National Energy Requirements}

Senegal is currently undergoing a rapid demographic shift from a primarily rural population to one that is increasingly concentrated in dense urban areas. As people move away from small villages where biomass is the primary energy provider, the toll on the national electrical grid to supply these burgeoning population centers has been great. The urban population now represents a majority in the country (52\% in 2008) and the trend has shown no signs of abating, creating major stresses and shortages in the energy sector (Dia, 2010). This rapid rise in demand, coupled with rising costs for energy on

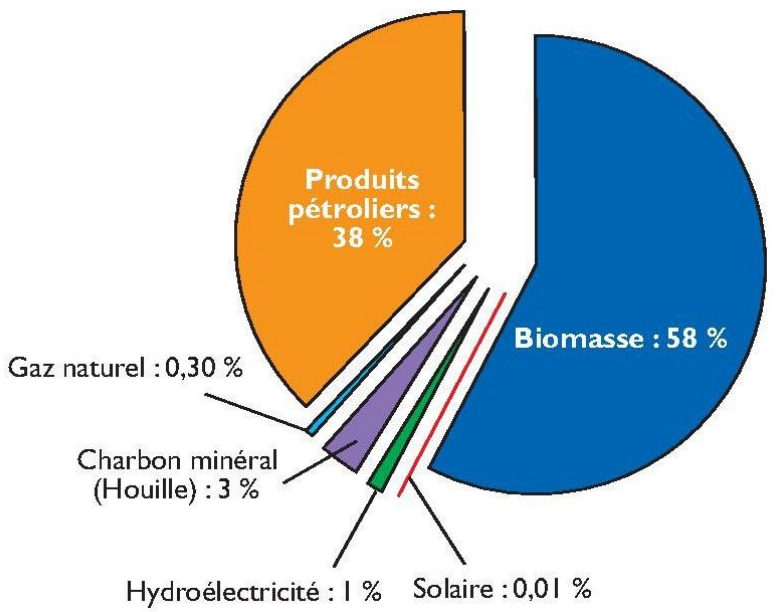

Figure 3.4: Senegal national energy sources by type, 2006

Source: SIE Statistics international markets, has created an energy crisis and put a strain on the nation's finances.

The majority of primary energy needs is still met by direct biomass combustion, as seen in Figure 3.4, but petroleum based fuels represent nearly $40 \%$. This is consistent with other subSaharan national energy demands, which on average rely on fossil fuels for $39 \%$ of base load energy (BAD, 2006). Biomass, primarily firewood and charcoal derived from logging operations in the south, represents the largest contributor to household energy needs, but transportation, electrical generation and industrial uses are heavily reliant on liquid fuels (Dia, 2010; SIE, 2007). The rising price of oil, and the subsequent demand from a larger urban population have created a difficult situation for the government of Senegal, who are still heavily reliant on imported fossil fuels. Between 2002 and 2008 the national fuel budget tripled, as seen in Figure 3.5.

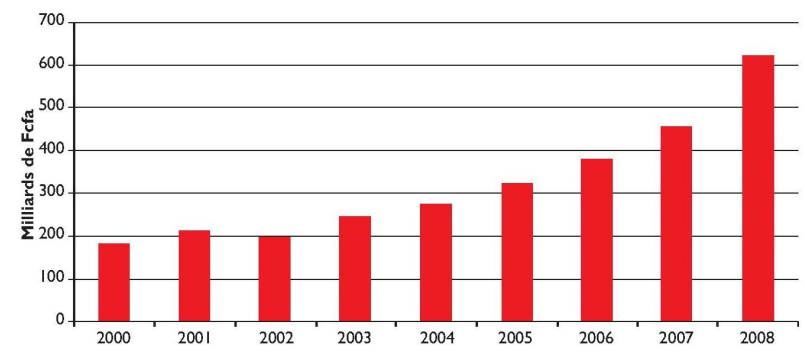

Figure 3.5: National fuel expenditures, 2000-2008 25 Source: SIE Statistics 
Aside from the rural energy needs accounted for by traditional biomass, the Senegalese government is intent on providing modern energy services for the growing urban base, of which households (54\%) and transportation (34\%) use the vast majority of available energy (ENDA, 2010). Low demand from the industrial (9\%) and agricultural $(0.8 \%)$ sectors provide evidence of a highly underdeveloped and under-mechanized economic base, which could portend large energy demand increases in the years to come should Senegal continue to improve its standing as a stable democracy and a desirable place to do business. Figure 3.6 breaks down the current petroleum products required by type, differentiating between gasoline and diesel products.

\begin{tabular}{|c|c|c|c|}
\hline Type d'énergie & Besoins en tonnes & Besoins en $\mathrm{m}^{3}$ & Nombre de litres \\
\hline Essence Super & 66600 & 88800 & 88800000 \\
\hline Essence ordinaire & 33000 & 45600 & 45600000 \\
\hline Gaz butane & 150000 & 300000 & 300000000 \\
\hline Carburateur & 203000 & 275000 & 275000000 \\
\hline Pétrole lampant & 8300 & 10500 & 10500000 \\
\hline Diésel Oil & 200000 & 235000 & 235000000 \\
\hline Fuel 180 & 41000 & 45000 & 45000000 \\
\hline Fuel Lourd & 390000 & 433000 & 433000000 \\
\hline \multicolumn{3}{|l|}{ Total } & 4682900000 \\
\hline
\end{tabular}

Figure 3.6: Senegal liquid fuel requirements by fuel type, 2007 Source: Senegal Ministry of Energy

\subsection{Senegal National Energy Generation Options}

Senegal has a wealth of renewable energy options at its disposal and, if properly integrated with other nations in West Africa, could satisfy a large proportion of its base load electrical supply from a combination of biomass, wind, solar and hydro generation. A comprehensive analysis performed by the International Renewable Energy Agency (IRENA, 2013) demonstrated the ability of the ECOWAS block to develop and deliver several times its energy requirements through an integrated transmission system, relying on an abundance of large hydro projects and an inexhaustible supply of solar energy. Wind energy sites have been proposed in both onshore and offshore locations, and biomass projects of various proportions could be developed in almost every member state. Senegal has enough capacity potential in hydro power production alone to completely satisfy its current energy demands, and is largely eclipsed in potential by its neighbors to the south and east. IRENA (2013) has assessed the nation's current electrical generating capacity - supplied through a combination of oil (395 MW), gas (49 MW) and hydro (68 MW) stations - at $512 \mathrm{MW}$, with negligible contributions from renewable energy sources. 
The balance of energy could change if wind sites are developed on the northwest coast, hydro capacity installed on the Senegal river in the north and the Sine-Saloum in the south, and solar generating technologies implemented for distributed grid production in rural settings.

One of the major challenges facing the country is its electrical distribution system, which is controlled by a single state-operated provider, SENELEC. This single utility has a functional monopoly on production and has not succeeded at meeting the rising demands of the Senegalese population (ENDA, 2010; Youm et al, 2000). The utility uses a combination of diesel and natural gas fired thermal plants that have not been properly maintained, distributed on a series of low and high voltage lines that are critically under capacity. National investment has not kept pace with load requirements. Another governmental structure, the Agency for Rural Electrification (ASER), was established in 1998 to encourage the adoption of renewable energy sources and promote micro-grid electrical generation services, though their contribution has been limited to a collection of demonstration villages rather than widespread national projects (Camblong et al, 2009; Diouf et al, 2013). Centralized generation and distribution is concentrated in the center west of the country, and energy services become increasingly sparse at greater distance from the capital.

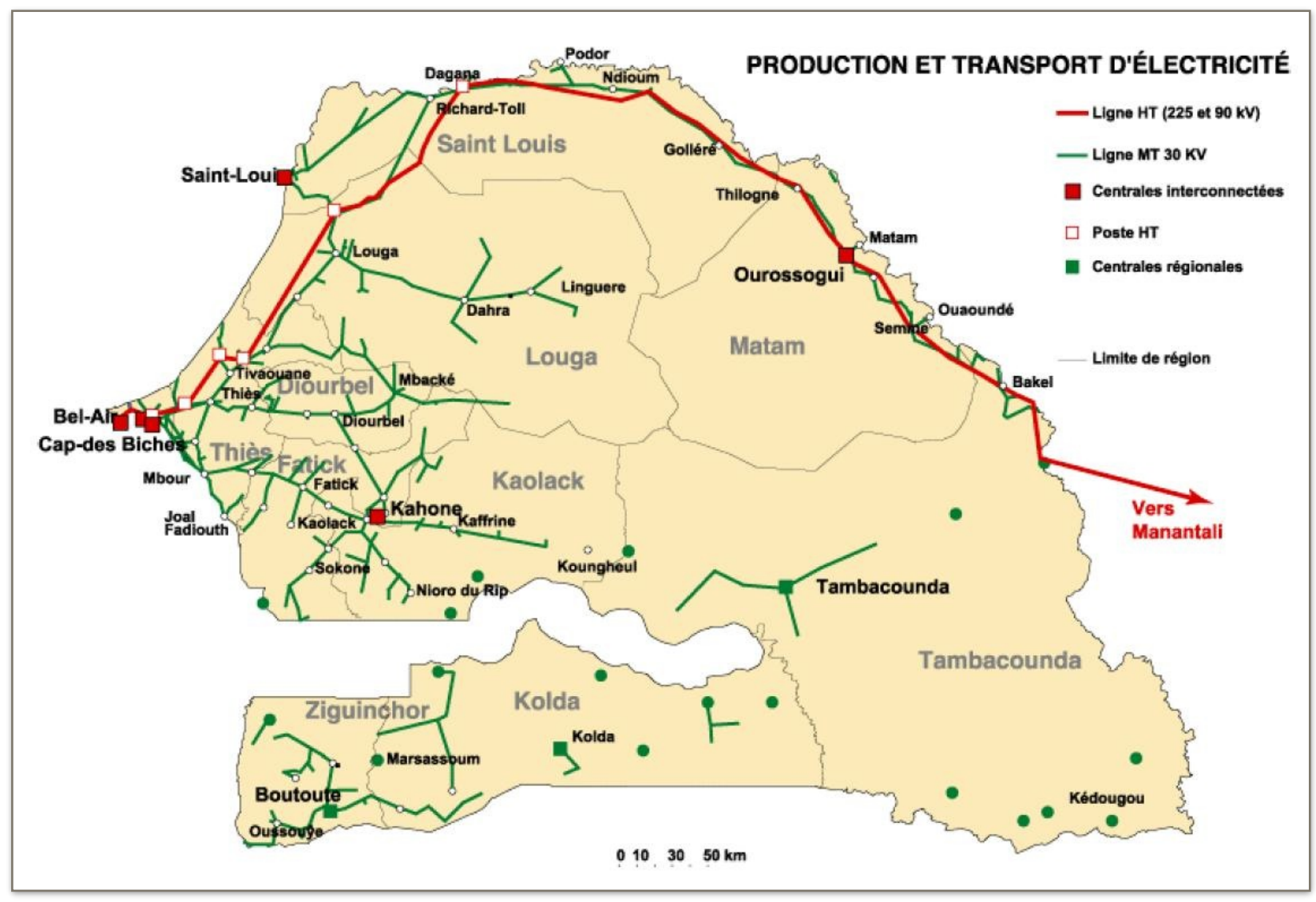

Figure 3.7: Senegal electric production and transmission network Source: Senegal Ministry of Energy; SENELEC 


\subsection{Foundations of the Senegal National Biofuel Program}

The impetus for the Senegal National Biofuel Program can be linked to a number of guiding documents that have steered the national energy policy since the late 1990s, and can be directly attributed to high oil prices in the early 2000s. There are three primary documents that have dictated Senegal national energy policy — issued in 1997, 2003, and 2008 - and together formed the basis for the SNBP (Dia, 2010; Deidhiou et al, 2010; IPAR, 2012). These documents, called Lettres de Politique de Developpement du Secteur de L'Energie (LPDSE) ${ }^{7}$ were intended to address the weaknesses of the existing energy infrastructure when the first signs of insufficient capacity began to appear. The first, drafted in 1997, aspired to achieve three main goals: (1) eliminate system inefficiencies; (2) reduce the cost of electricity delivered to consumers; and (3) encourage and facilitate financing to propel the energy sector. The second, LPDSE 2003, was largely in response to the failures of the first to measurably address the problems inherent in the system and moved to privatize certain functions previously controlled by the state to stimulate competition and drive down prices for consumers. However no effort was made to incorporate renewable energy into the national energy strategy.

The third guiding policy document, LPDSE 2008, was drafted in a period of particularly volatile energy markets that had seen the national energy bill expand by $40 \%$ in two years (Deidhiou, 2010). It was becoming clear that Senegal was far too vulnerable to rising energy costs and needed to diversify internally or risk being increasingly indebted to foreign energy suppliers. During this period of inflated energy prices, more than $46 \%$ of export revenues were required to pay the national energy bill, and energy stocks were insufficient to guarantee against daily service ruptures and blackouts (SIE, 2007). To address this crisis, three main objectives were outlined by the policy document: (1) guarantee an adequate national energy supply with the highest performance in quality, durability and cost; (2) increase energy access to rural populations and those without any prior modern energy services; and (3) reduce the nation's vulnerability to external variabilities, particularly from the international oil market. To achieve domestic energy autonomy and reduce dependence on external sources, the policy explicitly stated an intent to "develop and exploit potential national energy sources, notably in the domain of biofuels and renewable energy sources, and a diversification across the industries of charcoal, biofuels, biomass, solar, wind, etc., for the production of electricity." (LPDSE 2008) The effect of these three Lettres de Politique was to place a renewed obligation on extending energy services to underserved rural populations and emphasizing renewable energy sources.

\footnotetext{
${ }^{7}$ Lettres de Politique de Developpement du Secteur de L'Energie (LPDSE) are not laws in and of themselves, but rather guiding policy documents that provide a structure upon which other legislative measures can be implemented. While they lack the full force of a law, their role is to influence the long term legislative goals of the government in power.
} 
In the same period of time that Senegal was facing a deep energy crisis, it was experiencing a major loss of agricultural workers, especially youth, who were very important to the food security of the nation. Senegal is heavily dependent on food imports to meet its needs, importing as much as $60 \%$ of its annual food requirements despite $60 \%$ of the population earning their livelihoods from the agricultural sector (Hathie, 2013). This level of inefficiency has driven a number of national policies designed to reinvigorate the sector and provide opportunities to the nation's youth who are increasingly fleeing rural settings for urban centers and illegally emigrating to seek opportunities abroad. The REVA plan ${ }^{8}$, launched in 2006, and the $\mathrm{SCA}^{9}$ the year before, both sought to revitalize and recapitalize the agricultural sector to generate economic activity and contribute to national food security, while halting the clandestine emigration that was leading to a shortage of workers (ENDA, 2010). Both of these initiatives put a strong emphasis on local community engagement and the creation of distributed economic activity, which would be important contributors in the emergence of the Senegal National Biofuel Program.

\subsection{West African Comparisons}

Senegal is not the only, nor the first, African nation to experiment with biofuels to meet rising energy demands. Almost every Sub-Saharan African nation has suitable growing conditions for biofuel crops, and even countries that have a wealth of fossil fuel energy resources usually face problems of energy security and consistency that could be mitigated through a diversification of energy supplies (EREP, 2012; IRENA, 2013). Furthermore, due to the perception that African nations are more suitable for economically competitive biofuel production because of low production costs and relatively abundant land, large agroindustrial investors were eager to enter the market (FAO, 2008; Fischer et al, 2009). In the West African context, the policies and actions of several other nations in the region provided an example for the Senegalese National Biofuel Program, and highlighted areas of concern that would later become relevant for project developers and planners.

Ghana was one of the first nations in West Africa to experience the large scale exploitation of Jatropha curcas for biofuel production. The development of the Jatropha plantations was not, as in the case of Senegal, promulgated by the government, but instead driven by private investors and speculators who were intent on securing land before the true

\footnotetext{
8 Plan REVA: Retour Vers l'Agriculture; expansive national program launched in 2006 to reengage youth in the agricultural sector.

${ }^{9}$ The SCA: Stratégie de Croissance Accélérée, developed on a timeframe between 2005-2015, was designed to fortify the agro-industrial sector and drive development through strategic investments in IT, Tourism, Agribusiness, Textiles, and Aquaculture.
} 
performance characteristics of the plant were fully tested (Hagan, 2007). At the onset of the first land grabs in 2005, no guiding policy had been established for the regulation of the biofuel sector. In fact, Ghana would not draft an official renewable energy policy - the Renewable Energy Act (832) - until six years later, in 2011, by which point many of the initial interests had already failed and a large proportion of the land put under Jatopha cultivation was abandoned and vacant (Schoneveld, 2011). Although the primary purpose of using Jartopha curcas as a biofuel feedstock is to avoid compromising arable land suitable for food crops, field studies from Ghana demonstrated that the majority of the large commercial plantations were on highly fertile land that was previously used for traditional agriculture, of which $55 \%$ of the population still relies upon for sustenance and economic activity (Chamberlin, 2008; World Bank, 2010). Perhaps most startling was the quantity of land that was amassed for the production of biofuels, estimated at $4.6 \%$ of Ghana's total land area, and more importantly, $8.8 \%$ of the area suitable for agricultural production (Schoneveld, 2010; Schoneveld, 2011). Although the vast majority of the biofuel initiatives on these large plantations would ultimately fail, the land that was acquired from smallholder farmers would remain in the hands of large corporate entities.

The Jatropha initiatives in Ghana were mirrored by others of varying intensity and scope in three other West African nations, Mali, Burkina Faso and Benin, which would see many of the same results of large plantations failing to produce the results promised by early promoters of the crop. Of the three, Mali was the most active in creating a series of policy documents to codify the nascent industry and support the rights of farmers, as well as attracting external organizations whose role was to establish best practices and avoid redundancies. There are examples from as early as 1993 of experiments with Jatropha as a live fence and for ancillary goods such as soap and fertilizer (Weisenhutter, 2003). A series of national agencies have been responsible for leading the development of renewable energy projects, beginning the with the National Center for Solar and Renewable Energies (CNESOLAR) in the 1990s, and eventually the National Biofuel Development Agency (ANADEB), created in 2009. ANADEB is charged with the task of stimulating local biofuel development as an economic tool and to foster local energy markets, as well as to provide for national energy demands (Favretto, 2012; MMEE, 2012).

These agencies, while not necessarily guaranteeing the success of Jatopha projects throughout the country, provided the technical and administrative guidance for early adopters and occasionally mediated the needs of farmers and project developers, whose priorities were not always aligned. Senegal would in due course use some of the tools developed by these countries with prior experience in the field of biofuels to establish their own comprehensive biofuel policy, in several cases predating several of their regional neighbors in drafting legislation. To what extent this written organization would operate as intended still remains to be seen. 


\subsection{Social and Environmental Considerations}

The Senegal National Biofuel Program has an explicit expectation that the development of a biofuel industry in the country will lead to a higher quality of living for its rural inhabitants and provide much needed economic activity to help stimulate rural communities. Aside from alleviating some of the energy demand pressures facing the country, it was important that there be social gains as well, without compromising the environment for purely economic gain. The national plan goes so far as to list the following goals (République du Sénégal, 2007):

- The creation of 100,000 jobs, with fair remuneration

- The creation of a rural environment with an attractive lifestyle

- Improvements to the natural environment

- Reduction of poverty and the disparity between the urban and rural world

- The electrification of villages that previously had no modern energy services.

Although the primary intent of the program was to improve energy security for the country as a whole, the plan was built in concert with the REVA plan and the SCA, as well as the Lettres de Politique 1997, 2003, and 2008, all of which embody a commitment to supporting rural livelihoods and the wellbeing of underserved communities. In many cases, as with the example of Ghana, the land rights of smallholder farmers were abused and land lost under the pretense of economic prosperit. A formal report by the European Union's Contract Commission in 2011 highlighted many areas in which biofuel initiatives in developing nations failed to deliver for smallholder farmers and in some cases brought negative environmental consequences due to drastic land use changes (EU, 2011). Although some projects were complete failures and actually created greater food insecurity in the short term, the FAO (2008) argued that long-term development of local biofuel industries would guarantee cheaper and safer energy supplies and long-term food security.

In order to create a local biofuel industry with positive social and economic results, the land requirements for the crop under consideration and the potential for environmental damage in pursuit of economic gain must be taken into account. Jatropha has been proposed for marginal land that would not be in competition with food crops, but it is well documented that the best environmental and agricultural practices most often do not reach poor rural areas where much of this marginal land lies (PANGEA, 2012). The risk of environmentally sensitive areas being converted for biofuel production is therefore high, as is the substitution of crops on arable land. There have been very successful biofuel initiatives that provided jobs for the local community and access to energy services, for example in the cases of Thailand and Brazil (Amatayakul \& Berndes 2007). There have also been cases where biofuel initiatives collapse, leaving smallholder farmers in a more dire situation than they were in originally, such as in Tanzania and 
Kenya (GTZ, 2009). The challenge, then, is to build policies that will address the energy needs of a nation, contribute to the mitigation of climate change, reduce poverty and inequality, and extend some of the energy services back into the communities that are developing the energy for consumption. It is perhaps no better stated than by Laura German and colleagues from the Center for International Forestry Research (2011): “our findings provide a more nuanced picture of costs and benefits, and point to a host of risks that need to be proactively managed to leverage the potential of the industry as an engine of national social and economic development."

\subsection{Conclusion}

This document review revealed a number of important questions regarding the Senegal National Biofuel Program, and specifically the selection of Jatropha curcas as the primary plant feedstock. The global demand for liquid energy sources is strong and projected to grow at a higher rate in developing nations. Senegal's current energy demand is especially low in the agricultural and industrial sectors, indicating their history of underinvestment and the probability that they will experience strong demand growth in the coming decades. There are a number of renewable energy generation options available to the country, including a reliable supply of hydroelectricity from the Senegal river in the north and the Casamance and Sine-Saloum in the south, as well as favorable conditions for wind energy along the coast and an abundance of solar energy throughout the country. With a variety of energy generation options at the disposal of the Senegalese government, there is little documented evidence to support the decision to pursue biofuels with such a significant national program without similar support for viable alternatives.

Jatropha is a well known plant in the region, and its resilience and drought tolerance has seen it used for many generations as a live fence, a deterrent for pastoral animals, and an erosion control substrate. Its oil exhibits qualities that make it useful for soap making, cosmetic additives and even medicinal purposes, but its suitability as a feedstock for biofuels has been called into question in other countries in the region and on the wider continent. Similarly constructed programs in East Africa and West Africa have had difficulty creating an economically sustainable biofuel program based on Jatropha curcas for reasons related to the plant's agronomic performance, the way in which programs were structured to work with smallholder farmers, and the supporting policy structure of the governments and commercial interests involved. It is unclear why such a sweeping program was built around a feedstock that still lacks validation from prior practitioners, and no documentation has been produced by the Senegalese government to shed light on the results of the program. The literature reviewed here provided a basis of understanding on where to expect deficiencies in the national policy and potential pitfalls, and this research project set out to validate or refute those assumptions in the field. 


\section{Chapter 4 - Agronomic Limitations}

\subsection{Introduction}

In this chapter we explore the agronomic suitability of Jatropha curcas for biofuel production and its place within the Senegal National Biofuel Program. Using a combination of primary and secondary data, this chapter provides an in-depth examination of the potential of Jatropha in agronomic terms. The background and provenance of Jatropha are discussed in greater detail, as well as the important conditions that influenced the crop's performance in Senegal. The environmental impact of a national biofuel program and the implications this has on the debate over food versus fuel are also examined. To cover these points in thorough detail, semistructured interviews were performed with policy makers who were involved in the drafting of the SNBP, project managers and commercial interests who were promoting and planting Jatropha, as well as smallholder farmers who have planted and tended to these crops within the scope of the national program and preceding it. In order to protect the identity of some respondents, the names of interview participants are not included in this report, and in some cases the name of the organization in question is withheld. Policy related responses were sourced from organizations, agencies and ministries located in the capital, Dakar, and field responses were collected in the regions of Fatick, Kaffrine and Kedougou, running along the central axis of the country on the national highway (Figs $2.2-2.4$ ).

The national program was administered by several partners under the direction of the Ministry of Agriculture, and the primary partner responsible for the reproduction and dissemination of plants and seedlings (Phase 1) was the Senegalese Institute for Agricultural Research (ISRA). Under the terms of the SNBP, this institute was responsible for the production of one billion seedlings and cuttings that would then be distributed throughout the country with the help of various partners and intermediaries. The plan called for each of the 321 rural communities (a governmental classification) to plant 1,000 hectares of Jatropha, irrespective of the communities' growth characteristics or particular climatic conditions. The dissemination of seedlings and cuttings was coordinated by the National Association of Rural Councillors (ANCR), who would determine the rate at which rural communities would receive them. Guidelines included in the plan recommended a $2 \mathrm{~m} \times 2 \mathrm{~m}$ grid spacing, with a total of 2,500 plants per hectare. The SNBP assumed seed production from plantings would begin immediately in the first year, with 0.5 tons (T) of seed per hectare (ha) planted, and progressively increase to 5 T/ha in the third year and ultimately 10 to $12 \mathrm{~T} / \mathrm{ha}$ in the fifth year and beyond. Phases 2 and 3 of the SNBP, oil production and distribution, respectively, are not discussed in this section as they are not impacted by the agronomics of Jatropha, and will be covered in Chapters 5 and 6 . The full provisions of the Senegal National Biofuel Program can be reviewed in Appendix A. 


\subsection{Provenance and Regional Adaptability}

Jatropha curcas is native to Central America, and has been propagated widely throughout the tropical region. It was first brought to the Cape Verde Islands, several hundred kilometers off the Senegalese coast, by Portuguese traders and later to the African mainland (Heller, 1996). The plant is a member of the Euphorbiaceae family, and is adaptable to numerous climatic zones and soil types, which contributed to its spread through the tropics. In particular, the ability to sustain long drought periods made it attractive to farmers in the Sahel, which is susceptible to extended spells without rain. West Africa has been subject to an extended drought for the past several decades, with shorter rainy seasons leading to retreating forests and an expansion of the Sahara desert (Shanahan et al, 2009). This, coupled with mass deforestation, has led to large expanses of land that were once fertile and forested converting to dry scrubland with poor soils. Jatropha, which tolerates such conditions, was seen as a useful tool to hold the top soil horizon in place and replenish the nutrient content of the land for future agricultural production. As depicted in Figure 4.1 below, the plant was introduced and spread throughout the continent, thriving as both a domesticated and wild plant. It's tolerances are much wider than that of other biofuel feedstocks, such as the very high yielding oil palm, allowing it to be integrated into agricultural production systems where no others could survive.

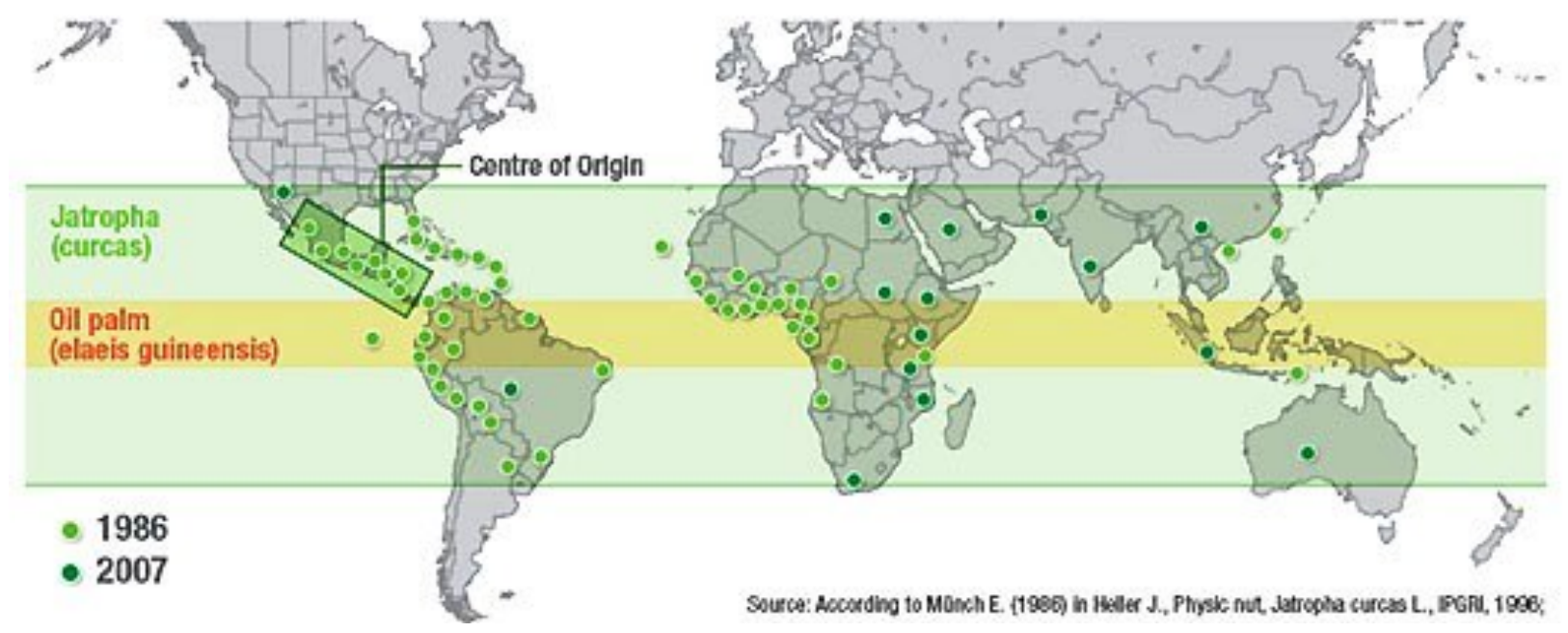

Figure 4.1: Global Distribution of Jatropha curcas and Oil Palm, 1986 - 2007

The plant's resilience allowed it to spread throughout Senegal, both by human hands and through natural processes. This hardiness in the face of drought did not necessarily guarantee high seed production, nor a reasonable yield of oil from plants in areas where soil nutrients were severely lacking. Plants could take root and survive in difficult conditions, but this did not assure that they could be successful feedstock generators for a commercial biofuel industry. In order for Jatropha to be successful in terms of the guidelines of the SNBP, it would have to take root and produce on arid wasteland in the north as effectively as on fertile soils in the verdant south. 


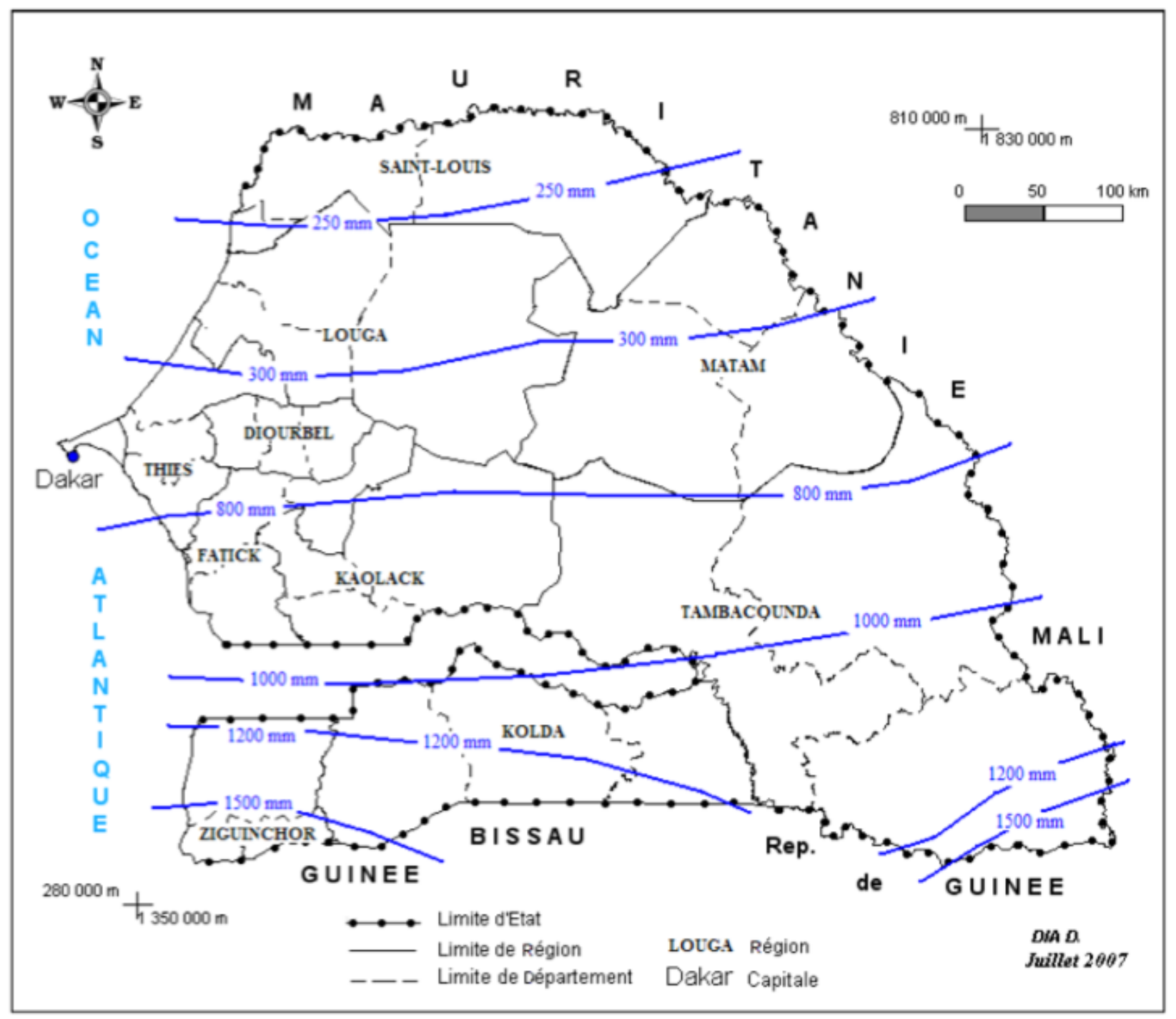

Figure 4.2: Senegal rainfall patterns

Source: Dia. 2007

Senegal, despite being a relatively small country, has a large range in rainfall from the north to the south due to its latitudinal location on the border of the Sahel. From north to south, there is a difference of more than $1000 \mathrm{~mm}$ of rainfall per year. Jatropha is well adapted to rainfall between 250 - $3000 \mathrm{~mm}$ rainfall per year, which technically allows it to be fully integrated across the country, except for the extreme north, as seen in Figure 4.2. The northern border is the Senegal river, and plantations in this zone were proposed to be established using irrigation systems feeding off the river's water supply.

A research project run by Brent Simpson (2009) for USAID found that projects on the Senegal river were unsuccessful due to inexperience with proper irrigation techniques, and overwatering often led to devastating soil borne diseases that, over the course of three years, completely decimated test plots of early adopting producers. Unlimited access to water meant 
that there were no biophysical limitations to growth, but technical knowledge was severely lacking. Furthermore, no systematic approach was being pursued to determine the best practice protocols needed to ensure successful propagation of Jatropha in these conditions.

The projects evaluated in the regions of Fatick, Kaffrine and Kedougou during this study were all comfortably within the plant's growth range, between 800 - $1500 \mathrm{~mm}$ rainfall per year, but there was significant variability in the performance of plants across this range. Farmers in the center of the country experienced much higher morbidity rates and slower growth, with no seed production for more than three to five years in most cases.

When considering the goals of the SNBP, specifically the expectation that plantations could produce seeds and oil within the first year, and achieve full production capacity by the fifth year, it is clear that Jatropha was not performing at the levels needed for a successful program. In fact, in 2014, seven years after the inception of the program, none of the projects surveyed reported seed production even equal to the first year assumptions $(0.5 \mathrm{~T} / \mathrm{ha})$ built into the SNBP. The only region performing at levels of production close to the outlined goals of the program was Kedougou, where farmers reported being able to reliably harvest seeds two to three times a season, due to favorable rain and soil dynamics. Unfortunately, this region was not developed to the same extent as areas closer to the capital, and no organized production was in operation.

\subsection{Seed Source and Yield Variability}

Although there is a general consensus that Jatropha has a favorable disposition to a wide range of climatic conditions and can survive in even very harsh environments, it is still a wild plant and there is very little consistency in the performance characteristics of different varietals. With respect to genetic improvements of seed and oil yield, the plant is in its infancy, and a lack of information on desirable traits for specific growing conditions has been observed by some as a risky proposition (Jongschaap, 2007; Divakara, 2010). Seed selection is quite important in determining the long term performance of plantation crops, and an evaluation of soil types can make a significant difference in yields. A study performed in the Guangxi Province of China sampled 21 different Jatropha plots and correlated climatic conditions and soil types to seed size and oil content, finding as much as a $20 \%$ difference in yield (Wen, 2012). Soil type, humidity, and annual insolation were all directly correlated to positive growth characteristics. In order to develop realistic growth projections and ensure success amid the diverse climatic conditions, an analysis of soil types and the appropriate seed stocks for specific areas is essential.

According to officials at the National Institute for Agricultural Research (ISRA) the seeds sourced for the SNBP had multiple origins, including India, Guinea, Guinea Bissau, the Gambia, 
as well as stocks found internally within Senegal (P.C., March 2014) ${ }^{10}$. At the inception of the program, the demand for seeds was so high that the only consideration was supplying the seedling nurseries, which had a mandate to produce one billion plants. Officials explained that the seed supply was so restricted due to competing Jatopha programs in neighboring West African countries, especially Mali, that the price for seed had been inflated by as much as $500 \%$. As we can see in Figure 4.3, Senegal has a diverse range of soil types and ideally seeds would have been selected according to the soil zones they were more suited to in order to guarantee higher performance. Unfortunately, ISRA did not track the origin of the seeds for the program, nor did they make any attempt to pair different varietals to the soil profiles of the regions for which they were destined. Because the SNBP required all regional communities to plant the same land area in Jatropha regardless of their location, plantations were supplied with seeds with preference paid to political connections and ease of distribution, rather than land suitability.

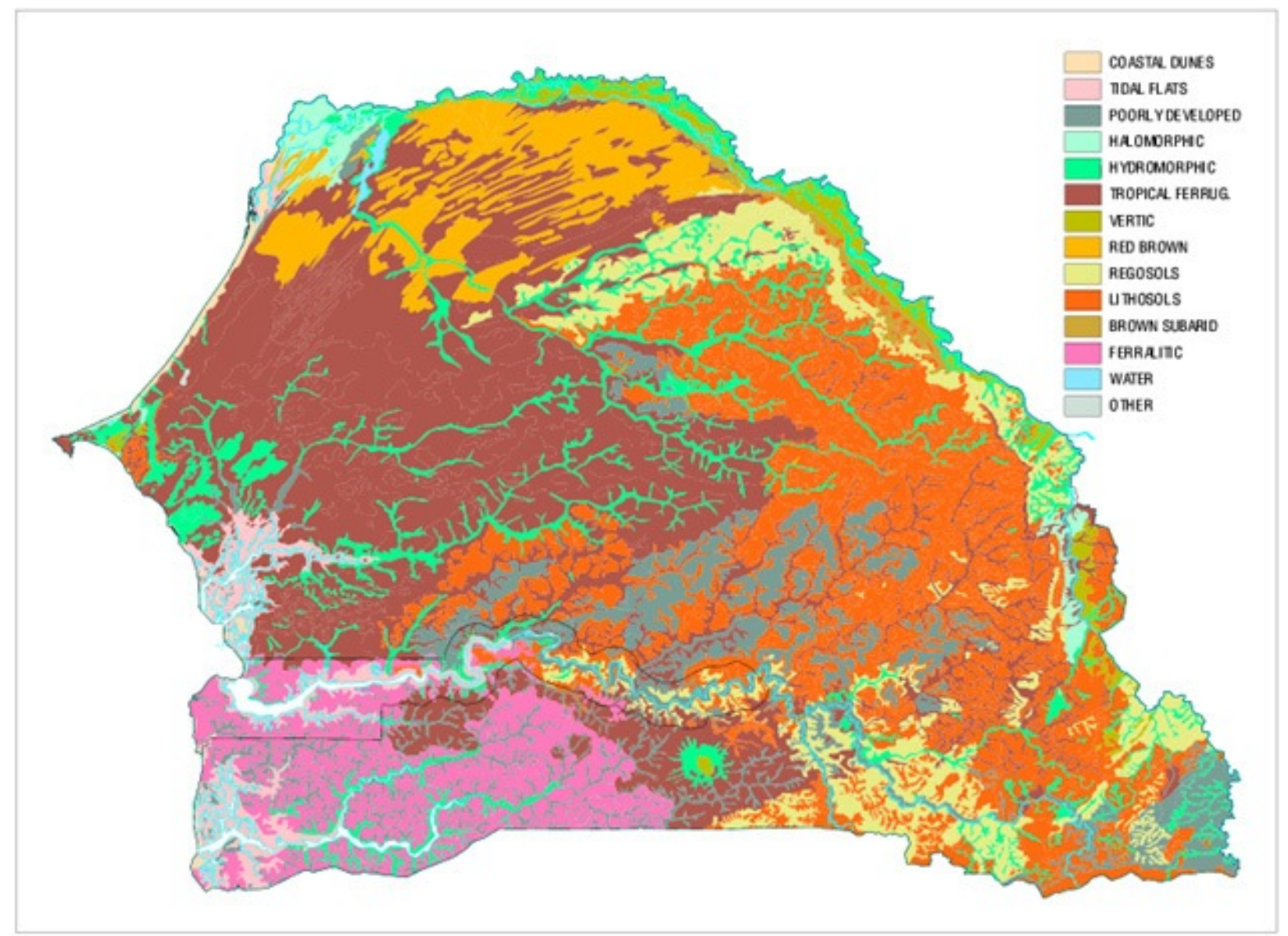

Figure 4.3: Soil Types in Senegal

Source: US Geological Service

${ }^{10}$ P.C. denotes a personal communication attained through a semi-structured interview, and will be referenced as such for the remainder of the report. 


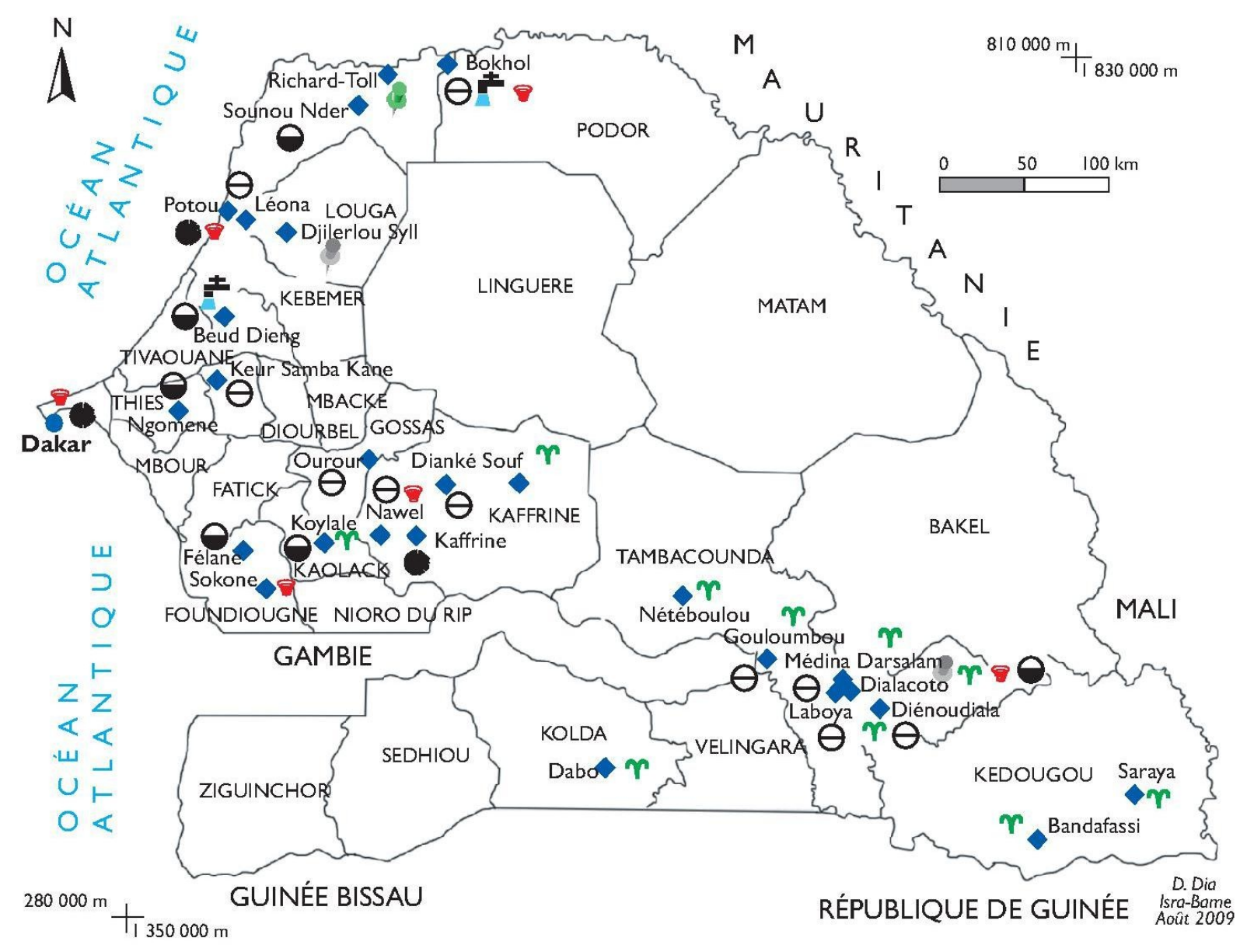

\begin{tabular}{|lll|}
\hline Jatropha en culture irriguée & Sites de recherche expérimentale \\
Jatropha en culture pure & $\Upsilon$ Jatropha comme haie vive et limite pour les champs \\
Association Jatropha-cultures vivrières & Transformation artisanale de Jatropha en biodiesel \\
Sites de production de pépinière & Transformation industrielle de la canne à sucre en bioéthanol
\end{tabular}

Figure 4.4: Jatropha projects in Senegal, 2008

Source: Dia, 2009

Figure 4.4 illustrates how widely dispersed the Jatropha growth program was within the country in 2009, with irrigated plantations on the Senegal river in the north, experimental plots in at least five administrative regions, and several projects that sought to incorporate traditional agriculture with biofuel cultures. By 2014, most of the projects indicated in this map had been abandoned due to severe under-performance and a general lack of technical support from ISRA, whose funding for the SNBP was significantly reduced. Remaining endeavors were universally funded through independent investors outside of the purview of the national biofuel program. 
This haphazard and unsystematic methodology prompted wide variability in growth characteristics and plant yield, frustrating farmers and project developers who could not replicate the targets delivered to them by the national government. Farmers surveyed in the Fatick region had experienced extreme differences in plant performance. One of the earliest villages to receive seeds and seedlings, Diagele, still has not produced any fruit since they were planted in 2007 (F.S., April 2014) ${ }^{11}$. Meanwhile, a neighboring village that was supplied with seeds and plantings two years later has been harvesting small quantities of seeds for the last two years. This disparity could come from many factors, and it is difficult to assess whether this was due to soil nutrients, rain variability, or seed provenance, because these metrics are not actively recorded.

In many cases, farmers were so disillusioned with the poor performance of the crop that hundreds of hectares were ripped up by their roots and the land replanted with alternative crops or left barren altogether. One farmer, despite poor performance, is still supportive of the SNBP and had planted nearly 1000 plants surrounding his fields and even planted two fields in the grid formation recommended in the national guidelines. After five years he was experiencing the first harvest yet from his plants, for a total of 6 kilograms. According to the guidelines established within the SNBP, by the fifth year he should have expected a cumulative harvest of more than ten tons of salable seed. This substandard performance was experienced by individual farmers and large corporate structures alike, and the National Institute of Agricultural Research remained unprepared to advise on how to improve yields, because even in 2014 no record of seed provenance was kept (P.C., March 2014).

\subsection{Agricultural Inputs and Physical Infrastructure}

The rate of seed and oil production from Jatropha curcas is reliant on the nutrient content in the soil and other agricultural inputs affecting growth and strong performance. Additionally, in order to add value and prepare the seeds for oil production, a physical infrastructure of processing facilities is necessary at both local and national levels. The SNBP has provisions for both of these elements, with initial capital outlays for laboratories and nurseries, as well as equipment, such as tractors and tools. Although the plan recognizes the need for oil presses and filtering equipment, a centralized processing facility was not a feature of the project. A sizable budget for fertilizer was also built into the original cost structure, with the expectation that farmers would use amendments to stimulate growth on an annual basis. Figures $4.5 \& 4.6$ detail these costs. To evaluate the effectiveness of these measures on Jatropha growth, direct feedback was sought from ISRA and smallholder farmers who had been planting under the SNBP.

\footnotetext{
${ }^{11}$ F.S. denotes information obtained from the farmer survey, and will be referenced as such for the remainder of this thesis.
} 


\begin{tabular}{|c|c|c|c|}
\hline & Cost (Franc CFA) & Cost (Euro) & Ratios \\
\hline $\begin{array}{l}\text { Laboratory construction and } \\
\text { furniture }\end{array}$ & 458500000 & 705000 & $\begin{array}{l}\text { Plant cost from } \\
\text { Laboratory: } 54 \text { FCFA }\end{array}$ \\
\hline $\begin{array}{l}\text { Plant multiplication in } \\
\text { nurseries }\end{array}$ & 53441530000 & 82200000 & \\
\hline $\begin{array}{l}\text { Institutional assistance, } \\
\text { training, subsidies for } \\
\text { fertilizers, and agric. tools }\end{array}$ & 10880000000 & 16700000 & $\begin{array}{l}\text { - Subsidy for fertilizers: } \\
100000 \text { FCFATon } \\
\text { - 50\% subsidy for agr. } \\
\text { Tractors and equipment }\end{array}$ \\
\hline Total & 64780030000 & 99600000 & $\begin{array}{l}201807 \text { F CFA Ha } \\
300 \text { Euro / Ha }\end{array}$ \\
\hline
\end{tabular}

Figure 4.5: Phase one agricultural inputs for Jatropha cultivation Source: ENDA Energie; Senegal National Biofuel Program

\section{Cost of production for a hectare of jatropha starting from the first year}

\begin{tabular}{|l|c|c|c|c|c|c|}
\cline { 2 - 7 } \multicolumn{1}{c|}{} & 1 $^{\text {st }}$ year & $2^{\text {nd }}$ year & 3 $^{\text {rd }}$ year & $4^{\text {th }}$ year & 5 $^{\text {th }}$ year & $6^{\text {th }}$ year \\
\hline CFA francs & 38.540 & 44888 & 47608 & 49422 & 51236 & 56813 \\
\hline US Dollar & 77,1 & 89.8 & 95.2 & 98.8 & 102.5 & 113.6 \\
\hline
\end{tabular}

Figure 4.6: Farmer outlays for Jatopha production in Senegal, years one through five Source: ENDA Energie; Senegal National Biofuel Program

Officials with ISRA confirmed that fertilizer had been used in the nursery facilities in the propagation of Jatropha seedlings, but none was distributed to smallholder farmers. According to project managers, funding for the national program had already been curtailed by the second year of its operational lifetime, and the cost of fertilizer was passed on to the farmers (P.C., March 2014). It was also confirmed that no tractors or similar mechanized farm implements that could have sped up the planting and field preparation stages of the program were distributed, and that even distributing the seedlings became a major challenge as financing became more restricted. Seedlings were typically prepared in nursery facilities near the capital, with two satellite facilities in the regions just north and east, where the largest commercial operations were concentrated.

Irrigation is the single largest cost for commercial Jatropha production in arid climates, but in most cases the additional cost is economically prohibitive. However, in the dry northern region of the country along the Senegal river, this is the only method that makes cultivation practicable. A pilot project performed by Terren et al (2012) in the town of Bokhol put 6 hectares under cultivation to test drip-irrigated Jatropha production. A series of spacing and fertilization techniques for commercial production were tested with repeated failure. Irrigation actually 
stimulated a devastating soil borne vascular disease that wiped out large portions of their test plot over the course of three years. Of all the projects surveyed within the country, this pilot project was the most intensive user of agricultural inputs, employing drip irrigation, fertilizer, pesticides and experimenting with various pruning techniques. Despite all of these contributions, after five years of cultivation, the plot was only producing 0.5 $\mathrm{T} /$ ha, far below the expected $10-12 \mathrm{~T} / \mathrm{ha}$, and at a significant economic loss.

\begin{tabular}{ccc}
\hline Year & $\begin{array}{c}\text { Expected yield per hectare } \\
\left(\text { tonne. ha-1 }^{-1} \text { under irrigation }\right. \\
\text { and the least favourable conditions }\end{array}$ & $\begin{array}{c}\text { Yield obtained } \\
\text { at Bokhol } \\
\left.\text { (tonne. ha }{ }^{-1}\right)\end{array}$ \\
\hline Year 1 & 0.75 & 0.13 \\
Year 2 & 1.00 & 0.35 \\
Year 3 & 4.25 & 0.50 \\
Year 4 & 5.25 & 0.50 \\
\hline
\end{tabular}

Figure 4.7: Comparison of expected and actual yields in Bokhol, Northern Senegal Source: Terren et al, 2012

Smallholder farmers who had been extended seeds and seedlings for live fencing denied the application of soil amendments and fertilizers to stimulate growth. In most cases, the additional cost was a barrier for these farmers, who were reluctant to invest in a new crop that would not show any remuneration for several years (F.S., April 2014). Natural fertilizers such as cow manure were reserved for the seasonal vegetable production plots. Pruning was not actively practiced, and the majority of respondents did not remove other plants from the base of Jatropha crops to reduce competition during the rainy season. According to one farmer, the work involved was far too intensive to justify, even with the aid of his three sons. Tractors are still extremely rare at this level of agricultural production, and none of the communities surveyed were using advanced tools or mechanized farm implements, which severely limited their growing capacity.

\subsection{Pests}

It was widely reported in early literature that Jatropha was highly resistant to pests and did not require the use of pesticides to protect it from disease or insect attackers, possibly due to the natural toxicity of the plant and its oil. These observations were most likely from wild specimen that were individually thriving, but conditions in monocrop agricultural production are much different, and introduce blights that can spread with great speed and devastating affect. Due to this assessment, no provisions were included in the SNBP to safeguard plantations from insect invaders or the potential threat of fungus and disease, and no technical guidance was offered to smallholder farmers or commercial project managers on how to manage pests. Unfortunately, pests would prove to be a major difficulty for Jatropha growers at multiple growth stages, in some cases eliminating individual plants and in others wiping out entire fields. 
Technologies for Human

Development (THD), an organization that has worked with smallholder farmers in the Fatick region to produce Jatropha biofuel since 2008, reported several important pests that have affected their farmers under a variety of circumstances. In the first year of the SNBP, project managers were encouraged to plant Jatropha with a direct seeding technique, whereby seeds would not be raised in nurseries, but instead planted in and around farmers' traditional agriculture plots in

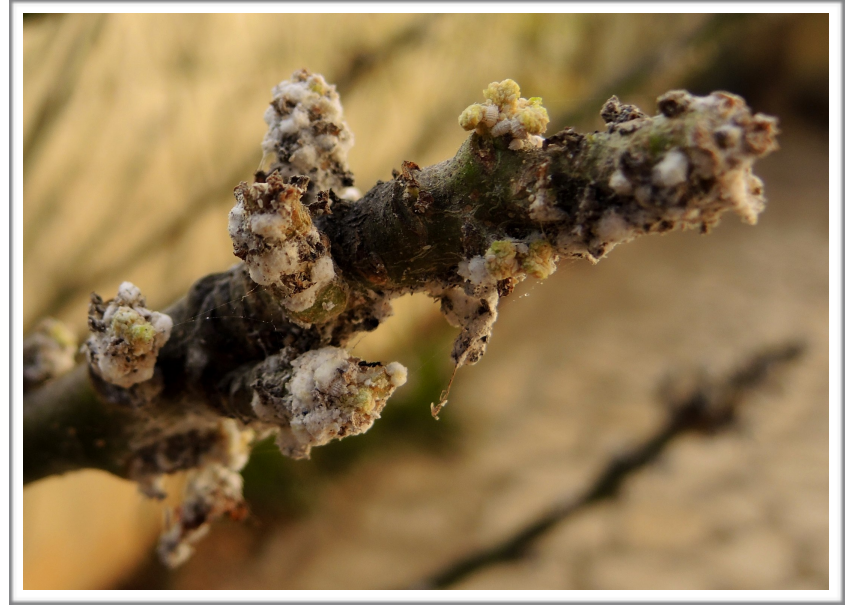

Figure 4.8: Attack by cochineal insects at a THD test plot. advance of the rainy season, and allowed to grow from natural rainfall. This method had a very low success rate, in part because the germination rate was poor, but also because the young shoots were susceptible to attack by millipedes who were not repelled by the toxicity of the plant and indiscriminately ate Jatropha as readily as the other plants growing in the vicinity (F.S., March 2014). The combination of poor germination and the millipede attack resulted in a near universal loss in the first planting year. Seedlings that were grown in nurseries proved to resist the millipede attacks because their lignified stalks proved less attractive to this pest. THD adopted a seedling nursery policy for all future plantings and their success rate markedly improved.

Mature plants are susceptible to their own set of pests, and although plants that make it through their first full year of growth generally resist with much more success, they are vulnerable to attack throughout their lifetime. In all of the surveyed regions, termites were a major problem for growers, and the thick woody stalk of Jatropha plants were especially at risk in the dry season when they were unable to resist attack as effectively as in the rainy season, presumably because they were in a dormant cycle and lacked the energy to repel the insects. Termites were generally observed to attack plants that had previously been weakened by another pest. THD had documented attacks by cochineal insects at a pilot growing center which completely killed mature plants that had thrived for four years (P.C., March 2014)

These insects stripped the leaves and buds from woody Jatropha stalks and left a telltale white film, as seen in Figure 4.8. In similar fashion, fungus was particularly damaging in zones with intermittent periods of wet and dry cycles, and would alternatively weaken or entirely rot the main stalk of Jatropha plants. Similar vascular diseases were the apparent downfall of the irrigated pilot project in Bokhol. Specimens affected in this manner would then be susceptible to termites, who could destroy a fully formed trunk within a matter of days. Although there are 
products on the market to counter termite infestations, they are costly and farmers were again reluctant to invest in their plantations before there was any observable economic benefit.

Despite the observable presence of several pest varieties that have posed problems for farmers and project developers in all growing regions of the country, and literature that lists a far greater number of potential pests not encountered during this study, no effective pest management regimes currently exist in Senegal. Officials questioned at ISRA with regard to this problem insisted that there were research projects aimed at identifying the major pests in the country, though no supporting documentation could be provided (P.C., April 2014). In the absence of clear technical guides or extension material for farmers, the sole commercial scale operator still present in the country, Africa National Oil Corporation (ANOC), has dealt with its pest problems on a trail and error basis, resulting in a several year delay in production. The only recourse for a plant lost to severe damage from termites or fungus was to uproot the stalk, remove the woody matter that might attract further attacks, and replant a new seedling in the same location. This has not been an effective strategy, however, as the length of time for a plant to mature and bear fruit with regularity is too long and every measure must be taken to preserve live specimens.

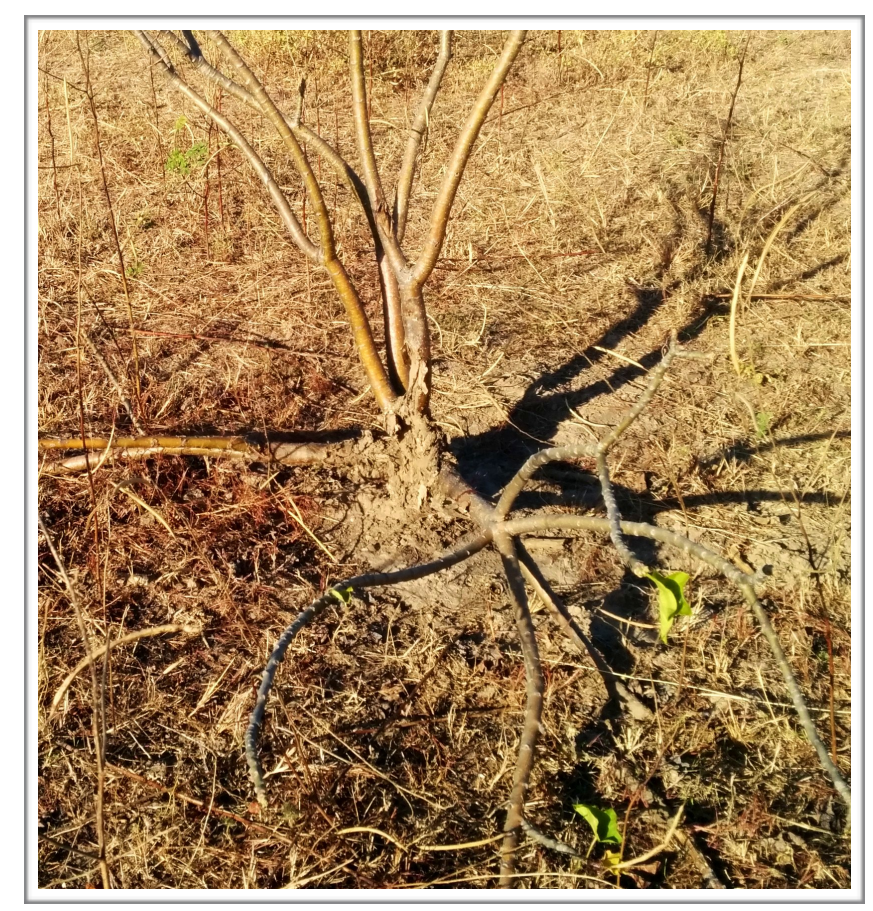

Figure 4.9: Termite attack on mature plants at an ANOC plantation in central Senegal

\subsection{Improved Seed Varieties}

The challenges posed by the initial seed stock of random provenance provided by the SNBP have prompted most of the remaining Jatropha cultivation programs and commercial operations to seek their own supply, despite the financial burden of importing seeds. Some have looked to internal sources for high-performance Jatropha stock within Senegalese borders, while others have looked outside to research centers and foundations that have been working to improve the performance characteristics of the plant. The National Institute for Agricultural Research still maintains a research center in the town of Thies, in conjunction with the Ecole Nationale 
Superieure d'Agriculture (ENSA) ${ }^{12}$ who have been working to produce an improved seed variety, though positive results have not been forthcoming. Until the SNBP can coordinate a new seed distribution policy or develop its own strain of improved seeds with the help of ENSA, project developers and farmers have been left to find alternatives on their own, with markedly different approaches.

Two projects that have sought internal varieties are the Africa National Oil Corporation (ANOC), based in Gossas but with large tracts of Jatropha under cultivation in the Kaffrine region, and Trees for the Future (TFF), which operates primarily in Kedougou. ANOC has one of the largest landholdings cultivating Jatropha in the country, and are using an agroindustrial operational model, employing tractors and improved farming equipment for their planting and harvesting, but experienced heavy losses in certain areas and poor

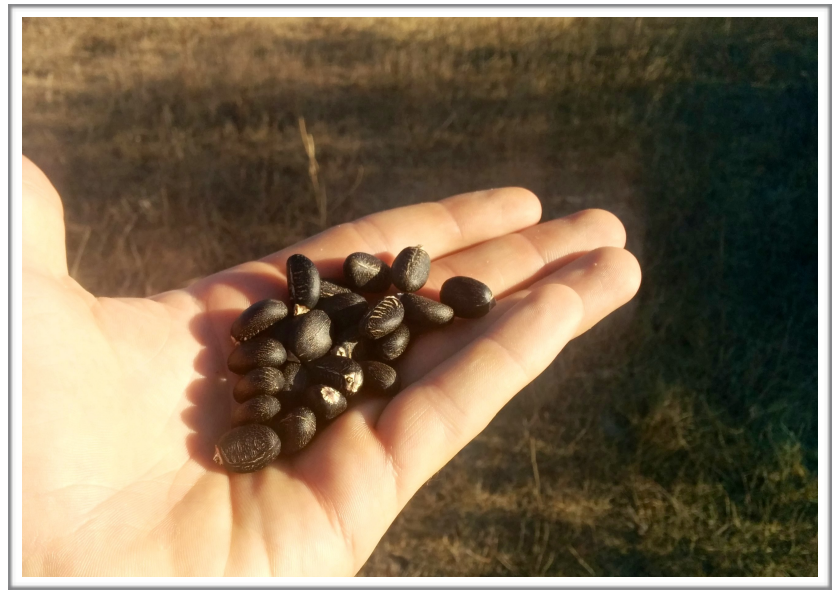

Figure 4.10: Seeds from the Africa New Oil Corporation (ANOC) plantation in Gossas production in others. Their methodology has been to scout individual specimen with aboveaverage production, and use these individuals as feeders for large field plantings.

A project coordinator with ANOC confirmed harvesting thousands of seeds from a single plant with above average production in the center of the country, though the performance of its progeny as yet unable to be reported on. Trees for the Future has repeatedly sourced its seeds from a series of villages in the far southeast of the country, in the region of Kedougou. Several villages, including Kafori, Toge and Baku, which have traditionally grown Jatropha and used it extensively for live fencing, annually supply TFF with 200,000 - 300,000 seeds for direct plantings in other villages. Plants in this region have been known to exhibit above-average performance, though it is unclear whether this is due to the quality of its seeds or other important growth factors such as rainfall and soil type. Both of these projects rely on primitive seed selection techniques however, and cannot guarantee that the seeds harvested from high performing plants will reproduce their results in regions with vastly different climatic conditions.

\footnotetext{
${ }^{12}$ ENSA is the national agricultural research center formed in 2006 at the University of Thies, approximately 100 kilometers east of the capital. This center is responsible for training agronomists and scientists to combat Senegal's agricultural and environmental challenges. The Jatropha program is headed by Dr. Ibrahima Diedhiou.
} 
The alternative to sourcing seeds locally has been to look externally for support from researchers and foundations that endeavor to improve the quality of the seed through scientific and agronomic improvement programs. AYWA International and THD, both of whom intend to produce biofuel for local consumption, have initiated projects with research bodies in the United States after experiencing major difficulties with their early production. AYWA International has been the most proactive, having partnered with an agrochemical company, GANTEC ${ }^{13}$, which specializes in isolating genes from West African plants and developing high performance compounds for the agricultural industry. Their research is still at an early stage, but they have partnered with local farmers to provide seed from different communities, later subjected to genetic analysis in the US. The lead project manager for AYWA International explained that their first several years of production have been disappointing, especially in regard to the expected outcomes promoted by the SNBP (P.C., April 2012). Nonetheless, they are confident that they can succeed with Jatropha cultivation if high performing strains are isolated, and are building their experience with farmers and establishing collection networks through other valuable seeds, such as those from the Neem tree, in advance of the successful reintroduction of Jatropha for biofuels.

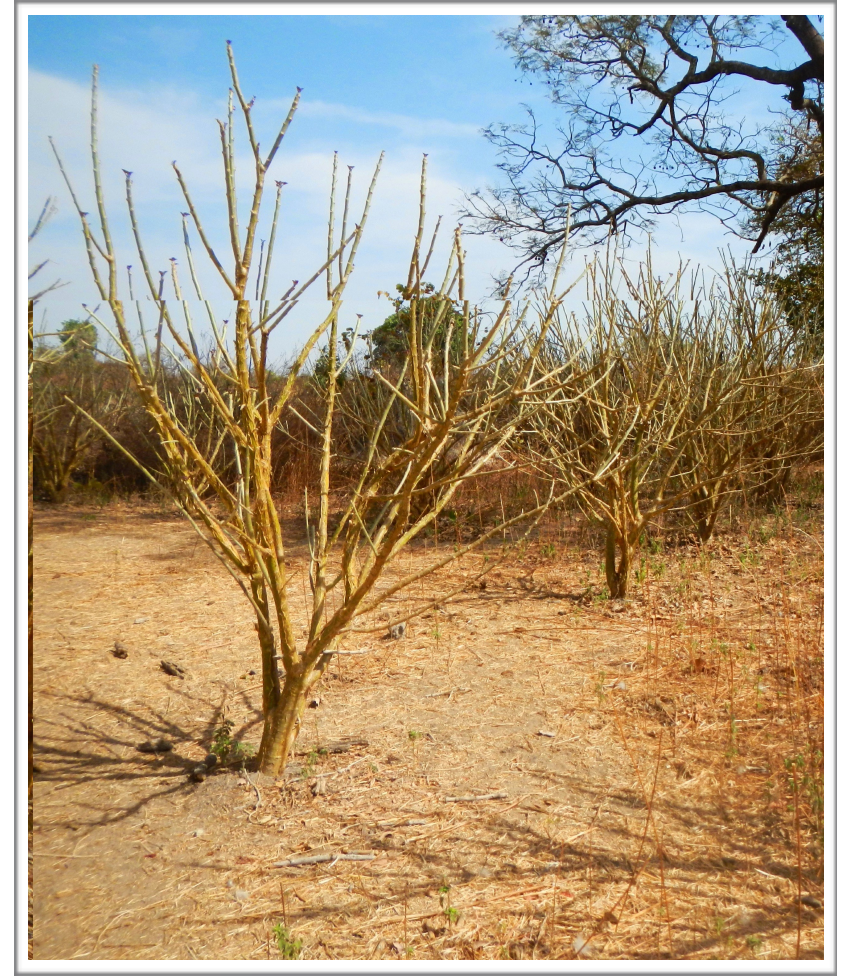

Figure 4.11: High performance local plants in Kafori, southeastern Senegal.

Technologies for Human Development (THD), which is the sole project operator to have developed a full pressing facility in the region of Fatick, has also struggled with their Jatropha seed output, despite partnering with the local farmer federation, extending initial seed supplies, and offering technical expertise on crop management. Farmers have struggled to produce any seeds whatsoever for the first several years, and the oil press has had to exploit other seed varieties to meet its operating requirements. Initially they sought seed from experienced producers in India, but the results were not markedly different. Their need for higher performing

\footnotetext{
${ }^{13}$ GANTEC has performed its research in collaboration with researchers at Michigan State University, and specializes in commercializing high performing products for the agricultural sector. Online at: http:// www.gantecinc.com
} 
seeds brought them into contact with SGB Biofuels ${ }^{14}$, who have reportedly developed a strain of Jatropha with superior growth characteristics to the wild stock found in Senegal. Although as yet unverified by THD, SGB Biofuels claims to have produced a series of hybrid strains with significantly greater yields than other commercially available seed supplies, outperforming such competitors with a $250 \%$ yield gain. Their team of scientists and agronomists have done this by assembling a substantial germplasm library from Central America which contains a wide array of genetic traits enabling SGB to produce more than 2 million hybrid crosses. The traits include enhanced fruit yield, disease and pest resistance, high oil content, and soil adaptation, all of which have been major challenges in Senegal. If verified, the impact of such seeds could be substantial.

\subsection{Environmental Impact and Land Use Change}

One of the central concerns over the development of biofuel projects is the associated land use changes that can completely negate the greenhouse gas mitigation potential that crops like Jatropha curcas have been hailed for. There are concerns that a rush to develop biofuels will stimulate harmful environmental practices such as deforestation, overuse of chemical fertilizers and an abuse of scarce water supplies (Deluchi, 2010), all of which are already pressing concerns in West Africa. The SNBP was designed with the intention of incorporating Jatropha cultivation in tandem with traditional agriculture and on marginal land previously exhausted by abusive practices that have left vast swaths uncultivable in many parts of the country. However, experience in other countries, such as Ghana, has shown that biofuels are often planted on arable land perfectly suited to food crops even under such policy regimes. Furthermore, there are no explicit regulations within the national plan that dictate where and how Jatropha should be planted to curtail unwanted environmental damages, with considerably more emphasis placed on how to extract economic value.

For the most part, the practices observed in the field and reported on by smallholder farmers and project developers suggest that harmful environmental practices have not been a major feature of the Senegalese experience with Jatropha. Officials at ISRA explained that large land concessions provided by the government for early commercial operations were located in areas where the former peanut plantations had heavily exhausted the soils and were generally considered wastelands (P.C., March 2014). There were reports of deforestation affiliated with an Italian operation under the name of Senhuile in the region of Tambacounda, but these could not be independently verified. The projects that remain are predominantly being run in concert with smallholder farmers who have been encouraged to plant Jatropha as a live fence surrounding

\footnotetext{
${ }^{14}$ SGB Biofuels, based in California, is an agricultural biotechnology company specializing in proprietary plant genomics to maximize yields. Online at: http://www.sgbiofuels.com
} 
their traditional plantings in lieu of full field plantations. There were, however, several cases of individual farmers who had cleared land in the southeastern region of Kedougou in order to make space for Jatropha plantings specifically as a biofuel crop, though this was not occurring on a large scale and appeared to be the result of the price spike for seeds as a result of the early promotion (F.S., May 2014). The primary field agent for Trees for the Future in Kedougou rarely encountered farmers who cleared new land for Jatropha plantations, and would if anything shift into plots abandoned by other farmers if their productivity was greatly diminished after corn or cotton cultivation.

The concerns over excess water consumption and fertilizer use have not been observed in Senegal largely because both would require an investment that is beyond the means of most smallholder farmers engaged in Jatropha cultivation. The only case of irrigation uncovered during this study was the test site in Bokhol in the north of the country, but their failure to produce seeds anywhere near expected levels of output, in addition to the heavy initial investment for drip irrigation systems, virtually guaranteed that this practice would not be attempted elsewhere. The remainder of the projects surveyed in the country have relied on rainfall as the sole source of water, and although this is seen as one of the primary barriers to better growth rates, there is not enough information available on the correct watering regimes to justify an investment in this area.

Although fertilizer applied to monocrop plantations can run off into sensitive waterways, pollute groundwater and increase eutrophication after heavy rainfall, this was not reported at any of the sites in the country. The average annual cost of fertilizer and other agricultural inputs for one hectare of cultivated Jatropha in the SNBP was estimated at 48,000 FCFA (approx. US \$97), which was beyond what most farmers were willing to invest. The average daily wage for an agricultural laborer in Senegal is 1000 - 2000 FCFA (approx. US \$2 to \$4), and unless the market value of Jatropha seeds improves dramatically, fertilizer will not be adopted as a standard crop input (F.S. April 2014). Several farmers in the Fatick region explained their intention to reinvest all proceeds from Jatropha production back into their plantations to strengthen the plants and encourage seed growth, but after many years of care many had yet to see any profit from their efforts whatsoever. Environmental degradation and land use change, however, were not found to be byproducts of the SNBP. 


\subsection{Conclusion}

The agronomic case for Jatropha curcas production for biofuels in Senegal is difficult to make under current conditions. It was chosen above other potential feedstock options due to its resilience, ease of reproduction, low maintenance and quick maturation. The Senegal National Biofuel Program was so confident in the ability of Jatropha to meet the domestic biofuel production targets that no other feasibility studies were run to assess alternatives, and to date there have been no comparable plans to achieve their goals. The results from this study suggest that Jatropha was selected prematurely, and that far more work is required before it can be considered a viable feedstock for liquid biofuels in West Africa.

Although the plant shows a high level of resilience in the Senegalese climate and has been grown throughout the country for several generations, there is a significant difference between the traditional performance requirements of the plant and those for a commercial biofuel operation. For the purposes of live fencing, stabilizing the soil and reforesting areas lost to desertification, Jatropha has proven effective. However, Senegal's location on the border of the Sahel and the wide variability of the seeds introduced in the country have not produced a stock of plants with regular or easily replicable yields. Seeds originating in Central America and India were not necessarily appropriate for the drier climatic conditions of the plains of central Senegal, and there was no attempt by the National Institute for Agricultural Research to pair seed varieties with the distinct soil conditions found throughout the country. The SNBP projected yields of between $10-12 \mathrm{~T} /$ ha by the fifth year of production, whereas after 7 years most plots have not achieved even the first year production targets of $0.5 \mathrm{~T} / \mathrm{ha}$. This result is poor by all measures, and suggests that ISRA and the other technical bodies in charge of plantings and technical guidance did not have the capacity to advise farmers and project planners on best practices.

The vulnerability of Jatropha to local pests, which was assumed to be a low level threat, have proved to be a major challenge for smallholder farmers, who in most cases do not have access to the agricultural inputs required to protect their stock or increase hardiness and performance. Jatropha was found to be vulnerable to a variety of blights and insect pests at multiple stages of development, and an effective pest deterrent regime needs to be developed for the entire lifetime of the crop before it can be a regular producer. Millipedes were devastating to directly-seeded plantings, termites and cochineal beetles attacked mature bushes, and soil borne vascular diseases proved to be a major challenge for irrigated crops. Furthermore, farmers were not actively fertilizing their plants to improve production or treating them against pests with chemical products, largely due to the costs of these inputs, which were prohibitive considering the lack of seed production and income. A national extension program, in addition to improved pre-planting land analysis would ensure that plants reach maturity and continue to produce even in the face of local pests. 
Environmental damage often associated with large scale biofuel programs, such as detrimental land use change and unsustainable water and chemical use, were not found to be problems in the SNBP. Land conceded by the government for commercial plantations were generally sited on exhausted land previously exploited by the groundnut industry, and most smallholder farmers were using Jatropha as a live fencing material instead of displacing food crops. Few cases of land cleared with the express intent of farming biofuel crops were found, and these were generally driven by elevated market prices for seeds in the early days of the national program, which have since plummeted. Due to many years of substandard performance, the projects that have continued operating in Senegal are now looking to increase the yields of their plantations through improved seeds. Some have sought high-performance plants within the country, while others have consulted with outside organizations that are working to create hybrid varietals tailored specifically to local climatic conditions and soil types. Developing a seed supply with greater performance levels than those seen at present is a crucial step for the future of the Senegal National Biofuel Program.

The Senegal National Biofuel Program cannot succeed until the agronomic limitations of Jatropha curcas as the singular feedstock are addressed. The National Institute for Agricultural Research and their technical partners must improve their role in seedling propagation, as well as disseminating sound growing practices to farmers who are not familiar with Jatropha as a commercial crop. A national program to distribute fertilizer and soil amendments, develop improved seed strains, and create effective pest management regimes are critical factors. At present, Jatropha has been a major disappointment for biofuel production, but if the appropriate steps are taken, it is not unreasonable to expect that commercial biodiesel is achievable. In order for these measures to be successful and a regular output of Jatropha seed guaranteed, the socioeconomics of the oil market must be fair for smallholder farmers and sound policy developed to encourage further development of this fledgeling industry. 


\section{Chapter 5 - Socio Economic Limitations}

\subsection{Introduction}

The Senegal National Biofuel Program was designed with the expectation that it would provide opportunities for smallholder farmers and create wealth in rural communities in addition to improving the nation's energy balance. The guiding laws and legislation that preceded the plan have mandates to provide work opportunities for youth and reduce the gap in living conditions between rural and urban areas. The SNBP itself sought to create a robust new industry that would provide over 100,000 new employment opportunities, increase and diversify agricultural incomes currently dominated by a few cash crops, reduce poverty and improve rural living conditions. In this chapter, we evaluate the success of the plan in generating positive economic activity and contributing to the communities in which Jatropha has been planted for biofuel production.

To achieve the goals of the SNBP, Jatropha would be cultivated in both smallholder farmer networks and on extensive commercial plantations, with vastly different socio-economic outcomes. The models for economic exploitation employed in Senegal were generally either large and centralized or small and dispersed, with advantages and disadvantages inherent in both approaches. These choices have important implications for land use change and the possibility of competition for farmland traditionally dominated by food crops. Prior experience in Ghana, Benin and Kenya demonstrated how institutional investors often claimed large swaths of land in parts of the country vital to agricultural production by offering attractive terms to smallholder farmers. They quickly transformed the land for biofuel production at great risk of leaving farmers destitute if projects failed to produce in line with early projections. In order to achieve its central goals, the SNBP would not only help the national economy by reducing dependance on external energy providers, but create wealth in the communities where Jatropha was cultivated.

The socio-economics of Jatropha cultivation hinge on a variety of factors that are often specific to regional or local context, and this study sought to evaluate the different methods under practice in the country. We will first discuss the larger fundamental approaches of projects observed in Senegal, with regard to the scale of operations and target market for oil production, and then examine how these models affect smallholder farmers. Three case studies will be presented to highlight the detailed approaches of projects carried out in Fatick, Kaffrine and Kedougou and the factors that contributed to the success or failure of projects in these areas. Primary data was collected through semi-structured interviews with project developers and farmers, and complemented with secondary sources to compare approaches utilized in other African nations. Of the three indicators evaluated in this study, the socio-economics of Jatropha cultivation are paramount, and ultimately determine the result of the National Biofuel Program. 


\subsection{Different Approaches and Models}

The African continent has seen renewed interest from institutional investors in the agricultural sector, often resulting in large scale land acquisitions tailored to export production, that have raised questions about the validity of such business models on a continent that has long been dominated by smallholder farmers operating at a local or regional level. However, there are a variety of alternative economic models that do not necessitate large scale land acquisitions and result in more collaborative arrangements between investors and farmers. A thorough report by Vermeulen and Cotula (2010) in collaboration with the FAO enumerates the diversity of options available for agricultural developers including contract farming schemes, joint ventures, supply chain innovations and new management contracts that provide value at multiple levels. Each carries its own set of opportunities, constraints, and risks, and varying levels of inclusivity with local farmers. The Senegal National Biofuel Program did not define any norms for structuring business models, and it was left up to individual projects to determine the level of engagement and value shared with partners involved. There were several important differences observed in the nature of projects surveyed in the country.

\subsubsection{Agro-Industrial vs. Permaculture-Local}

One of the most important factors when evaluating the structure of an organization and its business model is the scale at which it intends to operate. The SNBP has a mandate to produce large quantities of oil to meet the country's liquid fuel demands, which favors a centralized and commercial operational model on a regional or national level, yet endeavors to create a large quantity of local jobs, which favors a decentralized and local operational model based in smaller communities. Projects observed in Senegal and across West Africa were generally weighted in one direction or another, though the most successful and resilient operations were crafted on business models characterized by centralized organization and technical guidance in partnership with local participants. A consulting firm evaluating the state of Jatropha cultivation in West Africa, E-Sud Developpement ${ }^{15}$, outlined the principal differences in the structure of projects delineated in Figure 5.1 below. The primary variations emerged in the nature of capitalization and the organizational relationship between investors and farmers. On one extreme, projects rely on heavy capitalization and large scale acquisition of land that can be exploited with modern machinery, producing seeds and oil in quantities sufficient to market to commercial interests at the national and international level. On the opposite extreme, projects are built to suit the local market exclusively and tailored to meet the requirements of a community, often in cooperation with farmer federations and government councils who take an active stake in the joint venture.

\footnotetext{
${ }^{15}$ E-Sud Developpement, based in France, provides development agencies with expertise on north-south
} collaboration strategies. Online at: http://www.e-sud.fr/groupe/ 


\section{Business and Operational Models for Jatropha Plantations in West Africa}

\section{Capital Intensive}

\section{Market Focused}

Autarkic Production and Utilization
Projects are characterized by high capitalization of the production and transformation of oil for commercial sale. Focus is on scale and efficiency, with a priority of delivering positive financial returns to initial investors, both domestic and international. Investments at this level may include land acquisition, farming implements and agroindustrial machinery, pressing and processing technologies, and storage facilities. The product focus for this model is biofuel, though carbon credits and other environmental credits are often applied to the business model in concert with the offset programs of international corporations. Success with this business model relies on tight control of production, innovative financing and supportive financial tools, and a guaranteed market for large scale oil production.

Example: Africa National Oil Corporation (ANOC) - Heavy capitalization in all levels of production, including tractors, presses, storage facilities and transformation technologies. Utilization of carbon credits and energy provisioning contracts with external buyers.

Projects are characterized by a moderate level of capitalization, with a focus on working as an intermediary between producers and buyers of the final product. Investments at this level may include processing facilities for seed collection and storage, as well as pressing and transformation technologies. There is less capital risk at this level, but less control of supply and demand, and quality of stock is difficult to control. Projects of this nature generally operate at the regional scale, building contracts and collection agreements with a number of partners within an organized network. Success relies on efficiencies of production and transformation and the cost of energy on the national market, which effectively determines the sale value of biodiesel.

Example: New Ecological Oil (NEO) - Heavy capitalization in pressing equipment and processing facilities in the town of Gossas, Fatick region. Total reliance on farmers for seed production and a focus on building supply contracts with government organizations and external oil buyers.

Projects are characterized by a moderate level of capitalization and a primary focus on local energy needs and the specific product requirements of a defined community. Business models employed will create close linkages between project developers and smallholder farmers, with joint venture status, shared profits, and local consumption of value-added products. Capitalization does not include land acquisition, which remains in the hands of local landowners, but requires investment in pressing and transformation equipment, stocking facilities, and means of returning the energy and products to the community, through multi-purpose platforms or a small scale electricity grid. Success relies on close collaboration and intense integration between farmers, product producers, and energy users.

Example: Technologies for Human Development (THD) and SOPREEF Community integrated project design with the goal of local energy provisioning for water pumping and local energy grid utility. Low capital requirements built in collaboration with local farmer federation.

Figure 5.1: Economic development models of Jatropha producers in Senegal 


\subsubsection{Domestic Production vs. Export Production}

The SNBP was designed for local energy production, and all oil and biodiesel produced under the direction of the national plan was intended for domestic markets. However, in practice this goal has never been enforced by the national government and there are no legal bounds on where oil is marketed. This is a major source of contention for project developers and the local communities within which they are operating. Officials at the Ministry of Agriculture explained that as it became apparent the program would not perform under the expectations written into the SNBP, certain restrictions were loosened to ensure that organizations still moving forward with their Jatropha production would have all options at their disposal (P.C., April 2014).

Furthermore, a change of government several years into the timeframe of the SNBP saw a shift in several important national priorities, and the body in charge of renewable energy was carved up and dispersed among other existing ministries, reducing their capacity to regulate the industry.

The socio-economics of domestic oil production and export production are fundamentally different. Those generating energy for local consumption have closer ties with the farmer communities engaged in cultivation, improve the technical capacity of the farmer and increase the value of their land, and bring much needed modern energy services to areas that traditionally have none. The economics rely on a diversity of income streams from the Jatropha value chain, and may include oil for energy, the waste seed press cake for fertilizer, and waste glycerine from biodiesel transesterification for soap production. Export-related activities are generally more exploitative of the land and farmers with an emphasis on the economically efficient production of oil. Local communities under this production model see less benefit for the effort invested in their plantations, and may never receive the energy service upgrades called for in the SNBP. However, the large-scale, export model is far less complex than a domestically tailored program, and project developers argue that this model still achieves the goals of increased prosperity and economic activity that the national plan hoped for. Officials at ISRA acknowledged the difficulty of building energy supply systems in each of the 321 rural communities included in the SNBP, all with unique requirements, political difficulties and agronomic conditions (P.C., March 2014).

The challenge for projects seeking to produce liquid biofuels for the domestic energy market lies in matching the financial expectations of smallholder farmers for the initial seed stock and still producing a salable oil product that can compete with fuels already offered on the national market. A further breakdown of the costs associated will be discussed in the following section. Projects with an export focus are not beholden to the prices of the domestic market, and can operate under more favorable economic conditions if contracts are drafted with large institutional buyers. Furthermore, they can seek alternative sale opportunities for the Jatropha oil, which has value as a commercial lubricant, as a straight vegetable oil, and for its insecticidal properties, among other things. Finding a working model for either purpose has been elusive. 


\subsection{Economic Constraints of Jatropha Oil Production}

It has been very difficult, if not impossible, for any organization to transform substantial quantities of Jatropha seed into oil for sale on the national market, and seven years after the inception of the SNBP, which had a target production of 1,000,000,000 liters a year after the fifth year of operation, there is no organized system for the treatment and sale of Jatropha biodiesel. This is due in no small part to the agronomic challenges faced by producers in Senegal, as discussed in Chapter 4, yet also due to the strict economic limitations inherent to producing a domestic biofuel from plant feedstocks. The SNBP was built on best-case scenario assumptions that would have allowed farmers to make a profit either from seed sales alone, or achieve higher profits if they converted their stock to oil. The base case suggested each farmer would cultivate 1 $\mathrm{Ha}$, producing $10 \mathrm{~T}$ of seeds, which at $37 \%$ percent oil content produces 3,700 liters of unrefined vegetable oil. The suggested sale price for 1 liter of oil was 100 FCFA (approx US \$0.20), which would have earned the farmer a net 292,000 FCFA (approx US \$585) after factoring in associated production costs, with additional revenue from seed press cake and oil production byproducts. The observed net benefits were far below these calculations, and both large and small scale producers have struggled to create value from their Jatropha stock.

\section{Base Case Assumptions for Biofuel Production in the Senegal National Biofuel Program}

\section{Avg. Farmer Cultivation}

Annual Seed Production

Oil Extraction from Seed

Revenue from Oil Sale
1 Hectare or equivalent 2,500 individual plants

10 Tons/ha - mature plants after 5th year

3,700 liters, assuming $37 \%$ oil content in pressed seeds

292,000 FCFA/ha net - assuming $100 \mathrm{FCFA} / \mathrm{L}$ and 78,000 FCFA costs

Figure 5.2: Economic Assumptions of the SNBP

Source: Ministry of Agriculture; Senegal National Biofuel Program

The assumptions of the Senegal National Biofuel Program were too optimistic, and have not been replicated at any of the project sites surveyed in this study. On average, farmers are producing far less Jatropha than the plan assumes, and instead of full-field plantations they have chosen to continue the traditional practice of live fencing. All of the smallholder farmers surveyed considered Jatropha cultivation to be a secondary economic activity, and reported having between 300 - 750 individual plants under cultivation (roughly 20\% of SNBP projections) (F.S. April 2014). There was one exceptional case of a farmer in the village of Ndiafe Ndiafe in the region of Fatick who considered his plants part of his primary economic activities, and had planted as live fencing and in full-field format, with a total of 945 plants. Despite his best efforts, he only produced $6 \mathrm{Kg}$ of seeds in 2013, with a value of 600 FCFA (approx US \$1.25). THD reported a total of between 700 - 800 kilograms of seed harvested from 40,000 plants in the 
whole Fatick region, from more than 200 farmers (P.C., April 2014). These seeds were not pressed for oil as they are still used for new plantations.

This low production is due in part to the low price for Jatropha seeds, which makes it difficult for smallholder farmers to justify its cultivation. Seed prices across the country vary from 50 - 100 FCFA a kilogram, which is less than they could expect from traditional crops such as corn, millet, and groundnuts, with which they already have much experience. However, seed purchasers are limited to these prices or they cannot produce a fuel that can compete on the national fuel market. The price of diesel fuel at the pump in Senegal at the time of this study was 792 FCFA (approx US \$1.60), therefore Jatropha oil must be produced below this price point or it is not competitive in the domestic market.

\section{Observed Biofuel Production in Senegal}

Avg. Farmer Cultivation

Annual Seed Production

Oil Extraction from Seed

Revenue from Oil Sale
300 - 750 individual plants

Little to no production in years $1-5$, nominal production thereafter

Approx $35 \%$ oil content in pressed seeds, no significant production

No significant oil revenues

Figure 5.3: Observed Jatropha biofuel activity in Senegal

During the initial phase of the SNBP, demand for Jatropha seeds was so elevated that the resultant price in the country was as high as 500 - 1,000 FCFA (approx US \$1 to \$2) per kilogram in certain regions (F.S., April 2014). These prices set unreasonable expectations in the eyes of smallholder farmers who believed they could earn these revenues after production had ramped up, and the resultant fall in prices has left many frustrated. The farmer federation in the Fatick region, which had partnered with THD to produce local biofuels, has in 2014 refused to sell any feedstock until the $100 \mathrm{FCFA} / \mathrm{kg}$ purchase price was raised, but THD reported that even at this cost, Jatropha biofuel is produced at a financial loss (P.C., April 2014). Oil producers must not only take into account the cost of seed feedstocks, but pressing, centrifuge, storage and treatment equipment and facilities, staff and transportation costs, as well as marketing and sales costs and taxes. Similarly disappointing results were obtained in a study of Kenyan Jatropha farmers, who tracked the harvest results over a period of ten years. Monocrop and intercrop plantations were universally failures, and only Jatropha planted as a fence was economical after a five year period.

In order for Jatropha biofuel to be economically viable on the domestic fuel market, the balance of production costs and fuel prices will have to improve measurably. Figure 5.4 indicates fuel prices available at the pump in Senegal since the early 1990s, with a clear upward trend over 


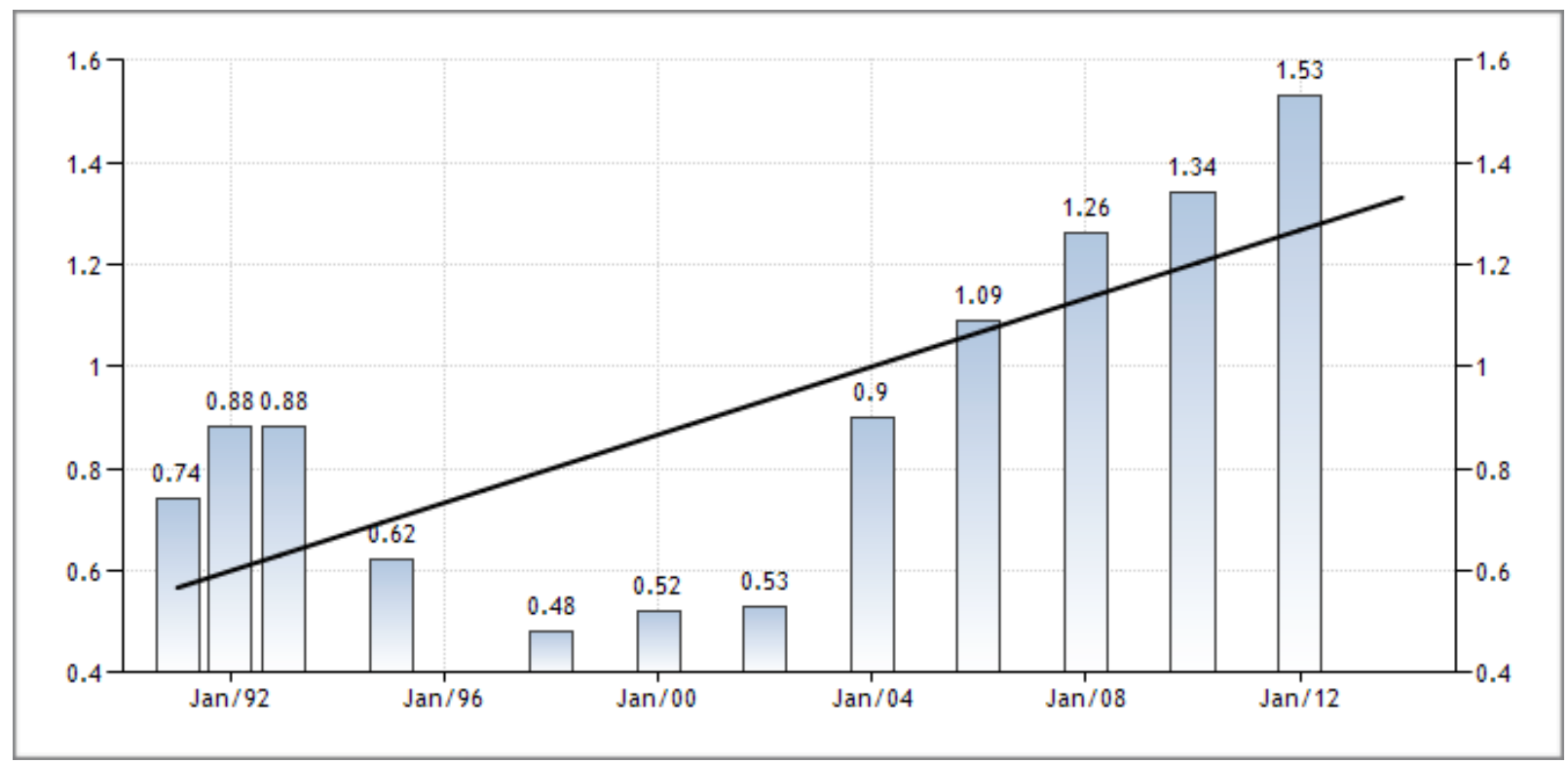

Figure 5.4: Pump price for diesel fuel (US dollar per liter) in Senegal, 1992 - 2013 Source: World Bank

time, which, if sustained, will eventually allow oil producers to offer farmers more for their seed feedstock. The production of individual farmers must dramatically improve as well, or the economies of scale that are required for the SNBP to succeed will never be achieved. The national biofuel plan projected that the raw oil from Jatropha plantations could be produced for $100 \mathrm{FCFA} / \mathrm{L}$, with a marketable biodiesel on offer for approximately $530 \mathrm{FCFA} / \mathrm{L}$, in line with Malian price indices. However, the current value of crude pressed Jatropha oil is 300 FCFA/L, and under their same calculations the market price should be a corresponding 1,590 FCFA/L, twice the current price of diesel at the pump. Following the current trend in energy price increases, and assuming no changes are made to the SNBP as it now stands, Jatropha oil will not be cost competitive with available fossil fuels for another 16 years.

Projected Jatropha Oil Price from Anticipated Seed Prices, FCFA and US \$

$\begin{array}{lcc} & \text { FCFA } & \text { US \$ } \\ \text { SNBP Seed Price Projection } & 100 & 0.20 \\ \text { SNBP Market Oil Price Projection } & 530 & 1.10 \\ \text { Actual Seed Price (2014) } & 300 & 0.60 \\ \text { Actual Fuel Pfice (2014) } & 1,590 & 3.30\end{array}$

Figure 5.5: Projected and actual seed prices, with corresponding market oil prices 


\subsection{Social Considerations for Smallholder Farmers}

There are important social considerations for Jatropha cultivation in collaboration with smallholder farmers in developing countries. The Senegal National Biofuel Program has clearly stated commitments to improving the livelihoods of rural communities though the economic activity derived from biofuel generation, and extending energy services to areas that have never had access. Former president Abdoulaye Wade believed that implementing the SNBP would help Senegal reach its Millennium Development Goals in poverty reduction and the provision of energy (Republique de Senegal, 2007). Officials with ISRA confirmed that the program was built with his conviction that biofuels would help stabilize the country and bring prosperity to rural areas, using the success of the Brazilian biofuel program as an example of what could be achieved on the African continent (P.C., March 2014).

However, many biofuel programs have been disappointing for smallholder famers, in many instances leaving them more vulnerable at the conclusion of multi-year trial periods than they were beforehand. This was particularly true in East Africa, where agronomic conditions similar to Senegal's led to poor crop performance. A study by German Technical Cooperation (2009) concluded that "it makes no economic sense for farmers, especially those that are food insecure, to be investing in a crop that will fail to yield positive returns." Longitudinal studies of crop performance prior to sweeping programs would prevent unnecessary hardship.

Farmers consulted during the course of this study understood the importance of developing local energy sources, and respondents in the regions of Fatick and Kedougou were particularly willing to take part in local biofuel initiatives to develop local energy supplies (F.S., April 2014). Fatick is centrally located, with much more restricted access to water, and requires considerable amounts of energy for water pumping, generally performed by diesel pumps. Farmers have a strong incentive to develop stable and consistent energy supplies or they risk their access to water. Kedougou is the most distant region from the capital and has traditionally had the least access to energy supplies. Rural electrification is sporadic, and farmers see modern energy services as a key element in development and progress.

For these reasons, farmers have been willing to continue their biofuel plantations with impressive resolve despite poor harvests, and misleading projections could encourage them to continue expending effort and resources for a crop that may never deliver as promised. This commitment to energy crops has not been universal, however, and officials at ISRA reported large swaths of land where Jatropha was uprooted after several years of poor performance, either to be replanted with alternative crops or left fallow or abandoned altogether (P.C, March 2014). Farmers in these areas, already resistant to change, have lost their confidence in Jatropha and 
even if improved seed varieties are eventually introduced it will be very difficult to convince them to replant.

\subsection{Alternative Value Streams for Jatropha Production}

The Senegal National Biofuel Program does not factor in the alternative value streams offered through Jatropha cultivation, focusing on the oil production capacity of the plant alone. This model may be sufficient under the low-input, high-output scenario assumptions of the SNBP, but under observed performance the economic value of Jatropha crops was insufficient. However, there are production byproducts and other sources of value that can help improve the economic balance and could make the difference between a system with negative returns and one that can perform competitively. All of the Jatropha biofuel projects surveyed in Senegal had resorted to incorporating secondary economic value from the crop's value chain in order to help finance their operations, with different strategies better suited to various business models.

\subsubsection{External Financing Tools}

Carbon credits and reforestation credits are two supporting financial mechanisms that can be implemented to support the balance of trade for Jatropha oil. These tools are especially valuable in the first several years, when plantations are being established and there is no revenue from the sale of seeds or oil. A regional consulting body tasked with promoting biofuel production in West Africa, JatroREF, has encouraged Senegalese producers to develop projects to take advantage of carbon offset schemes in three classes (1) carbon credits for emissions offsets using Jatropha biodiesel, (2) carbon credits allocated for reforestation and sequestration, and (3) carbon credits allocated for sustainable agriculture. Carbon credits are calculated differently for each of these classes, and offered by different regulatory bodies and certifying agencies. Since there is no coordinated international carbon price or tax arrangement, most of these credits are allocated by voluntary schemes or through corporate carbon mitigation programs. Mali Biocarburant ${ }^{16}$, one of the more successful biofuel producers in neighboring Mali, derives a significant portion of its operating costs from carbon sequestration partnerships with Trees for Travel and KIA Motors (2014). The Africa New Oil Corporation (ANOC) completed certification for carbon sequestration credits for reforestation in 2014 , but are the only operation in country to do so.

Although carbon credits could be an effective measure to improve the economics of Jatropha cultivation, this tool still faces many challenges to proper implementation. Primarily, the considerable devaluation of carbon credits on most international emissions trading platforms,

\footnotetext{
16 Mali Biocarburant has become one of the most successful community-based Jatropha oil processors in West Africa, and is expanding contractual agreements with farmers in Senegal and Burkina Faso. Online at: http://www.malibiocarburant.com/malibio/
} 
as seen in Figure 5.6, has significantly reduced the incentive for carbon sequestration schemes. Furthermore, the certification process is lengthy, costly and bureaucratic, and out of reach of small producers who cannot afford the upfront costs of the verification process. Officials with GERES ${ }^{17}$, a French organization that specializes in carbon financing and local energy grids that has been active in certifying projects in West Africa, confirmed that the process was so rigorous that most projects had not chosen to proceed with certification.

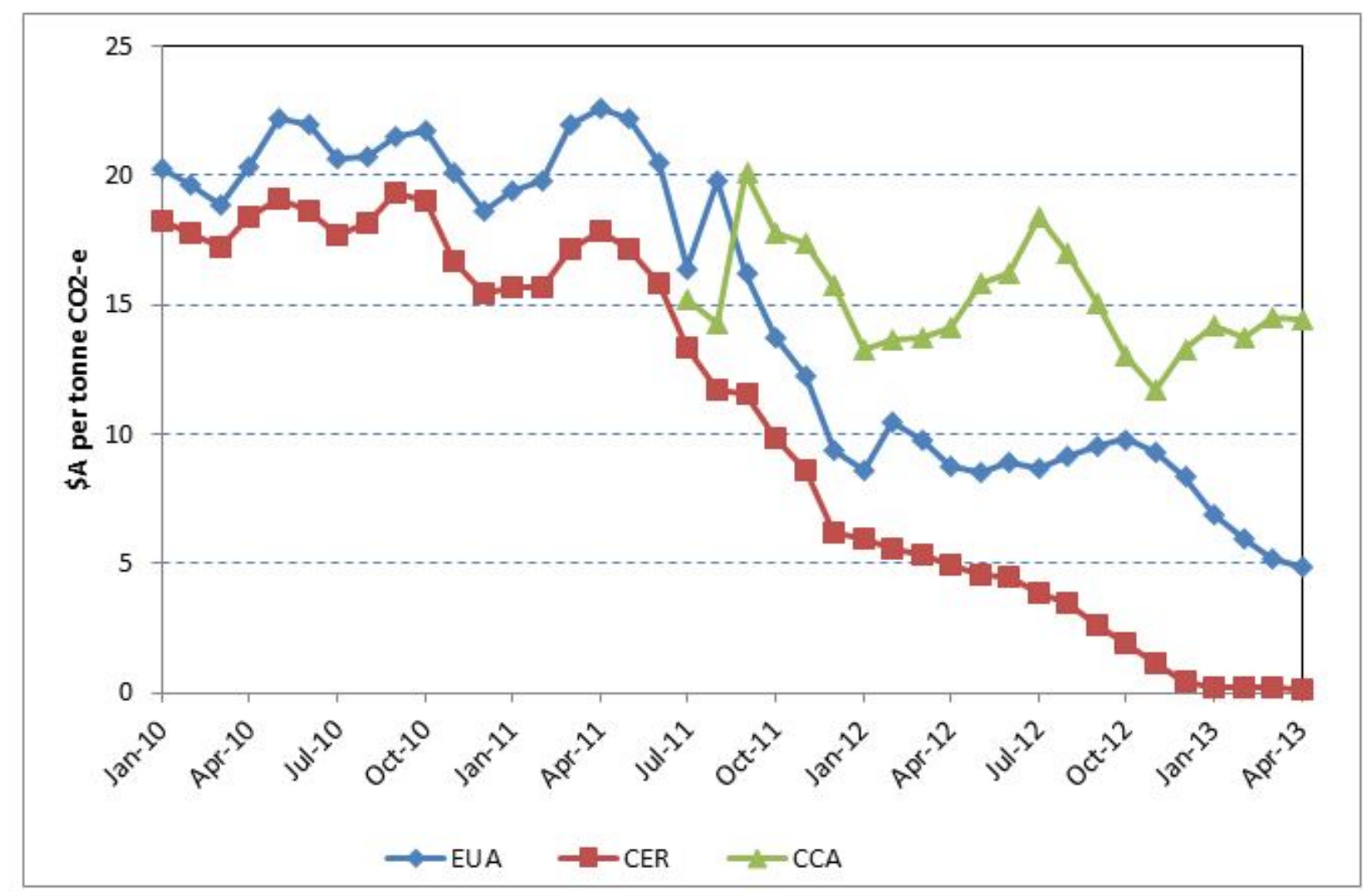

Figure 5.6: International ETS price trends 2010-13

Source: Parliament of Australia (2013)

Among the most challenging aspects was that projects could not be considered for certification unless they have been active for a minimum of 5 years, and a portion of the credit value is kept as insurance against catastrophic loss of plants by fire, pests, flood, etc. GERES evaluated a number of plants for carbon credit certification, and Jatropha has a particularly high risk profile for sequestration schemes, resulting in $35-50 \%$ of its credit value being held against

17 GERES: Groupe Energies Renouvelables, Environnement et Solidarites, provides carbon credit auditing services and Jatropha evaluations in West Africa and Asia. Online at: http:// www.geres.eu/en 
the risk of catastrophic loss. The combination of low carbon credit value and the effort required for certification has dissuaded the vast majority of project developers from participation.

\subsubsection{Oil Production Byproducts}

Under current market conditions, it is difficult to produce Jatropha biodiesel at prices competitive with fossil fuels readily available on the market. Incorporating salable byproducts from the Jatropha oil production process can help improve the financial equation, and this has been especially useful for small producers who are embedded in a tight community. The greatest source of additional value lies in the waste seed presscake derived in the pressing process, which is still rich in organic matter and retains a certain degree of its oil content unless a chemical solvent is applied in a secondary extraction. Solvent pressing requires large volumes to be commercially viable, and at present only mechanical press technology is being used in West Africa (JatroREF, 2013). Waste presscake can be sold as an organic fertilizer and soil amendment, combined with animal waste for biogas production, and returned to livestock as an energy rich feed substitute.

In addition, the waste glycerine created during the transesterification process of transforming straight vegetable oil into biodiesel can be used for soap production (JatroREF, 2012). Incorporating these value streams into the Jatropha production process has proved easier than the carbon credit certification process for smaller project developers. Technologies for Human Development (THD) has successfully marketed seed presscake in local markets in the region of Fatick, and sold initial stocks of straight Jatropha oil to soap producers since the market for biodiesel is still in its infancy. AYWA International has incorporated the press cake and centrifuge sediment into their economic calculations, with a resultant revenue increase of 17\%, as shown in Figure 5.7.

\begin{tabular}{|c|c|c|c|c|c|c|}
\hline & $\begin{array}{l}\text { UNI } \\
\text { T }\end{array}$ & $\begin{array}{l}\text { FCFA } \\
\text { UNIT }\end{array}$ & $\begin{array}{l}\text { UNIT/ } \\
\text { HR }\end{array}$ & $\begin{array}{l}\text { FCFA } \\
\text { /Hr }\end{array}$ & $\begin{array}{l}\text { FCFA/L Clean Oil Unit } \\
\text { Revenue }\end{array}$ & \% of Total Revenue \\
\hline Jatropha Oil & $\mathrm{L}$ & 631 & 6.0 & 3,815 & $\mathbf{6 3 1}$ & $\mathbf{8 3 . 1}$ \\
$\begin{array}{c}\text { Seed } \\
\text { Presscake }\end{array}$ & $\mathrm{Kg}$ & 65 & 11.5 & 746 & 123 & 0.5 \\
\hline $\begin{array}{c}\text { Centrifuge } \\
\text { Sediment }\end{array}$ & $\mathrm{Kg}$ & 65 & 0.4 & 27 & 4 & $\mathbf{1 0 0}$ \\
\hline $\begin{array}{c}\text { Total Sales } \\
\text { Revenue }\end{array}$ & & & 4,588 & $\mathbf{7 5 9}$ & \\
\hline
\end{tabular}

Figure 5.7: Sales revenue from Jatropha and associated byproducts Source: AYWA International 


\subsection{Case Study Economics}

The social and economic determinants of success or failure in Jatropha cultivation varied significantly across the survey area, and this variety of conditions would ultimately have a major impact on the implementation of the Senegal National Biofuel Program. The SNBP was designed to be carried out universally across Senegal, in partnership with the 321 administrative rural communities in the country irrespective of their agronomic capacity, political organization, committed infrastructure or financial condition. The uniformity of the plan was intended to bring the prosperity of biodiesel production to all regions instead of selectively investing in particular regions or partnering with specific commercial interests. The effect of this decision was an unfocused distribution of resources and a plurality of methodologies for cultivating and planting, transforming and refining the oil, and developing a sales model for distribution and consumption.

In this section we will present three case studies that shed light on the particular aspects of projects in the regions of Fatick (western Senegal), Kaffrine (central Senegal) and Kedougou (eastern Senegal) that have approached Jatropha cultivation under very different conditions. A primary focus of this research was to determine why and how Jatropha biofuel operations had achieved positive results or failed to succeed, and to examine the unique circumstances of these projects to provide insight on the many relevant elements that must be considered when building a biofuel project. Interviews and surveys were conducted in consultation with both commercial project coordinators and oil producers as well as smallholder farmers to present the challenges faced by multiple stakeholders.

These case studies are intended to provide a brief snapshot of the projects surveyed in this research study, and are not a comprehensive representation of all organizational models that have been tested in Senegal under the SNBP. Many of the largest investments in the biofuel sector have ceased operation in the country and have not been evaluated. Each case will provide a brief analysis of the entity under observation, with critical information pertaining to location, population dynamics, market conditions and organizational structure. The underlying conditions of each case will then be presented, followed by a project history and the primary outcomes. The strengths and weaknesses of each case will be discussed, with pertinent information concerning political, agronomic and socio economic challenges faced in these regions. 


\subsubsection{Case Study 1: Fatick-Technologies for Human Development (THD)}

Region: Fatick Capital: Fatick

Land Area: $\quad 6,849$ / sq km (2,644 sq mi)

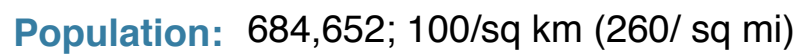

Case Study Entity: Technologies for Human Development (THD)

Type of Entity: Joint Venture; Community Based

Products: Seeds, Seedlings, Pressed Vegetable Oil, Presscake Fertilizer, Soap, Other plant oils

Target Market: Domestic, local community

Investment Structure: Moderate capital investment, domestic and international investors

Energy Services: Grid connectivity in towns; Diesel generator electrification in select villages

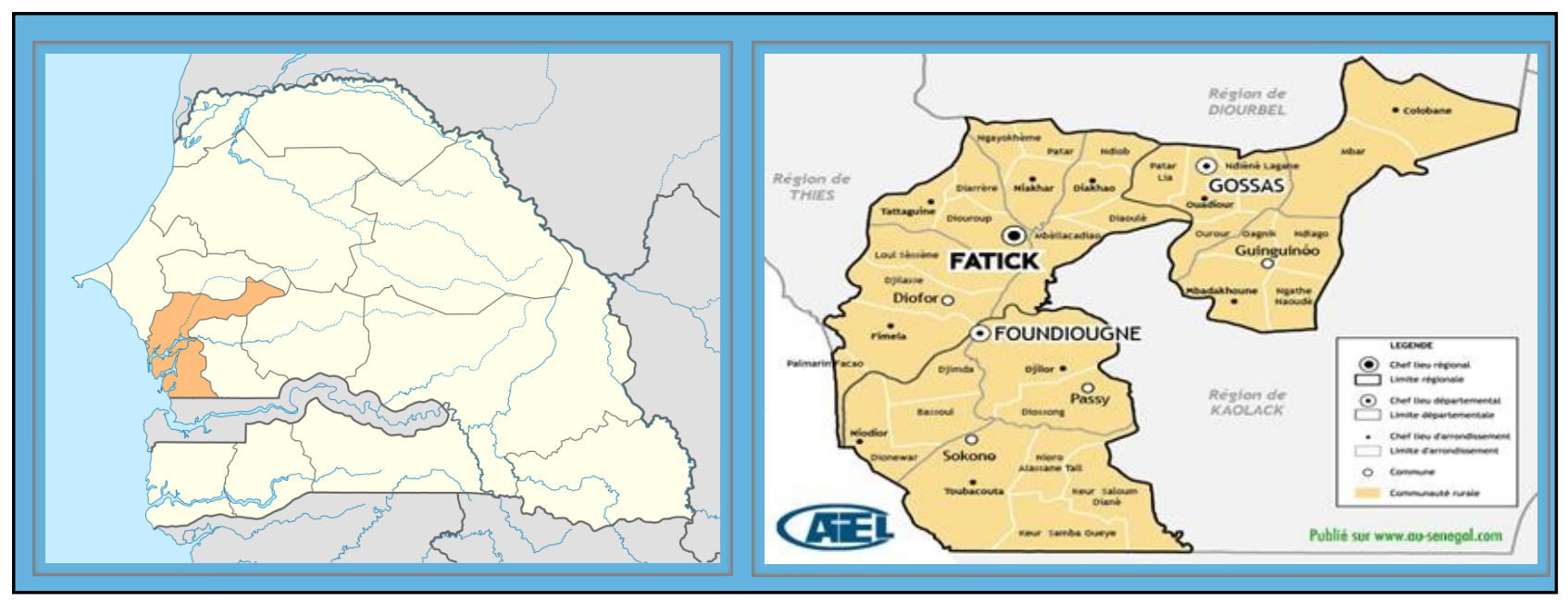

Underlying Conditions:

The Fatick region is the closest to the capital and the most accessible. Transport networks in Senegal are limited and road conditions poor; therefore access to markets and proximity to the capital are advantages in this area. This region is the most densely populated and therefore has the highest energy demand. Power is provided through grid access in larger towns and diesel generators in smaller communities, though many villages have no electrification and rely on biomass for heating and cooking. Jatropha based fuels could be consumed by the local population, who require considerable amounts of fuel for pumping water, or sold to consumers in the adjacent capital. Agronomically, Fatick has relatively poor conditions for growth, characterized by a restricted rainy season, sandy soils with quick drainage, and little nutrient content. Jatropha has been cultivated in this region for many generations and is well known to the local population, though it is not commonly used for economic gain. 


\section{Project History and Outcomes:}

Technologies for Human Development (THD) has been working to develop Jatropha biofuels since 2008 and remains one of the longest continuous operations in the country. The goal of THD was to create a closed loop system of producers and consumers operating in concert within the region. In this system, smallholder farmers would grow Jatropha as a hedge crop surrounding their traditional full-field agriculture plots and sell their harvested seeds to a centralized cooperative seed pressing mill. The co-op would process and refine the fuel, and market by-products for additional value. Biofuel from the local

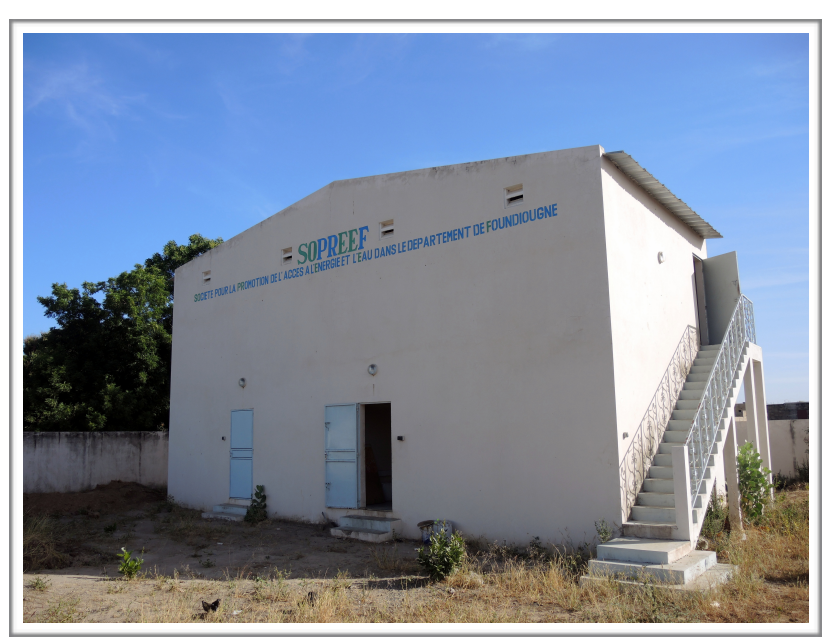

Figure 5.8: Technologies for Human Development (THD) pressing facility in Fatick mill would then be sold at guaranteed prices to service deep-bore water pumping stations that are currently reliant on diesel powered generators. The entire concept was designed to insulate this region from energy spikes and the perpetually rising costs of liquid fuels that could one day threaten local water supplies and the livelihoods of these communities.

THD was built as a collaborative enterprise, partnering with the Fatick region's Farmer Federation and guaranteeing smallholder farmers one of the highest prices for Jatropha seed in West Africa (100 FCFA/Kg). THD currently works with over 200 farmers, extending seeds, technical expertise, and organizing collection and payments, and 180,000 seedlings have been planted under their program. An oil press and processing facility, the only functional one of its kind in Senegal, has been built in the town of Sokone, central Fatick, and serves 10 villages within a 50 kilometer radius. Although they have the capacity to produce 50,000 liters of fuel per year, early crop failures and consistently poor agronomic conditions have limited the seed supply from smallholder farmers. No Jatropha biodiesel has been commercially produced, though planting and cultivation continues. The oil

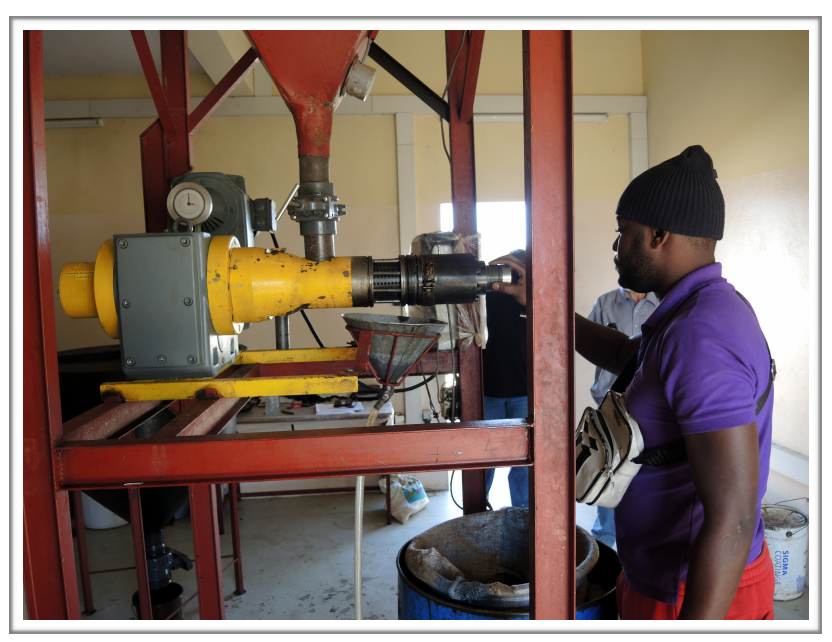

Figure 5.9: THD oil press, an AXIA $4 \mathrm{KW}$ model with $50,000 \mathrm{l} / \mathrm{yr}$ capacity 
press continues to operate with other highvalue seeds sourced from the community, including Neem, Moringa, Sesame, and Baobab, and the revenues from these oils has financed the Jatropha biofuel program.

Despite early setbacks, THD has a long term strategic plan to replicate the community based oil press model and produce a series of micro-biofuel production and consumption nodes throughout the country. Under theoretical conditions and by the calculations of THD staff, up to 18

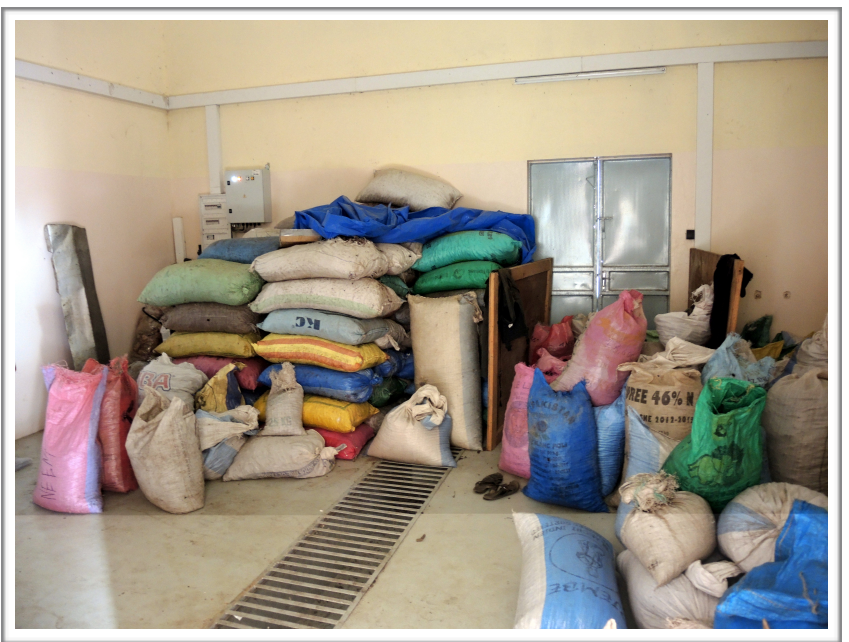

Figure 5.10: Seed and press cake storage at the THD pressing facility pressing facilities with a capacity of 300,000 liters/yr could be operational in Senegal based on the Jatropha growing conditions in the country. The success of this model relies on its decentralized nature. Transport is costly and difficult in a country with a poor infrastructure; thus production and consumption in the same area drives costs down and reduces waste. The goal is for each of these pressing facilities to be independently operated and financially self-sufficient; however THD operations are still dependent on the support of several external funding sources, including two French nongovernmental organization, KINOME and Present D'Avenir, which provided financing for the original pressing facility and the technical assistant who liaises with farmers on agronomic issues. 


\section{Strengths and Weaknesses:}

Technologies for Human Development has not successfully produced Jatropha oil in line with the expectations of the SNBP, nor in line with its own aspirations, and still faces many challenges. It has created a strong working collaboration with the community and has gained the trust of local farmers. This has allowed them to share risk among multiple partners and develop a system in which financial gain will be realized throughout the value chain. Socially, this model is heavily focused on local wealth creation and will provide long term job opportunities and

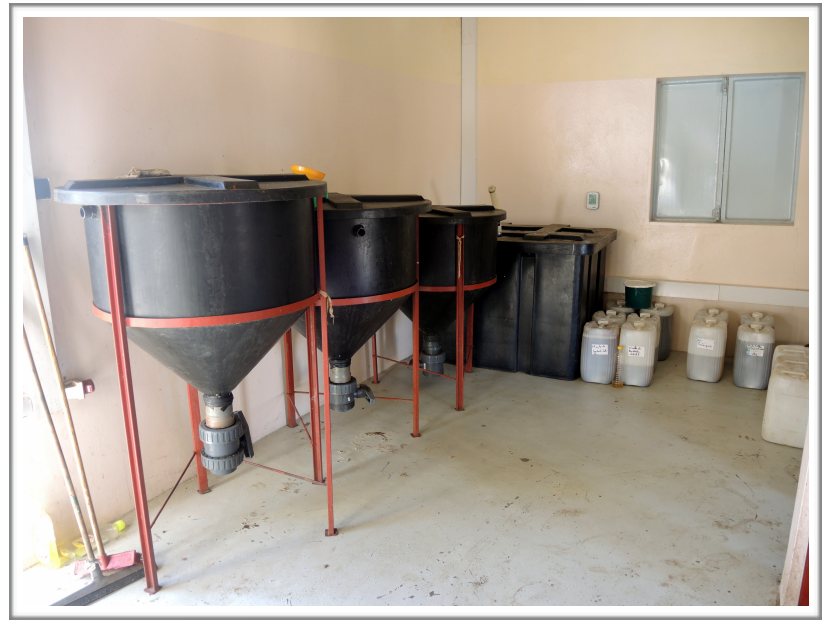

Figure 5.11: THD oil decantation and storage tanks extend energy services while minimizing transport costs and system inefficiencies. Farmers are not at risk of losing their land, and the technical guidance of THD should allow them to increase productivity over time.

The close collaboration with farmers has created its own difficulties, however, and there have been significant challenges with working in concert with the Farmer Federation, who have tried to refuse seed sales until purchase prices are raised beyond the point of economic exploitation. Farmers have not followed the advice of THD regarding agronomic best practices in many cases, and replicating results across the participating villages has been very difficult. An emphasis on community integration has come at the cost of control, and their outstanding challenge remains in ensuring adequate seed harvests to cover the operating expenses of the oil pressing facility and staff.

Financially, THD has been very nimble, and its single greatest strength lies in the commitment of its main institutional partner to the development of a local biofuel program. The structure of the organization has evolved over time and repeatedly attracted external funding from a diverse range of investors from government, private equity, and non-governmental organizations alike. A relentless focus on the long term viability of Jatropha biofuels in Senegal versus short term financial gain has forced them to dynamically manage their priorities, currently focused on the valorization of alternative plant oils. Among the organizational structures observed in this study, THD has the strongest prospect of success to the mutual benefit of institutional investors and smallholder farmers. 


\subsubsection{Case Study 2-Kaffrine; Africa National Oil Corporation (ANOC)}

Region: Kaffrine

Land Area: $\quad 11,262 \mathrm{sq} \mathrm{km} \mathrm{(4,348} \mathrm{sq} \mathrm{mi)}$

\section{Capital: Kaffrine}

Population: 544,011 ; 48/ sq km (130/ sq mi)

\section{Case Study Entity: Africa National Oil Corporation (ANOC)}

Type of Entity: Agro-Industrial; Domestic and Export Orientation

Products: Seeds, Straight Vegetable Oil

Target Market: Domestic, export

Investment Structure: High capital investment, domestic and international investors

Energy Services: Grid connectivity in towns; Diesel generator electrification in select villages

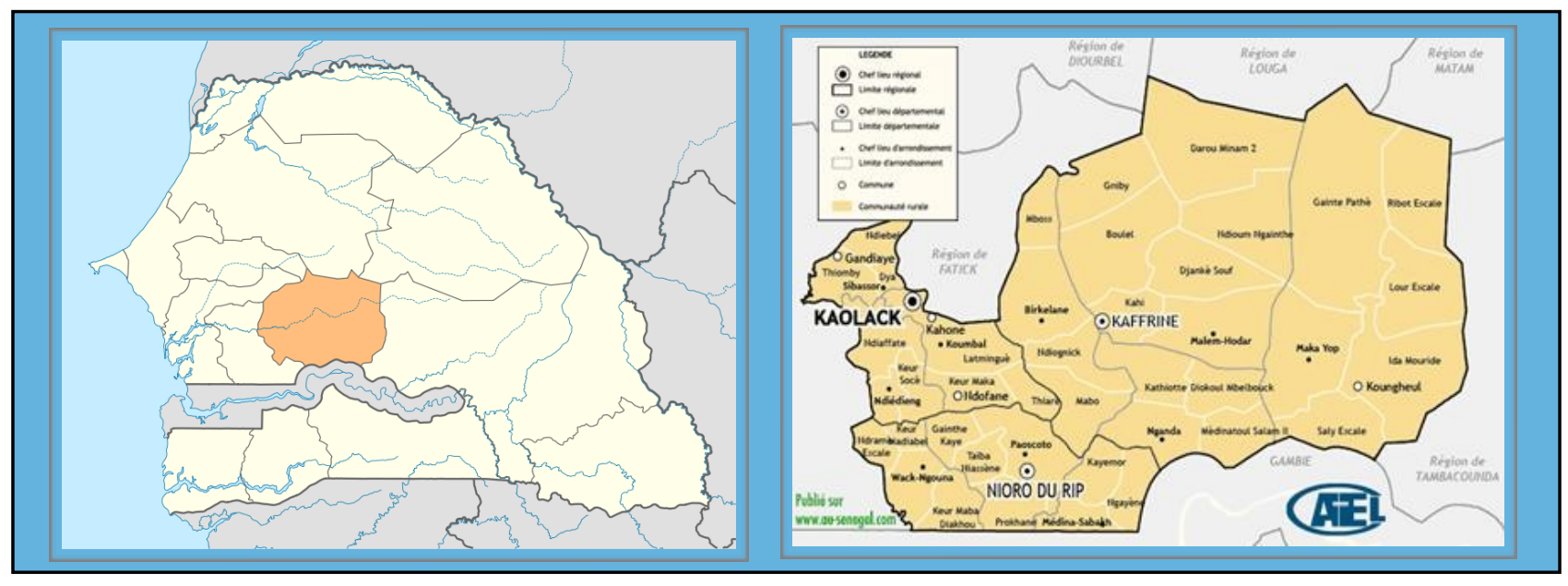

\section{Underlying Conditions:}

The Kaffrine region is centrally located and reasonably accessible to the capital. Transport networks run directly through the center of the region, with rail and highway links providing access to markets in the capital and neighboring Mali. This region is less densely populated than Fatick, yet still has high energy demands for urban centers and irrigation systems for crop plantations. Access to the electrical grid is possible in larger towns and diesel generators exist in smaller communities. Villages mainly rely on biomass for heating and cooking. Jatropha based fuels could be consumed by regional water pumping stations or sold to consumers in the capital. Agronomically, Kaffrine has average conditions for growth, with more rainfall, yet sandy soils with poor nutrient content remains a problem. Jatropha has much potential in this region due to the experience of the local population with large peanut plantations, which have performed poorly in economic terms and need to be replaced to provide jobs and stimulate the local economy. 


\section{Project History and Outcomes:}

Africa National Oil Corporation (ANOC) is the sole remaining commercial Jatropha corporation using a full-field plantation style in the country, having started operations in 2009. The goal of ANOC was to develop a central processing facility that could contract with farmers using extended land leases and control the agronomic conditions on these holdings. Initially, 1411 hectares of degraded land were leased for 25 years, with further expansion around the towns of Gossas, Kaolack and Kaffrine. The harvested seeds would be pressed on site and consumed by associated business interests or contracted out

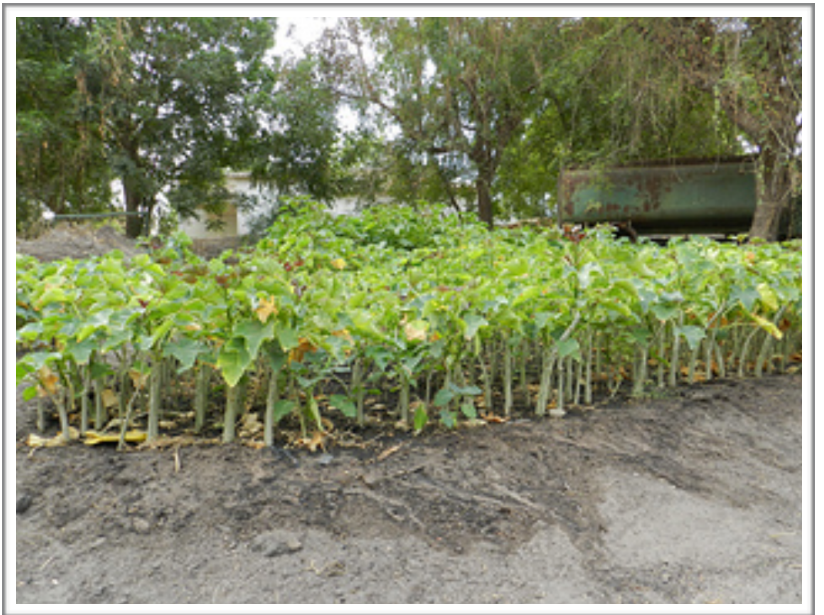

Figure 5.12: Africa National Oil Corporation seedling nursery, Kaffrine Source: ANOC to external facilities. The business model relies on a heavy initial capital input and several years of losses before oil production. On its inception ANOC was certified under a voluntary carbon sequestration scheme and received funds as a Verified Carbon Standard (VCS) partner for the value of the carbon in the Jatropha plants in their plantations. It has since undergone a further carbon sequestration audit by GERES and has started claiming carbon credits under their scheme since 2014. ANOC was not concerned with revenues derived from by-products, and has focused on seed production and large oil contracts.

The prime differentiating factor for ANOC was the intent to use all the oil produced in its plantations for other economic activities that would add value to the Jatropha product chain. The primary investors operate large ice factories on the coast serving the commercial fishing industry, and rising energy costs were making their activities cost prohibitive. ANOC and these commercial ice producers would act together to guarantee a market for the oil generated from the Jatropha plantations, and secure liquid fuel for their diesel generators at a predictable cost with long-term contracts.

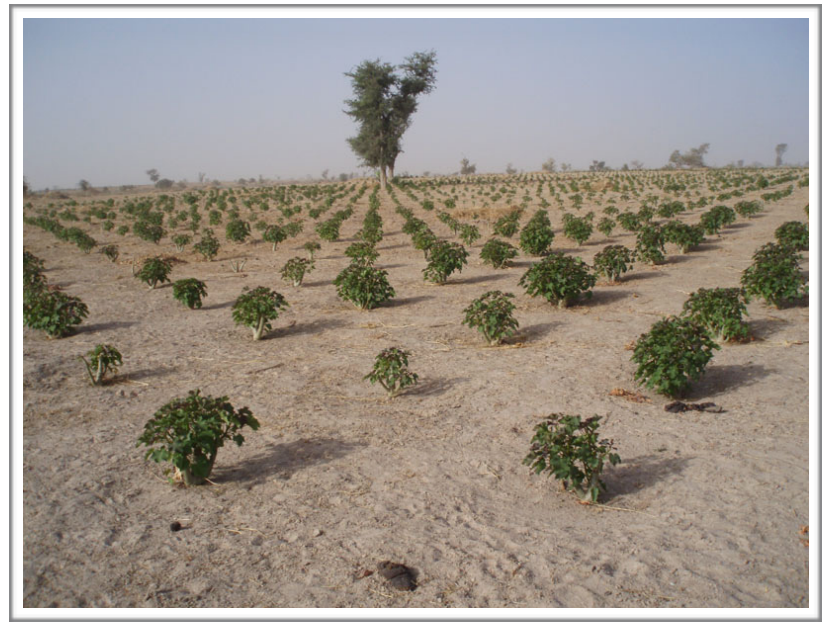

Figure 5.13: ANOC full-field plantation with $2 \mathrm{~m} \times 2 \mathrm{~m}$ spacing, year one Source: ANOC 
This arrangement does not favor smallholder farmers, as their lands are being controlled by an outside interest that will export the derived liquid fuels and internalize all of the profit elsewhere. This system creates far fewer jobs than joint-ownership schemes that engage smallholder farmers and provide multiple economic opportunities. However, project coordinators with ANOC explained that centralized production allows for more control, and under their $2 \mathrm{~m} \times 2 \mathrm{~m}$ spacing

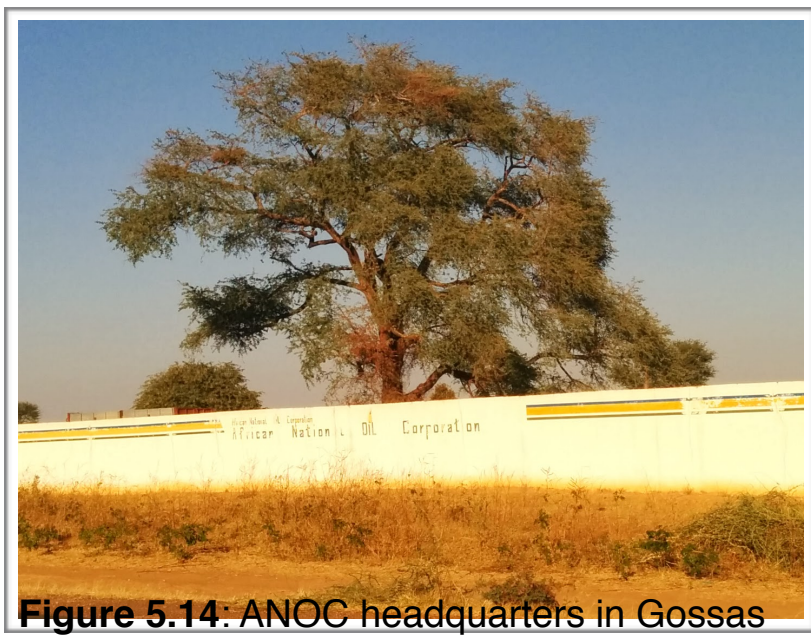
regime, they can effectively manage 3.5 million Jatropha bushes on the initial 1,411 hectares under cultivation. Assuming conservative figures of 3 tons of seed per hectare, they could harvest 4,200 tons of raw feedstock per year, yielding 1,411,000 liters of Jatropha oil.

ANOC has not successfully harvested significant quantities of seeds from its plantations to date. Agronomic difficulties with early seed stock and political challenges with farmers and competing investors were major setbacks, but they plan to continue with the project. Although the initial intent was to provide oil for the commercial ice facilities on the coast, in keeping with the guidelines of the SNBP, they have signed contracts with an export organization which has guaranteed to purchase the entirety of their seed supply. This has eliminated their need to invest in pressing facilities and absorb the cost of biodiesel transesterification. 


\section{Strengths and Weaknesses:}

Despite the various challenges that the Africa National Oil Corporation has faced in their early years of Jatropha cultivation, they have remained operational and active long after most of the plantation style investments withdrew from Senegal and focused their resources elsewhere. Like THD in the Fatick region, their core investors have a long term strategy that has allowed them to sustain early losses with the expectation of future remuneration. They have the advantage of strong capital resources that has allowed them to make necessary investments in advanced

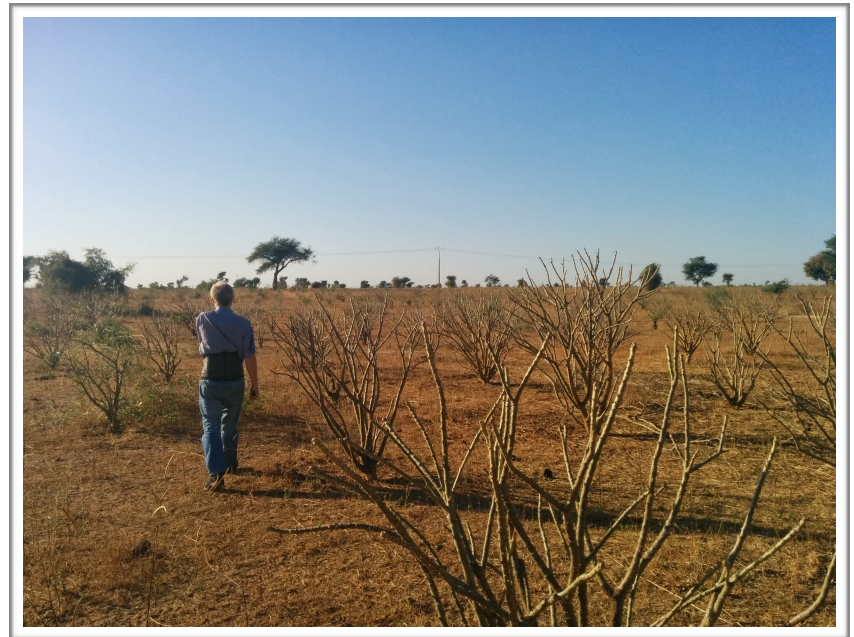

Figure 5.15: ANOC full-field plantation in year five agricultural implements and their centralized operating procedures allow a level of control that more dispersed operations cannot guarantee. As they learn the agronomic characteristics of Jatropha and improve their techniques, they will be able to apply those lessons with consistency across their plantations. The scope of this program is arguably the closest representation of what the SNBP hoped to stimulate, and this methodology is consistent with achieving the ambitious goal of energy self-sufficiency on a national level.

The centralized control and scale of their plantations has also allowed ANOC to tap into carbon sequestration credits that smallholder farmers would not have the resources to audit and quantify. However, because the carbon markets are severely depressed, the economic contribution of these credits is a small portion of the operating expenses of the corporation and the wisdom of investing the time and resources in the external auditing process is questionable. Their business model has come at the cost of the communities within which they operate, and the commercial advantage that this provides the organization has created a disadvantage for local communities who were supposed to be the major beneficiaries under the SNBP. Selling the seed feedstock to an export-oriented entity is contrary to their initial goals, and undermines any attempt to create a domestic biofuel market. If the social impact of Jatropha cultivation were weighed equally with the economic gains, this methodology would be underperforming due to its marginalization of smallholder farmers and the surrounding communities. 


\subsubsection{Case Study 3-Kedougou; Trees for the Future (TFF)}

Region: Kedougou

Land Area $16,800 \mathrm{sq} \mathrm{km}(6,500 \mathrm{sq} \mathrm{mi})$

Case Study Entity: Trees for the Future (TFF)

Type of Entity: Agricultural Extension Agency

\section{Products: Seeds}

\section{Target Market: Domestic}

Investment Structure: No production investment; Non-governmental organizational donor financed Energy Services: Limited electrification in towns; Diesel generator electrification rare in villages

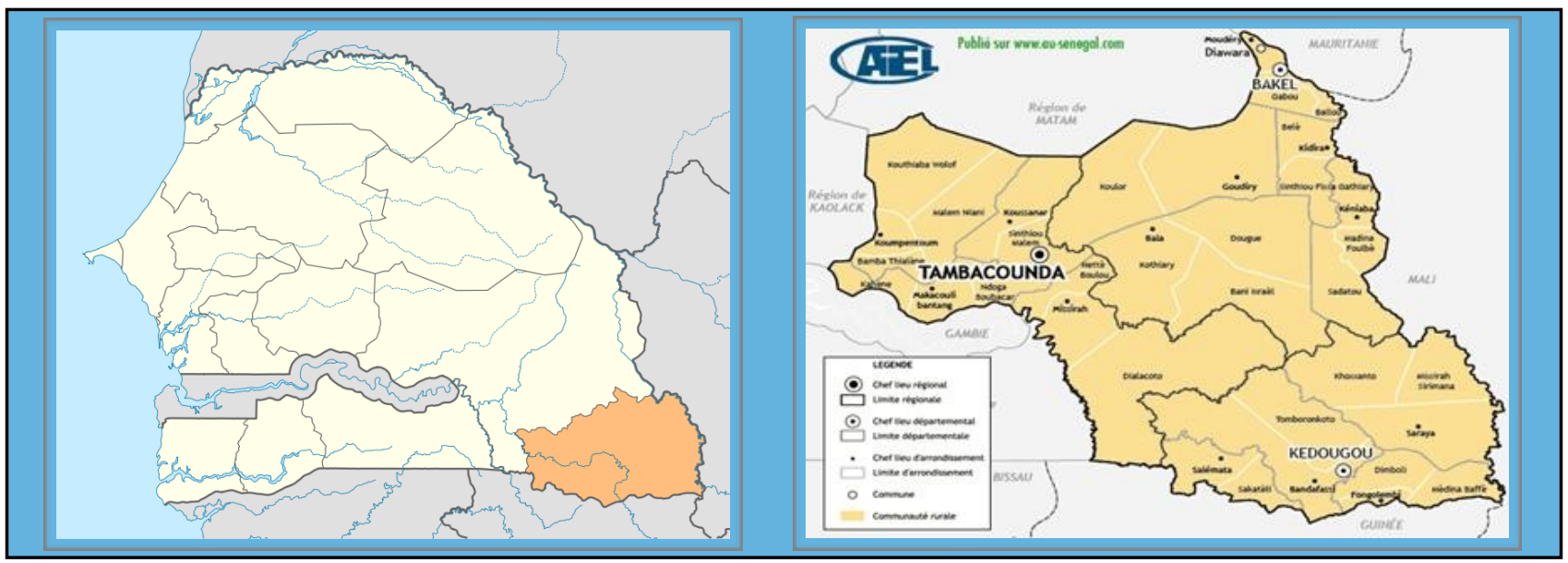

\section{Underlying Conditions:}

The Kedougou region is the most distant from the capital and the most isolated economically. Market access is a major challenge, and transport costs add significant cost margins to agricultural products from this area. With the lowest population density, the region is composed primarily of small villages that meet their energy requirements through direct biomass combustion for cooking and heating. The main urban center, Kedougou, and a series of commercial mining operations could consume the oil produced in this area, and rural electrification is among the goals of the government. Agronomically, Kedougou has the best conditions for Jatropha production, with much higher annual rainfall than the other case study regions and rich soils that have traditionally allowed Jatropha to thrive. This is the poorest region in the country, and a local biodiesel production system would be a valuable sector of the economy creating job opportunities for a large youth population and providing energy services in an area that has largely been underserved by the energy infrastructure of the country. 


\section{Project History and Outcomes:}

Trees for the Future has been operational in the Kedougou region for 13 years extending agricultural techniques and seeds for agroforestry programs with smallholder farmers. The US based organization has been working on reforestation projects for 25 years and is active in 16 countries in Africa, Asia and South America. They do not have any goals for financial gain, and are oriented towards information, education, and seed extension to improve the livelihoods of small rural communities. At present, one field technician is employed to survey villages in

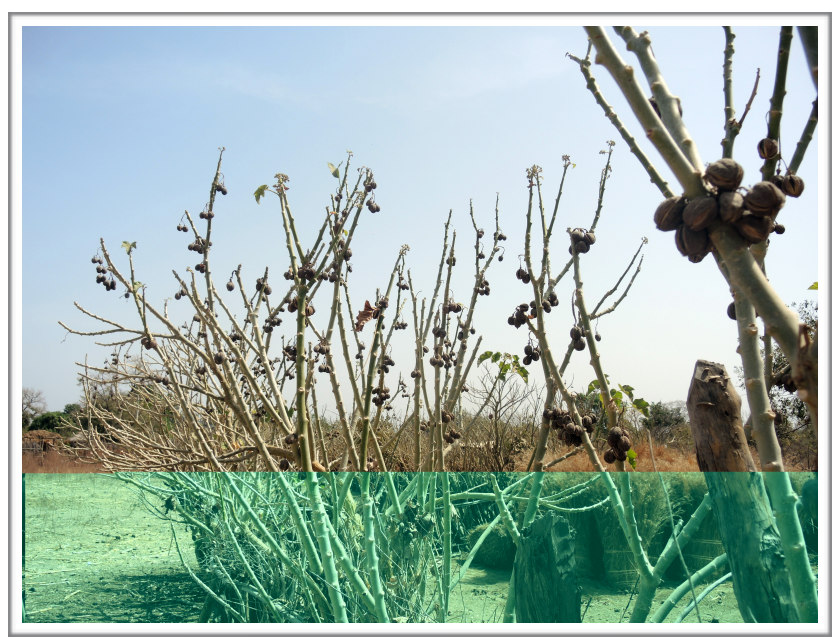

Figure 5.16: Above average Jatropha agronomic performance, Kedougou the entire region, covering more than five dozen communities. Trees for the Future was working with Jatropha before the implementation of the SNBP, with the sole goal of encouraging farmers to incorporate it as a hedge crop. They provide communities in the region with 200,000 - 300,000 seeds on an annual basis for direct planting, and have developed a test site to evaluate the growth characteristics of plants propagated under different conditions.

Jatropha has been used as a live fence for many generations in this region and is well known to farmers, though its economic importance has not been recognized. Aside from its use as a hedge crop, Jatropha has been employed for traditional soap fabrication and is known for its medicinal properties, though these uses are being lost with the introduction of modern goods. Trees for the Future estimates that there are at least 1,000 farmers in the region who could provide seed from their current stock of plants, which provide harvestable feedstock two to three times a year depending on the length of the rainy season. Their agents principally buy seeds from three communities near the Guinean border - Kafori, Toge, and Baku - which have very robust plants that produce well. In the early stages of the SNBP, the demand for seeds to

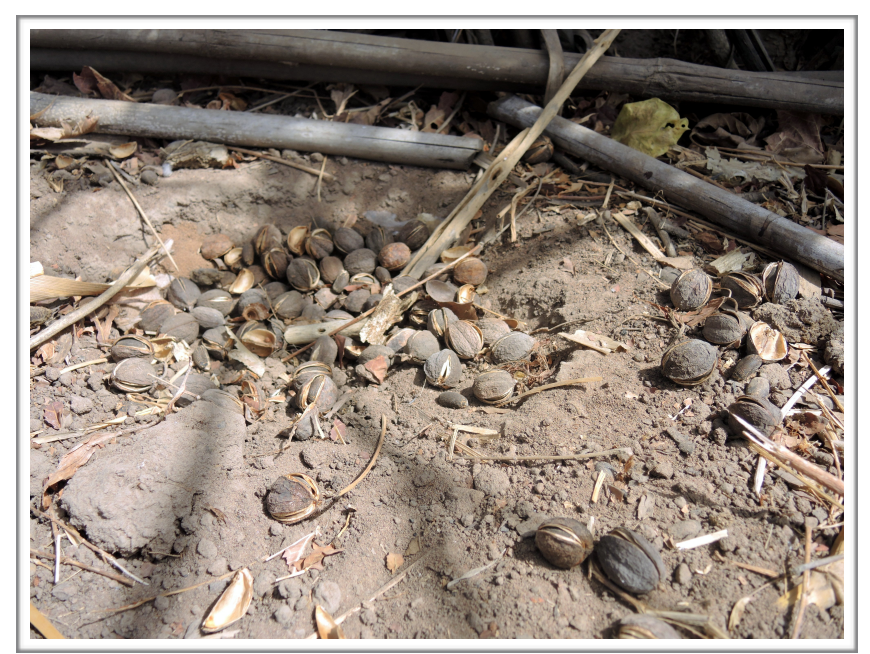

Figure 5.17: Unharvested Jatropha seed in the village of Kafori, Kedougou 
supply the center of the country was so high that prices were elevated to more than 500 FCFA per kilogram at one point, and this has since deterred farmers from selling their seeds at more modest prices. TFF has tried to explain to farmers that they will need to reduce their price expectations if they intend to sell seeds with large volume. However, the vast majority of the Jatropha seeds that are produced presently are not harvested whatsoever, and simply fall to the ground.

Trees for the Future currently has no

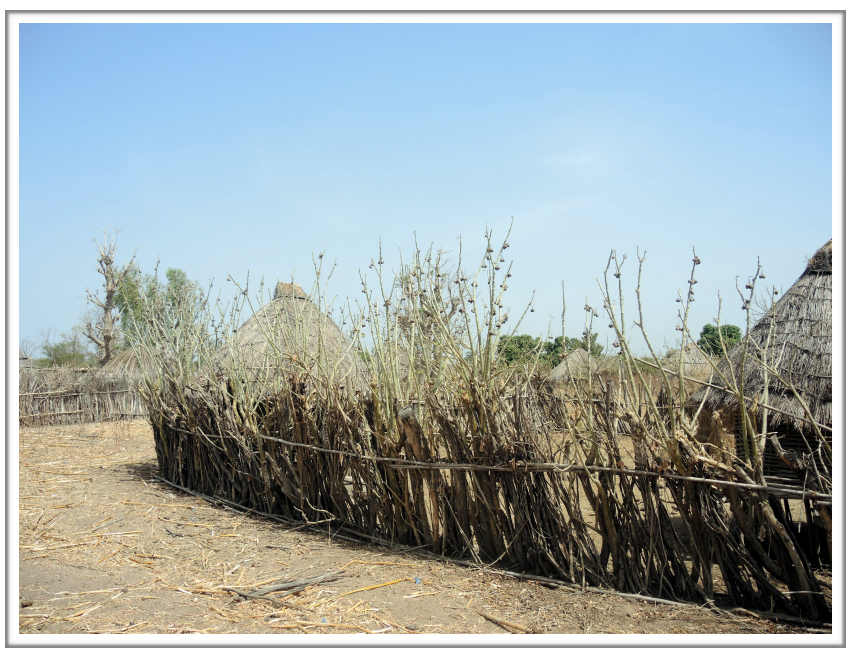

Figure 5.18 : Jatropha being used as a live fence in the village of Kafori, Kedougou plan to capitalize on the Jatropha production in the region, and will continue with its tree extension services. This is due in part to a lack of financing and a shortage of staff, but also because they have not built the technical capacity to store, press and market the Jatropha oil or identify partners who could help them with these steps. Their distance from the capital and the cost of transport is seen as a limiting factor to their production capabilities, although there are major oil users in the region who could absorb the liquid fuels produced under such a program. Farmers surveyed in the region expressed an eager willingness to build a local energy production system based on Jatropha oil, and because less than $5 \%$ of rural communities in this region have modern energy services, there is a large growth capacity. 


\section{Strengths and Weaknesses:}

The Kedougou region has the best growing conditions for Jatropha curcas in the country, with higher than average rainfall and comparatively rich soils, with a history of robust growth. It is a familiar crop for smallholder farmers, who have used it for many generations, and produces harvestable seeds two to three times a year. The regional capital, Kedougou, generates $100 \%$ of its electricity needs from a central diesel generator, and several commercial mining operations in the region rely on diesel power stations for their energy needs, suggesting a strong consumer market for liquid fuels produced locally. Based on the number of

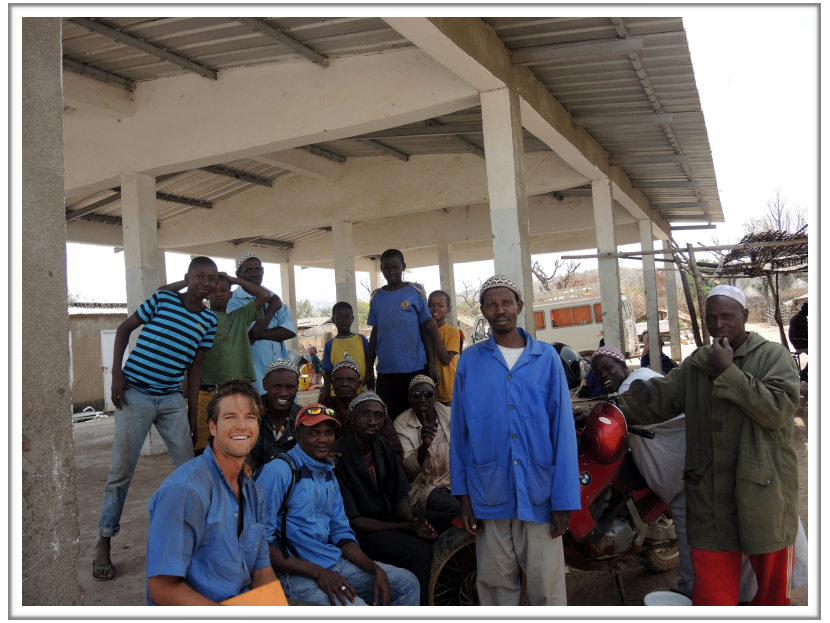

Figure 5.19: The author with Trees for the Future extension agent Karamba Diakhabi and farmers in Kafori farmers who are working with Trees for the Future in their current activities, as many as 130,000 liters of biofuel could be derived from $400,000 \mathrm{~kg}$ of seeds if harvested and processed, generating approximately 80 million FCFA (156,000 USD) for the local economy. If improved seed varieties are introduced and holdings are expanded within calculated boundaries, this could rise to 400,000 liters generating 240 million FCFA (480,000 USD). These figures only encompass $1 \%$ of the region's active farmers, leaving a large growth margin to produce a selfsufficient energy microgrid in southeastern Senegal.

Despite the potential of the region to produce large quantities of Jatropha oil, there is presently no guaranteed market for farmers to sell their Jatropha seed, and thus no incentive to pursue the plant as a contributor to their crop plantations. Due to transport costs, commercial fees and taxes, sending seeds to organizations that have established pressing facilities in the Fatick region would reduce the price of Jatropha seed from $100 \mathrm{FCFA} / \mathrm{Kg}$ to between $55-60 \mathrm{FCFA} / \mathrm{Kg}$, which is below the threshold at which the effort is worthwhile for local farmers. Alternatively, establishing a local pressing facility to service the Kedougou region directly would cost approximately 50 million FCFA (100,000 USD), which is more than local banks and credit unions are currently willing to extend on loans. The main weakness is the lack of a coordinating body, and unless a private or nonprofit organization with adequate financing moves in to develop the market and organize smallholder farmers, the biofuel capacity of the region will remain untapped. 


\subsection{Conclusion}

The socio economic outlook for Jatropha cultivation as a biofuel feedstock in Senegal is beset by many challenges, and the Senegal National Biofuel Program has failed to deliver the results outlined in its initial plan. Based on the interviews performed with program managers and smallholder farmers, one can conclude that the current performance of Jatropha curcas in Senegal does not justify the resources required for its cultivation. It has neither generated economic prosperity for commercial interests, nor created job opportunities or a new economy of biofuels for smallholder farmers and rural communities. Poor agronomic conditions, paired with the low price of available liquid fuels, especially diesel, have made the economies of Jatropha oil production very hard to realize. This combination of market forces has driven the vast majority of commercially oriented projects to abandon their holdings, from an estimated 24 holdings after the introduction of the SNBP in 2007, to two in early 2014. Beyond the economic constraints, there are important social challenges to biofuel production specific to different production models that have implications for the communities contributing to Jatropha cultivation.

The Senegal National Biofuel Program had projected goals of producing approximately one billion liters of salable Jatropha biofuel after five years of commencement, under the assumption that 321 rural communities throughout the country would be harvesting $10-12 \mathrm{~T} / \mathrm{ha}$ of seed from 1,000 hectares of planted land. This result has not been achieved in a single one of the rural communities, under even the best conditions. Furthermore, the financial projections of the SNBP proposed that smallholder farmers could expect a price of 100 FCFA per liter of oil, which equates to approximately $35 \mathrm{FCFA} / \mathrm{Kg}$ of seed, or roughly $30 \%$ of the value of seeds being purchased in 2014, and between $5-10 \%$ of the price of seed at their peak. In this regard, the SNBP was fundamentally flawed in their price projections for Jatropha biofuels, and it remains unclear whether Jatropha biofuel can be competitively produced under present market conditions. Currently, crude pressed Jatropha oil is $300 \mathrm{FCFA} / \mathrm{L}$, for a resultant biodiesel price of 1,590 FCFA/L, twice the price of diesel at the pump. Following the current energy price trends, Jatropha oil will not be cost competitive with available fossil fuels for another 16 years.

Case studies of operational programs in Fatick, Kaffrine and Kedougou suggest that Jatropha could be successfully exploited for commercial purposes under the appropriate framework. Full field, plantation style cultivation of Jatropha may result in a lower per-kg cost of seed that would yield a salable oil at a much lower cost, but with less economic gain for the local community and fewer jobs created for smallholder farmers. This model also requires a heavy initial capital outlay which may not begin to see returns for at least five years, and is reliant on a patient investor who can afford to offset early losses with better returns once plants mature and 
begin producing significant quantities of seeds. This business model has the advantage of centralized control, and its scale means that it can access alternative funding sources, such as carbon offset and reforestation credits through external partners, as well as lock in large contracts with institutional buyers.

The alternative is a a highly dispersed and community focused model creating strong relationships with smallholder farmers planting Jatropha as a live fence around existing agricultural plantations. This model is less capital intensive, and creates more value and economic activity for a number of actors, including farmers, processors and commercial oil onsellers. There is a greater emphasis on the valorization of byproducts in this approach, with contributions from the seed presscake as a fertilizer, waste glycerine as a soap feedstock, and organic residue for biogas. The dispersed nature of this model creates difficulties in managing the agronomy among hundreds, if not thousands, of contributing farmers, and auditing for carbon and reforestation credits becomes prohibitively expensive. However, the emphasis on creating an all-inclusive Jatropha economy on a community scale would reduce transport costs, provide more economic activity for local farmers, extend energy services to previously unserved areas, and insulate the community from external energy price shocks.

Current conditions are not favorable for Jatropha cultivation in Senegal, and until agronomic shortcomings are addressed, it is not advisable that farmers pursue Jatropha cultivation for any purpose other than as a live fence. Monocrop and intercrop plantations are still highly speculative investments that put smallholder farmers at undue risk of crop failure and do not provide an adequate return. The best production model to meet the economic and social requirements of the SNBP would entail close collaboration with smallholder farmers, active valorization of Jatropha biofuel byproducts and the development of local energy service networks to maximize value chain efficiency. 


\section{Chapter 6 - Policy Limitations}

\subsection{Introduction}

This chapter addresses the final area of focus of this research project: the policy limitations relating to Jatropha cultivation for biofuel production in Senegal. The Senegal National Biofuel Program was created under a paradigm of energy insecurity, rapidly escalating energy prices, and intense shifts in the population distribution in the country, from a mostly agrarian and rural population to an increasingly urban one. The Senegalese government, in its urgency to meet the rising energy demands of the country, drafted the SNBP in 2007 with the ambitious goal of replacing the nation's diesel fuel requirements with domestically derived Jatropha biodiesel, drawing from international examples and a swiftly rising tide of bioenergy developments emerging across West Africa. The plan was drafted under the direction of the Ministry of Agriculture, with technical guidance from the Senegal Institute for Agricultural Research (ISRA) and supported by a number of affiliate agencies and organizations. However, there has been no clear regulatory structure encompassing implementation, monitoring and evaluation, enforcement or policy review. The scope and breadth of the plan were comprehensive of economic, political and social impact areas, but little has been reported on the effectiveness of the plan to reach its goals even after the date of its intended completion in 2012.

This chapter of the report will discuss the policies that were established to support the Senegal National Biofuel Program and other political structures that were developed to nurture it. International projects and national programs were very influential in the creation of the plan, and we examine key differences between their implementation and the SNBP. Using supporting literature and interviews with key policymakers, institutional actors, and commercial project directors, the adequacy of the supporting policy is discussed. Land use and the prevalence of large scale land grabs in neighboring African nations are concerns that could have a major impact on future biofuel policies, and the experience of smallholder farmers in this area is presented. Due to a lack of an official regulatory body to monitor and enforce the SNBP, the policies of private Jatropha project developers, financiers and non-governmental actors were largely voluntary, and their influence on the industry is addressed. All of these elements played their distinctive roles in the outcome of the national plan, and they must be weighed together to reveal the adequacy of the policies created to guide the emergence of the fledgling Senegalese biofuel industry. 


\subsection{Underpinnings of the Senegal National Biofuel Program}

The primary impetus of the Senegal National Biofuel Program was to address the country's energy insecurity, yet the reason for pursuing Jatropha biofuel as the solution to this problem is unclear. Drawing from the literature review in Chapter Three, it is apparent that there are many energy pathways that the Senegalese government could have invested in to achieve their renewable energy production goals, including hydro, wind and solar. Limiting energy production to biofuels alone, there are many potential crop feedstocks that could have produced liquid fuels in Senegal-sugar cane, beet root, corn and potato for ethanol; castor, sunflower, colza, soy and other oilseeds for biodiesel - and the choice of Jatropha, a relatively new and unknown energy feedstock, is difficult to explain. The choice was not random, however, and was largely the result of international influences that pushed the Senegalese government to launch the SNBP even in the absence of clear evidence that it would produce positive results.

Perhaps the strongest explanation for the choice of Jatropha curcas for biofuel production in Senegal is rooted in the 'economy of appearances' concept developed by Anna Tsing (2000). This concept suggests that intangible perceptions play a large role in advancing economic goals in the absence of accurate projections in a way that may create the intended outcomes simply through their steadfast promotion. It is similarly expressed in the concept of 'economic imaginaries' developed by Jessop (2004) which describes how organizations and institutions attach meaning to particular economic activities that are largely illusory. Other iterations of this concept include Igoe's (2010) 'spectacular productions' and Hay and Rosamond's (2002) 'discursive constructions,' which all corroborate the similar theme of projected outcomes and the ideological promotion of certain economic activities which often lead to the outcomes suggested simply through the guidance of the discourse. An analysis by Carol Hunsberger (2014) of the 'economy of appearances' on Jatropha projects in Kenya produced results consistent with the theories established above and resonate with observations of this research project in Senegal.

The very creation of the Senegal National Biofuel Program was a central element in the 'economy of appearances' for Jatropha biofuel production in the country, effectively legitimizing it as an industry before any evidence existed that it could operate as proposed. The country went so far as to create a Ministry of Biofuels and Renewable Energy in 2007, an unprecedented move in Africa, presided over by physicist and academic Christian Sina Diatta. According to officials with the Senegalese Institute for Agricultural Research, the creation of this Ministry was mandated by Abdoulaye Wade, president of Senegal from 2000-2012, following promises to improve the energy security of the country during his reelection campaigns in 2006 (P.C., March 2014). Wade created a select committee to develop the nation's biofuel strategy and was 
instrumental in building the main points of the SNBP, which were driven by political, rather than technical, consideratiosn. This is consistent with Hunsberger's conclusions regarding Jatropha promotion in Kenya, which often found that "the promotion of a project was disconnected from the technical knowledge needed to support it." ISRA agronomists interviewed for this research explained that although they were assigned as technical specialists for the implementation of the SNBP, their input regarding the crop feedstock was overruled by the President, who was convinced that Jatropha was the best choice from international conferences he had attended on the matter of renewable energy, and by international literature, which was still projecting significant growth in the Jatropha biofuel sector (P.C., March 2014).

ISRA agronomists and technical staff at the Ministry of Agriculture were particularly discouraged by the formulation of the biofuel production targets for the SNBP, which are a clear illustration of the 'economy of appearances.' The projections were arbitrarily reverse engineered by the President's select committee from the liquid fuel requirements of the country (i.e. top down) rather than through a technical analysis of reasonable production capacity (bottom up). The country required roughly 1 billion liters of diesel fuel, which translated to 320,000 hectares of planted Jatropha, conveniently achievable by assigning 1,000 hectares of plantation to each of the country's 321 rural communities (P.C., March 2014). The discourse was positive and selfmotivated. Although there was almost no literature supporting positive results from Jatropha plantations on the international level, the momentum built into the SNBP at this point kept it moving forward. Hunsberger cites similar outcomes in Kenya, where the continuation of the national biofuel initiative was progressively more about "keeping up appearances that the crop could achieve development objectives" rather than achieving the program's outlined goals. Particularly telling, and similar to outcomes in Senegal, she found that "the lack of a market for Jatropha products at the time of [her] research supported the impression that the triumphant discourse of Jatropha's potential, presented by its promoters and in the media, was an illusion."

The SNBP was modeled on examples from international biofuel projects, most notably in the United States and Brazil, where national fuel blending mandates had stimulated large investments in their domestic biofuel programs. According to officials with the Ministry of Agriculture, a technical committee of Brazilian experts conducted field visits in 2006 and President Wade was convinced that Senegal could replicate the success of the Brazilian biofuel economy using Jatropha, despite the shortcomings of the Senegalese agricultural sector and a lack of adequate infrastructure (P.C., April 2014). Brazil's biofuel program had been built atop of an already robust sugarcane production system, whereas Senegal would have to build their Jatropha production chain without any prior experience or infrastructure. This ambition can be seen in the scope of the original national plan, with targets well beyond the abilities of the country to achieve in the timeframe allotted for the program, as acknowledged by officials at 
ISRA. Although drafted with the best intentions, the SNBP was fraught with overly optimistic projections from its outset.

\subsection{West African Comparisons and Collaboration}

The maturity of Jatropha biofuel schemes across West Africa varies greatly, and the policy framework adopted in these countries can offer guidance on how the Senegal National Biofuel Policy could have adapted since its inception in 2007. The program objectives found across West Africa are aligned on the same general principles: reduced dependence on imported fossil fuels; job creation and economic stimulation; reduced $\mathrm{CO}_{2}$ emissions; and the promotion of decentralized energy services to rural communities; however their implementation has been structured very differently, with clear implications for their overall success. The more successful programs typically create a large interconnected web of institutional partners working together to address the unique goals of the program, be they agronomic, economic or social, as visualized in Figure 6.1 below. In this schematic, developed by the regional coordinating agency JatroREF (2012b), Mali is the clear industry leader in the subregion, having begun Jatropha development programs in the early 1980s and progressively creating a support system that has resulted in the most active biofuel marketplace in West Africa, characterized by large and small scale projects tailored for export and domestic production.

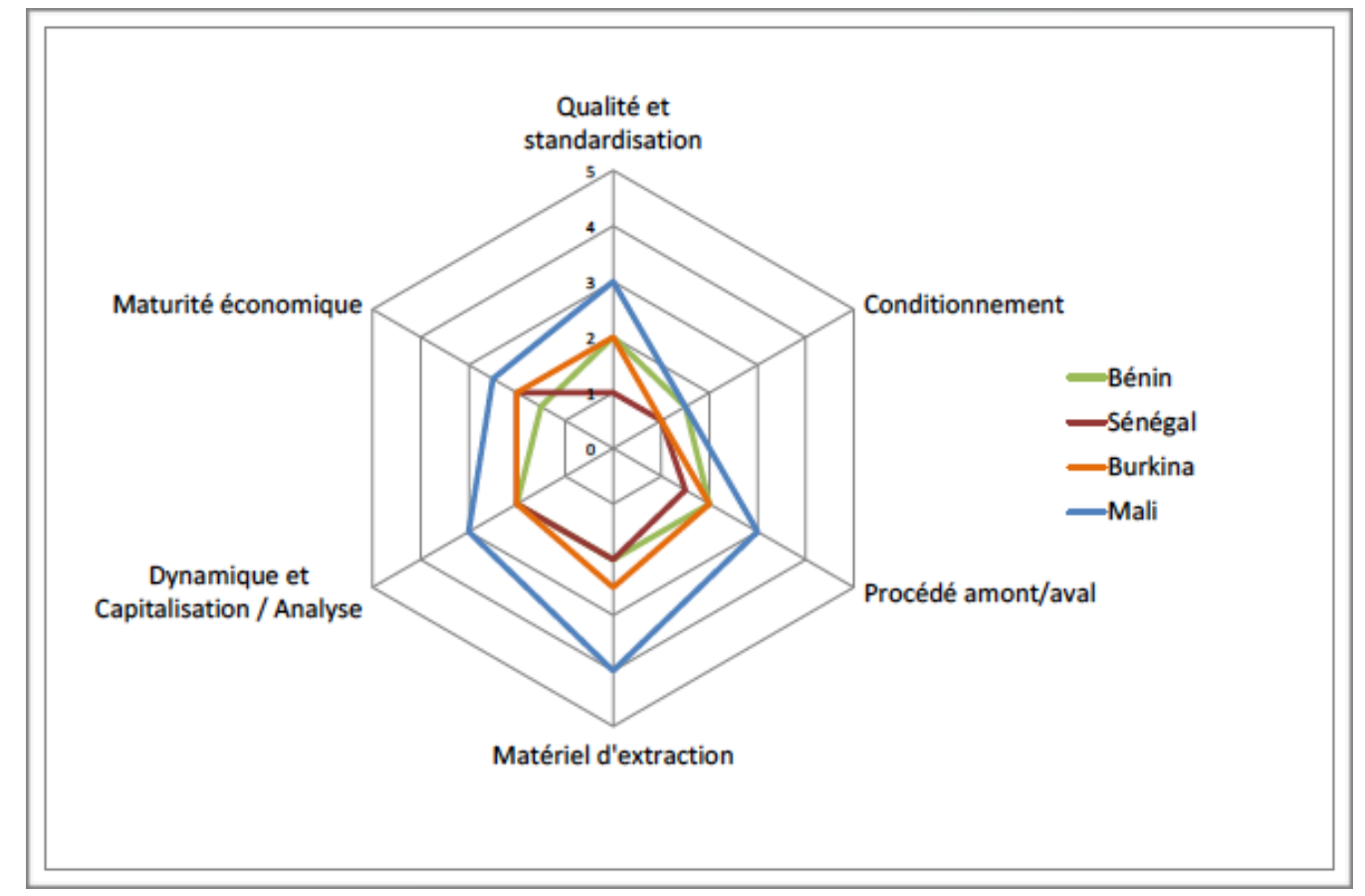

Figure 6.1: Jatropha industry support network maturity in Benin, Burkina Faso, Mali and Senegal, measured by 6 categories: Quality control and standardization, Post-press conditioning, Processing equipment, Extraction tools, Intellectual property exchanges, and Economic maturity Source: JatroREF (2012b) 
Senegal has the least developed Jatropha biofuel program in West Africa, though Benin is still in the early stages of project development, and could contract if met by the same constraints experienced in Senegal. Figure 6.2 illustrates the distribution of Jatropha plantations in West Africa coordinated through the JatropREF agency, with a clear dominance in Mali and Burkina Faso, which have created the strongest policy mix to support biofuel production. Mali in particular has done the most to support its national biofuel activities through the creation of the National Agency for the Development of Biofuels (ANADEB) ${ }^{18}$ in 2009, which fulfills a number of different roles under the direction of the Ministry of Energy and Water (ADECIA, 2012; JatroREF, 2012c; Republique de Mali, 2008). ANADEB serves both material and administrative roles, supplying producers with seeds, tools and processing equipment as well as defining norms and guiding the research and development for Jatropha and other biofuel feedstocks.

Both Mali and Burkina Faso built their national programs to provide fuel for domestic markets, with far more conservative goals stretched over a longer time frame. In Mali, Jatropha biodiesel would be blended into the national fuel system, slowly displacing fossil fuels at the pump, progressing from $10 \%$ in 2013 to $15 \%$ in 2018 and $20 \%$ in 2023, markedly lower than the

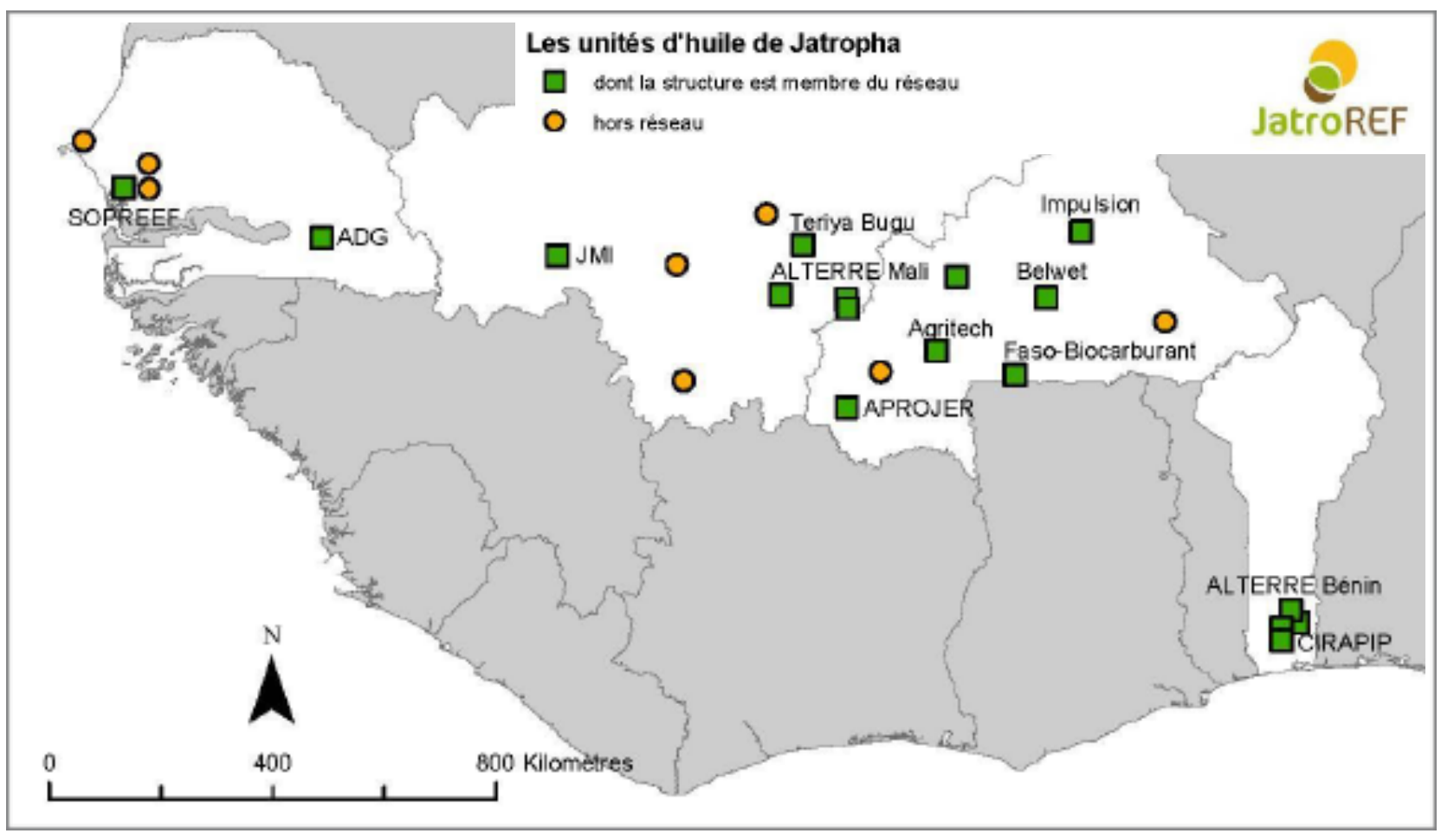

Figure 6.2: Jatropha cultivation and production in the JatroREF network, West Africa. Source: JatroREF (2012c)

${ }^{18}$ ANADEB: Agence Nationale de Développement des Biocarburants. Online at: $\underline{\text { http://anadeb-mali.org }}$ 
$100 \%$ fuel replacement target of the SNBP, slated for achievement within five years (Republique de Mali, 2008; Republique de Senegal, 2007). In Burkina Faso, biofuel integration was proposed under three scenarios: electrical generation for national grid power, liquid fuel substitution for transport, and incorporation into local production systems to power multi-function platforms (MFP $)^{19}$ distributed into the communities engaged in biofuel production, effectively creating micro energy generation and consumption subsystems. In all of these scenarios, the contribution of Jatropha biofuel to the national energy mix was a maximum of $30 \%$, to be achieved by 2020 (Burkina Faso, 2009). When projected against these two neighboring West African nations, it is clear that the SNBP was trying to achieve unrealistic goals and lacked the supporting policy structures to deliver the intended results. Figure 6.3 summarizes the main points of these national biofuel programs and their institutional bodies.

\begin{tabular}{|c|c|c|c|}
\hline $\begin{array}{l}\text { West African } \\
\text { Biofuel Programs }\end{array}$ & Target Production & Projected Completion & Project Oversight \\
\hline Senegal (2007) & $\begin{array}{l}100 \% \text { diesel fuel } \\
\text { requirements }\end{array}$ & 2012 (5 years) & $\begin{array}{l}\text { Ministry of Biofuels and } \\
\text { Renewable Energy }\end{array}$ \\
\hline Mali (2009) & $\begin{array}{l}10 \% \text { transport fuel } \\
15 \% \text { transport fuel } \\
20 \% \text { transport fuel }\end{array}$ & $\begin{array}{l}2013 \text { ( } 4 \text { years) } \\
2018 \text { ( } 9 \text { years) } \\
2023 \text { ( } 14 \text { years) }\end{array}$ & $\begin{array}{l}\text { ANADEB/ Ministry of } \\
\text { Energy and Water }\end{array}$ \\
\hline Burkina Faso (2008) & $\begin{array}{l}15 \% \text { of MFP Supply } \\
30 \% \text { of grid electricity, } \\
\text { transport, or MFP supply }\end{array}$ & $\begin{array}{l}2013 \text { ( } 5 \text { years }) \\
2020 \text { (12 years) }\end{array}$ & Ministry of Energy \\
\hline
\end{tabular}

Figure 6.3: West African biofuel programs and expected fuel production outcomes Source: Republique de Senegal (2007), Republique de Mali (2009), Burkina Faso (2008)

In comparison to the national biofuel schemes developed in other West African Nations, it is apparent that the policy in Senegal lacked consistency and commitment, moving too quickly to implement a sweeping program that did not have the required infrastructure or experience. Even the official documentation codifying the national programs is indicative of this, with the SNBP a mere 22 pages, compared to the respective 55 pages and 44 pages of the Malian and Burkinabe counterparts. Where the SNBP plan has rough guidelines and sketchy projections, the others offer detailed policy points and a clear representation of the roles required from institutional actors. Officials with ISRA who contributed to the draft SNBP acknowledged that it was not built with reasonable projections, primarily because it was politically motivated as a special program of President Wade (P.C., March 2014). Furthermore, the government's financial support of the SNBP did not extend beyond the first year, limiting the work of ISRA to continue

\footnotetext{
${ }^{19}$ The Multifunction Platform (MFP) is a concept and a structure developed by the United Nations Development Program (UNDP). The idea has been to place an MFP in a village which, driven by a diesel engine, powers devices such as pumps and grain mills and generators.
} 
plant propagation and extension services to farmers and project developers. Following a change in government in 2012, the Ministry of Biofuels and Renewable Energy was dissolved and replaced by the smaller National Agency for Renewable Energy, which has shifted focus from biofuels towards solar power and mixed fuel power production.

The success of the programs in Mali and Burkina Faso has been characterized by a strong central support agency that has aided the nascent industry to overcome early challenges, disseminate information, and coordinate research and development initiatives. This has been noticeably absent in Senegal, where the Ministry for Biofuels failed to provide the same services, and instead relied on independent organizations such as JatroREF to fill the roles provided by the appropriate ministries in neighboring West African nations. For the SNBP to achieve its intended goals, the state must first reevaluate the program with more realistic expectations, and commit to supporting industry partners with an effective management regime.

\subsection{Supporting Policy Structures}

Successful biofuel programs on the international level have relied on a broad set of supporting policies designed to create a more neutral environment and drive demand towards low carbon fuels, which are generally more costly to produce, particularly in the short run. These include a variety of fiscal, regulatory and pricing policies as well as infrastructure upgrades or investments to indirectly reduce the costs of production (Weisenthal et al, 2007; IEA-OECD, 2008; Weisenthal et al, 2009; Jumbe et al, 2009: Sorda et al, 2010). The Senegal National Biofuel Program has provisions that indicate the possibility of state-owned Jatropha production facilities and electricity generators run off of Jatropha oil and biogas production, as well as investments in the agricultural sector to hasten development, add capacity and stimulate the creation of agroindustrial nodes across the country (Republique de Senegal, 2007). To what extent these provisions were delivered has had a major impact on the results of the program.

Early stage biofuel programs often struggle to compete with existing fossil fuels due to the significant subsidies offered to oil and gas extraction and the global distribution system that efficiently delivers them to market. The International Energy Agency (2008) has developed a series of guidelines for policy incentives to support renewable energy schemes depending on their level of maturity, illustrated in Figure 6.4. Jatropha exists in the category of 2 nd generation biofuels, characterized by both immature technology development and low market deployment, leaving it open to a wide range of support mechanisms to bring it in line with established market players such as bio-ethanol and biodiesel found in commercial scale feedstock programs. These include program continuity, research and development, market stimulation, loans, subsidies and 
tax incentives. Later stage biofuels programs can focus on market stimulation and generating demand for green alternatives within the consumer base.

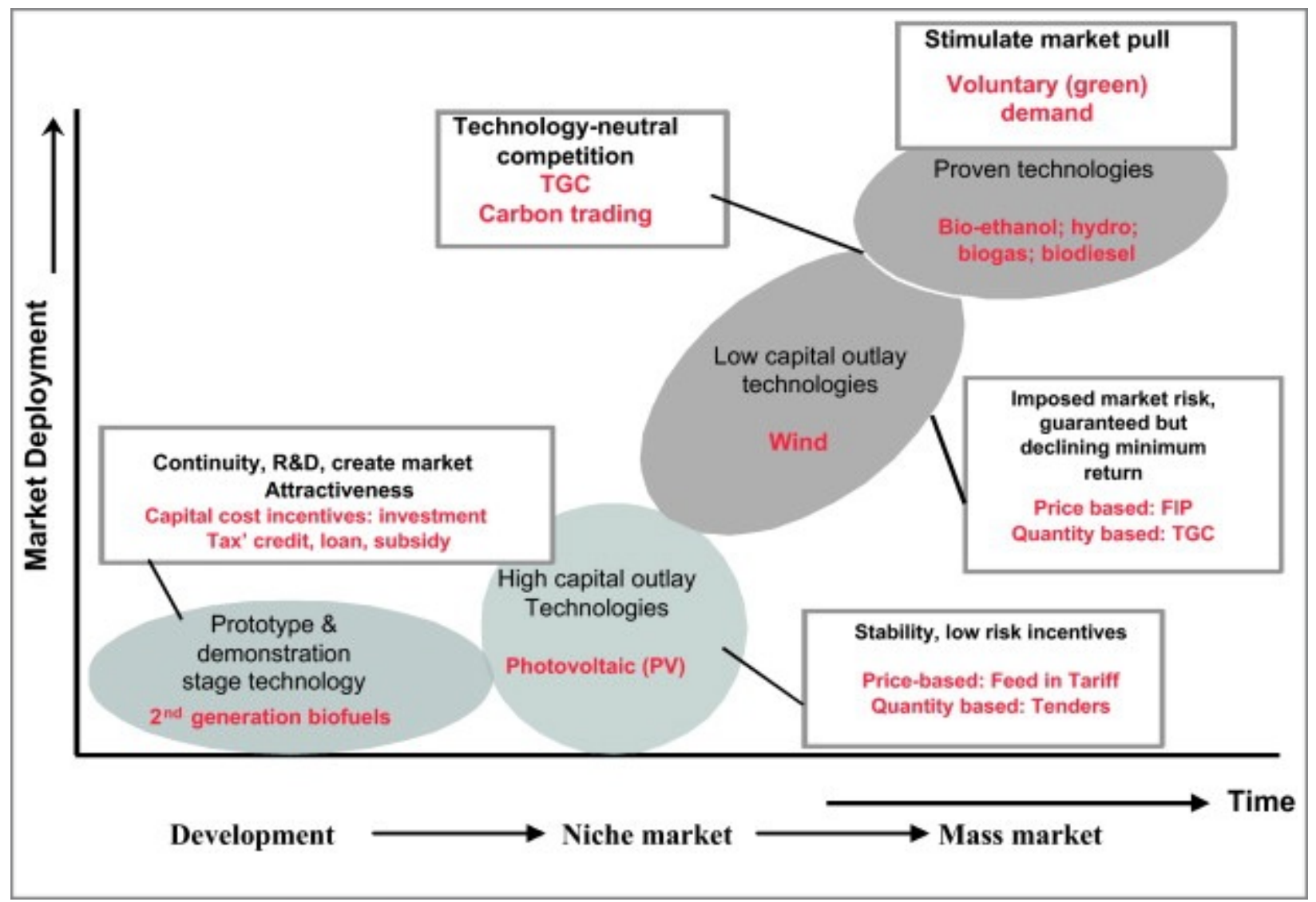

Figure 6.4: Combination framework of policy incentives as a function of technical maturity Source: IEA- OECD, 2008

The government of Senegal demonstrated its intent to build a strong national biofuel program through its creation of the Ministry of Biofuels and Renewable Energy in 2007, which could have used its position to generate a conducive policy environment for biofuel producers. A further National Committee of Biofuels ${ }^{20}$ was established in 2010 to allow officials from the ministries of Commerce, Finance, Environment, Agriculture and Energy to collaborate and create legislation with greater ease. According to officials with the National Agency for Renewable Energy (ANER), which has assumed the role of these two governmental structures since they were both dissolved following a change in government in 2012, these high-level moves had little material effect on national policy or the direction of the SNBP (P.C., April 2014). Continuity and guidance from government regulators, emphasized in guiding policy documents such as the IEA report, was notably absent, and the structural bodies in charge of the national biofuel program

\footnotetext{
${ }^{20}$ Le Comite National de Biocarburants was officially established on April 13th, 2010 by the Ministry of Biofuels and Renewable Energy to improve the coordination between separate administrative offices.
} 
changed hands three times between 2009 and 2012. The final annex of the SNBP clearly states the following guidelines for projects undertaken under its auspices:

(1) Companies established for biofuel production must constitute a minimum of 51\% Senegalese capital and control.

(2) Project promoters must guarantee prices for farmers involved in biofuel production.

(3) Fixed prices for seed feedstock must be established at the national level and purchases guaranteed by the State.

(4) Farmers must receive assistance from project promoters through agricultural inputs and technical expertise.

(5) Land rights must belong to local communities, not transferred through sale or lease.

(6) Oil must be produced and processed in Senegal.

A lack of coordination was matched by a lack of regulation and enforcement, and survey respondents from within government agencies and the private sector confirmed that none of these guidelines were adhered to in practice. A review of the Senegalese biofuel program by the private consulting firm ENDA Energie (2010) found that the program had by and large failed on all of these counts, and could only identify positive outcomes where farmers' collectives had organized with commercial producers to create partnerships, as seen with the THD operation in Fatick region. Officials with ENDA described the principal failures of the SNBP as follows:

(1) A distinct lack of information and training for local actors, in particular smallholder farmers.

(2) A total absence of pricing guarantees for seed feedstock and a general lack of regulation

(3) An absence of pricing and labor guarantees for smallholder farmers.

(4) A lack of understanding in technical aspects of agronomic performance of Jatropha and thus a large variability in the performance seen across the country, with marked ramifications for producers and farmers.

(5) Little apparent land protection for smallholder farmers against large commercial operations. Many cases of rural communities conceding land rights to large corporations solely for the development of biofuels were observed, with no resulting return upon project failures. Land speculation with undue harm to local farmers was a major risk.

(6) Oil production was not occurring exclusively in Senegal. Notably, the agro industrial producer ANOC in Kaffrine region had contracted with an oil exporter for the direct sale of Jatropha seeds to external markets. 
A lack of regulatory presence has been both beneficial and harmful for the private producers in Senegal. Commercial operations, such as ANOC in Fatick, have been able to secure large tracts of land that might have been beyond their grasp had the smallholder farmer protections been properly enforced, and they have been free to set contractual pricing agreements with local councils at their discretion. However, a lack of preferential taxes or subsidies from the state has kept their biofuel prices high in comparison with both domestically available fossil fuels and comparable biodiesel prices from across the subregion. Figure 6.5 illustrates how the governments of Mali and Burkina Faso have reduced or adjusted taxes and transport costs so that biofuel arrives at market at equal or less than the cost of traditional fuels. Despite the cost of diesel at the pump in Senegal being considerably higher than these neighbors, at 790 FCFA/L, the additional costs of production have pushed raw Jatropha biofuel above this threshold.

\begin{tabular}{|l|c|c|c|c|}
\hline \multicolumn{2}{c}{} & \multicolumn{2}{c|}{ Bali } & Burkina Faso \\
\hline Oil Type & Jatropha Oil & Diesel & Jatropha Oil & Diesel \\
\hline FCFA Base Price & 459 & 454 & 423 & 390 \\
\hline Transport Cost & 84 & 85 & 87 & 87 \\
\hline Margins & 22 & 30 & 36 & 62 \\
\hline Import Tax & 11 & 38 & 30 & 50 \\
\hline Value Added Tax & 69 & 39 & 0 & 146 \\
\hline Subsidies & 0 & 0 & 0 & -79 \\
\hline Final Sale Price & $\mathbf{6 4 5}$ & $\mathbf{6 4 5}$ & $\mathbf{5 7 6}$ & $\mathbf{6 5 6}$ \\
\hline
\end{tabular}

Figure 6.5: Fuel price structure in Mali and Burkina Faso for DDO (straight vegetable oil) and Gasoil (diesel); prices in FCFA.

Source: ADECIA, (2012)

In Senegal, infrastructure improvements and processing facilities that were initially promised by the SNBP never materialized, thus private producers had to increase their capital expenditures to equip themselves with the presses and filtration equipment necessary for biodiesel transesterification. The commercial operations manager of THD explained that under the original provisions of the SNBP, Jatropha biofuel would not have been subject to Value Added Tax (VAT), assessed at 19.5\%; however this was not legislated and remains an added cost (P.C., April 2014). Taken together, the absence of support and regulation has prevented the industry from moving forward. Although the Senegalese government established the proper administrative structures to adequately manage the SNBP, the observed result has only been a lack of consistency and a near total absence of regulation and support of the industry. No fiscal stimulus measures or preferential taxation was provided, and even the producers that have maintained operations struggle to market their Jatropha oil to an uninformed consumer base. 


\subsection{Non-Governmental Policy}

The absence of regulation and coordination within governmental bodies assigned to management of the Senegal National Biofuel Program resulted in independent policy decisions by nongovernmental organizations, including commercial producers, financial institutions, and consulting agencies that have become the de facto policymakers for the remaining program. The independent policy decisions of these actors has helped spread information, establish seed prices and generate market demand without the involvement of government agencies. There is a risk that policy decisions made in isolation will result in a fractured and disjointed Jatropha oil market operating under different market conditions from region to region, but the alternative is stagnation; therefore non-governmental organizations have taken their own initiative to continue moving forward until a more capable governing body is established within the Senegalese government.

The organizations presently wielding the greatest control over Jatropha policy are the private commercial producers who have remained nimble in the face of poor agronomic performance, and generally control all aspects of the production chain within their spheres of influence. All of the operators surveyed are subsidizing the cost of Jatropha cultivation for smallholder farmers in one way or another, extending seeds, providing technical guidance, establishing seedling nurseries and supplying farming implements as required (F.S., April 2014). THD, based in the region of Fatick, has supplied over 180,000 seedlings for plantation over 5 years at no cost to smallholder farmers, and TFF in Kedougou distributes 200,000 - 300,000 seeds on an annual basis for live fencing applications across the region (P.C., February 2014). ANOC, in Kaffrine, exerts control over all of their commercial plantings, but has provided all of the initial capital outlay for seedling propagation, as well as created hired positions for field maintenance filled by local farmers. Without the government support promised in the SNBP, commercial operators have taken the financial risk of Jatropha plantation away from smallholder farmers.

Agronomic policy is developed separately from one institution to another, with all commercial organizations surveyed having come to their own methodologies independently and advising their growing partners on best practices for soil amendments, pruning and pest management. This has created a visible difference in the performance across the regions surveyed, and is one respect in which the non-governmental organizations failed to successfully replace the capacity of a national coordinating agency. Due to their competitive nature, they have not satisfactorily shared best practices and come together to avoid common missteps. JatroREF, a private consulting agency based in France, has attempted to eliminate some of the inefficiencies created through commercial competition by staging regional conferences where different 
Jatropha biofuel interests across the West African subregion can interact and present the results of their work on a semi-annual basis. Their effort has helped operators across Senegal, Mali, Burkina Faso and Benin with challenges concerning agronomy and plant yields, and they are in the process of establishing norms concerning pressing technologies, biodiesel standards in accordance with international biofuel schemes, and an analysis of the performance characteristics of various diesel engines operated with Jatropha biofuel. Their presence has filled the communication and R\&D role left unfilled by the Senegalese Ministry of Biofuels.

Both ANOC and THD have adopted hybrid economic models to finance their continuing operations, accessing different financing tools until they achieve oil revenues from their plantations. Because of its centralized control and large land holdings, ANOC has been able to access larger institutional subsidy providers, and successfully sold carbon sequestration rights allocated to its Jatropha plantations for the first time in 2014 (P.C., March 2014). Due to its size and anticipated production capacity, ANOC has been able to negotiate long term contracts with seed and oil purchasers that have allowed it to underwrite some of its earlier expenditures, even if its full yields will not be forthcoming for several more years. This policy decision runs counter to their initial goal - to generate energy for local markets - and counter to the intent of the SNBP, but without the regulatory presence of the national government, they are acting independently.

THD has adopted one of the most comprehensive and flexible operating policies found across West Africa, and has used a variety of funding mechanisms to finance its operations since its foundation in 2008. Their executive staff is supported by a Senegalese consulting firm, Performances $^{21}$, their pressing facility and its operating staff based in Sokone were financed through partnerships with Cap Developpement Senegal ${ }^{22}$ and Present d'Avenir ${ }^{23}$, and their technical staff advising farmers on agronomic practices is supported by Kinome. ${ }^{24}$ They continue to seek alternative funding through innovative sources, such as impact investing firms and low interest financing schemes (P.C., February 2014). Their ability to offset nearly $100 \%$ of their operating expenses through various non-governmental organizations has allowed them to devote their revenues to supporting smallholder farmers. They are the sole commercial operator in Senegal offering a guaranteed market for Jatropha seed, and have set the pricing standard at its

\footnotetext{
${ }^{21}$ Performances Consulting, based in Dakar, specializes in integrated energy and water management systems in West Africa. Online at: http://vivredurable.net

${ }^{22}$ Cap Developpment Senegal, a subsidiary of the Veolia Energy Group, is tasked with fostering the emergence of an innovative rural development model based on local entrepreneurship. Online at: http://fondation.veolia.com/en/ actions/projects/8SD1106,cap-developpement-senegal.htm

${ }^{23}$ Present d'Avenir is a French NGO that raises funds for projects in sustainable development, focusing on potable water access, small scale electrification, and enterprise creation. Online at: $\underline{h t t p: / / p r e s e n t d a v e n i r . f r}$

${ }^{24}$ Kinome is an NGO based in France, which supports efforts to engage rural communities in Senegal to protect their natural assets, stop deforestation and develop sustainably. Online at: http://kinome.fr
} 
highest level across West Africa, at $100 \mathrm{FCFA} / \mathrm{kg}$. They extend soft loans for farm implements to farmers within their cooperative and have created 10 paid positions for community liaisons who collect statistics, relay information and disburse payments. Theoretically, these are all tasks that would fall under the regulatory umbrella of the Ministry of Biofuels, and without the actions of THD, there would be no Jatropha biofuel activity in the Fatick region. The ability of nongovernmental organizations to set effective policy without the intervention of the state suggests that a national Jatropha oil industry could operate without external regulation whatsoever.

\subsection{Conclusion}

The Senegal National Biofuel Policy has not been an adequate support structure to successfully implement Jatropha cultivation for biofuel production, and has been especially weak as a regulatory and coordinating document for this new industry. Interviews with officials familiar with the drafting of the plan suggest that the choice of Jatropha as the biofuel program feedstock was motivated more by the 'economy of appearances' rather than a systematic or scientific analysis of the country's agronomic resources. Policy was not drafted with realistic projections or reasonable timeframes, and juxtaposition with programs from other West African nations exposes major miscalculations and overly optimistic expectations of the potential of the biofuel's contribution to the national energy requirements. Senegalese governmental policy with regard to the biofuel industry is marked by inconsistency, with numerous agencies and ministries responsible for the outcomes of the program over its five year period, yet little to no coordination among them, nor a defined hierarchy of responsibility. Of the principal policy points defined in the SNBP, protecting the rights of smallholder farmers and creating the foundation for a biofuel market in the country, none were achieved.

The lack of centralized guidance from the Senegalese government and the Ministry of Biofuels has left the responsibility for policy creation and management within the hands of independent organizations and commercial operations, who have created their own systems of governance and filled the roles left vacant by the Ministry. Financing and R\&D have come through contributions from foreign NGOs and consulting firms, while price guarantees and seed sales agreements set by commercial operators have taken some risk associated with biofuels cultivation away from smallholder farmers. Although the SNBP and the government agencies responsible for its implementation have been wholly inadequate, the ability of independent organizations to create effective policy and self-govern offers some optimism that a national biofuel production industry could one day succeed autonomously. 


\section{Chapter 7 - Discussion, Recommendations and Conclusion}

\subsection{Introduction}

The goal of this research project was to evaluate the suitability of Jatropha curcas as a feedstock for liquid biofuel production within the context of the Senegal National Biofuel Program. As a nation faced with rising energy demands and an increasingly urban population, Senegal urgently needs to address its energy shortcomings and expand access to domestic energy production streams to hedge against external energy price shocks and transition to a low carbon fuel mix. In this chapter, we discuss the key discoveries of the research and assess likely causes of failure in the SNBP. General conclusions regarding the agronomic, socio-economic and policy limitations of the SNBP will be followed by a discussion of some of the key challenges of biofuel programs and their implications in Senegal.

\subsection{General Conclusions}

If evaluated purely against the goals outlined in the Senegal National Biofuel Program (2007), Jatropha curcas has been universally unsuccessful for domestic biofuel production. Under present conditions and policies, it cannot be recommended as a viable biofuel feedstock for commercial or local production. The national program failed to reach its goals in the following key categories:

- Land area under cultivation - est. 2200 ha vs. an expected 321,000 ha

- Seed production - no measurable production vs. an expected 3,210,000 tons/year

- Oil production - no measurable production vs. an expected 1,134,000,000 liters/year

- Job creation - an estimated 300 active farmers and employees vs. an expected 100,000

- Rural electrification - no village electrification vs. an expected $30 \%$ rural electrification.

In addition to these quantitative indicators, the SNBP has failed to reach its more qualitative goals in the following categories:

- Reduction of Senegalese energy imports - the SNBP has made no contribution to the national energy supply network, and expanding energy demand continues to rely on imported fossil fuels.

- Reduction of household energy costs - local communities have not received any infrastructure improvements to transform Jatropha into a rural energy supply.

- Improved technical capacity of rural farmers - little to no technical expertise has been extended to smallholder farmers to improve their agricultural capacity. 
- Improved environmental conditions - there is no data to support the positive impact of Jatropha plantations on soil quality, nutrient regeneration, or carbon sequestration.

- Diversified biofuel byproduct markets - there are no national market outlets for Jatropha byproducts including soap, biochar, organic fertilizer or others.

- Amelioration of rural livelihoods - there is no data to support improved economic or social conditions in rural communities as a result of the SNBP, and there is a real threat that communities are actually worse off due to the opportunity cost of alternatives.

Despite the overall failures of the program as a whole, there have been some positive developments that could lead to success in the future. These include:

- A greater understanding of the energy challenge faced in rural communities by local residents, and a commitment to creating autonomous energy production systems.

- Increased use of Jatropha as a live fence, which protects traditional cultures from foraging animals and helps improve soil stability.

- The creation of two commercially-oriented biofuel production organizations in the regions of Fatick and Kaffrine committed to long-term strategic growth.

- Coordination and sharing of regional technology and best practices through independent agencies such as JatroREF.

- The creation of guaranteed regional seed and oil markets by independent producers.

\subsubsection{Central Limitations}

In harmony with the findings of the literature review, there were three key areas in which the SNBP failed to deliver on its expected outcomes. The key findings are presented here.

\section{A. Agronomic}

Jatropha was promoted as a biofuel feedstock because it was reportedly robust, resilient, fast growing, and well adapted to the Senegalese climate. It has been grown in the country for many generations, and although there are anecdotal examples of very high yielding Jatropha bushes growing in the wild, by and large these claims are completely unfounded and have not been substantiated by local results.

Seed yields across the country are dramatically substandard relative to the projections of the SNBP, and have dissuaded farmers from working with it, sometimes resulting in entire plantations being uprooted in frustration. This is a particularly troubling result, as even if Jatropha is improved through crop science programs, it will be very difficult to convince local 
farmers to recommit to its cultivation in light of its failed performance and the distrust sown by promoters with unreliable information.

Jatropha has proven effective for the purposes of live fencing, stabilizing the soil and reforesting areas lost to desertification, and this is the only application in which Jatropha cultivation should continue. Full field plantation and intercropping methods are too risky until there is more experience with the agronomic conditions suitable for plant growth and associated factors such as pests, pruning and irrigation, and necessary soil amendments. Live fencing has practical applications for farmers irrespective of biofuel production, and could deliver positive results before the secondary benefits of biofuel production are realized.

The agronomic limitations of the plant and the climate were exacerbated by poor policy. The SNBP was designed for implementation throughout the country, with no regard to local soil conditions, rain patterns or the infrastructure requirements for plantation, cultivation and harvesting, and findings suggest that the outcomes could have been very different if energy and resources had been focused in the parts of the country with better conditions.

The Senegal National Biofuel Program cannot succeed until the agronomic limitations of Jatropha curcas as the singular feedstock are addressed. The seed quality must be improved to provide some measure of consistency in yield projections, which fluctuate wildly under present conditions. Jatropha has been a major disappointment for biofuel production, but if the appropriate steps are taken, it is not unreasonable to expect that commercial production for biodiesel could be achieved.

\section{B. Socio-economic}

The social and economic contributors to successful Jatropha biofuel production are complex, and largely tied to the expected outcomes of commercial producers. None of the commercial operations surveyed in the country have achieved biofuel production that can compete with fossil fuels available on the national market, and striking the balance between economic gain and smallholder farmer benefit remains a major challenge.

The parallel goals of low-cost biofuel for the domestic market and economic prosperity for smallholder farmers are at odds with one another, and have resulted in two entirely different investment models from commercial entities. Producing significant quantities of oil at low cost requires large plantations under centralized control that will not necessarily benefit rural communities. Conversely, highly integrated local energy production and consumption models would generate a great deal of economic activity for rural communities, but would fail to meet 
the demands of the larger population as a whole. The SNBP was built to address both of these problems, and due to the conflicting policy required for the two axes, it has achieved neither.

The plantation model, as practiced by the Africa National Oil Corporation (ANOC) in Kaffrine, requires a heavy initial capital outlay that may not see a return for a lengthy establishment period of 5-8 years, but can achieve economies of scale and tap into alternative financing schemes that may not be available to smaller producers. Credits for carbon sequestration and reforestation have contributed to their financial model and their scale has allowed them to lock in long term contracts with institutional buyers. This model marginalizes smallholder farmers and can result in land grabs that will ultimately benefit corporate interests at the cost of rural communities. ANOC has chosen to sell their harvested seeds to an exportoriented fuel producer, which runs contrary to the domestic energy security goals of the SNBP, but there is no regulatory body to monitor and control their behavior.

The intensive, community-focused production model, as practiced by Technologies for Human Development (THD) in Fatick, requires a much more modest capital investment, and relies on a close collaboration with smallholder farmers to provide the seed feedstock for biofuel production. This model is much more remunerative and socially beneficial for local communities, which may generate economic activity through a number of the functions associated with biofuel and its byproducts. This could include seed and oil sales, oil pressing and transformation, soap production, organic fertilizer sales, as well as a diversified natural oils market sourcing high value seeds from underutilized forest resources. This model suffers its own challenges as a direct result of its distributed nature. Disseminating and enforcing best agronomic practices is logistically complex, and can result in uneven yield results from different farms. Additionally, carbon sequestration and reforestation credits are out of reach due to the complexity and cost of the auditing process.

Jatropha curcas is not a wise economic investment at its current performance levels, but could be if the plant's agronomic performance is improved. The best production model to meet the economic and social requirements of the SNBP would entail close collaboration with smallholder farmers, active valorization of Jatropha biofuel byproducts and the development of local energy services networks to maximize value chain efficiency.

\section{Policy}

The complexity and logistical challenges of developing a national biofuel market requires the intervention and financing of a central government program. The Senegal National Biofuel Program was designed under just this logic, and the Ministry of Biofuels and Renewable Energy was created to oversee its implementation. Despite this apparent commitment, expectations 
projected in the SNBP were wildly over-optimistic, and almost assured its failure before it was ever implemented. Since the day of its inception, the plan has been marked by poor consistency and guidance, a near total absence of regulation, and a lack of financial commitment.

This study has drawn considerable input from policymakers and those close to the drafting of the SNBP. From their contributions, it can be concluded that the major points of the plan were driven more by political goals than a rational assessment of the agronomic capacity of the country. President Abdoulaye Wade, caught up in the 'economy of appearances' that presented Jatropha as an unquestionably positive investment by development agencies and international programs, created the major action points of the plan with a select committee while having no technical expertise in the field. Against the urging of ISRA agronomists to evaluate potential alternatives, the broad goals of the SNBP were reverse engineered, top-down, from the country's energy needs rather than founded on its fundamental potential.

When compared with the national programs of neighboring West African countries, the projected targets of the SNBP sought to achieve too much, too quickly. Mali and Burkina Faso conceived similar programs that would have contributed 20 - 30\% of national energy requirements over a period of 12-14 years and developed a comprehensive web of support agencies, fiscal policies and tax incentives to reach these targets. The SNBP, by comparison, sought to provide $100 \%$ of national energy requirements in a 5 year period, with none of the supporting policies and investments observed by other programs. For the SNBP to be considered a serious piece of national policy, it should be revisited and radically redrafted under more conservative estimates based on observed experience.

The SNBP has been so poorly designed and regulated that the majority of active policy guiding the Jatropha industry in Senegal is the work of commercial interests and independent consulting agencies. This has led to a fractured policy environment with unique expectations and economic working conditions in separate regions. The sole guaranteed market for seed is supported by THD in Fatick, on a purely voluntary basis, and R\&D and coordination between projects is administered through the JatroREF consultancy. The provision of low interest loans, tax incentives for domestically produced biofuels, and a guaranteed seed purchase market are all essential elements of a successful policy mix to support an early stage biofuel market. 


\subsubsection{The Importance of Data}

One of the key revelations of this research study was the paucity of reliable data to work with at all levels of the program's implementation. Data-driven decision making was absent from all of the major areas that have led to the principal failures of the SNBP, from the governmental agencies who drafted the SNBP, to the National Institute for Agricultural Research responsible for its implementation, to the commercial operators and farmers. Practitioners were found relying more on intuition, unrealistic future projections and hope rather than measurable examples, and this mindset had even infiltrated to smallholder farmers in some cases. This has resulted in irrational decision making and harmful long term side effects despite the best intentions.

One particularly poignant case was of a farmer in the Fatick region who had planted nearly 1,000 Jatropha bushes and painstakingly cared for them for more than five years. He had planted via live fence and full-field methodologies and unlike most others viewed his Jatropha plantations as a primary economic activity, trusting the generous projections provided to him by SNBP promoters. After many years without any harvest whatsoever, he finally collected $6 \mathrm{~kg}$ in 2014 , which will result in a payment of 600 FCFA (US $\$ 1.25$ ). He is openly ridiculed by neighboring farmers who have continued with their traditional cultures of millet, corn, and peanuts, but he continues to believe that eventually he will achieve significant harvests, even in the absence of any supporting evidence.

This case should be a cautionary tale for the entire Senegal National Biofuel Program, as it elucidates the harm that can be borne by poor rural communities when initiatives are undertaken without sufficient data. The opportunity cost of several years of stagnation and lost productivity are all the more significant in these areas, and the impact of sweeping national policies should carefully consider the potential effects of failed programs before designing and disseminating them. Hope and trust are powerful forces, and rural communities expect their governments to make decisions under the assumption that they have access to better information, yet the burden of the failure in the SNBP has fallen on these communities.

\subsection{Status of the Senegal National Biofuel Program}

The SNBP, although theoretically designed to reach its conclusion in 2012 , is still currently running albeit in a much more restricted iteration of its initial program. The Ministry of Biofuels and Renewable Energy was dissolved in 2012, following the election of current President Macky Sall, and a smaller agency, the National Agency of Renewable Energy, has been created for its oversight. This change is indicative of the government's orientation towards the SNBP, and functionally it exists in little more than name. The current regime has decided to support the 
development of solar energy for renewable electricity generation, and has not yet conceived of a plan to offset the high costs of imported fossil fuels.

The failure of the SNBP was due in part to the fact that it never had the chance to mature as a program. The project executors scarcely had a chance to understand its working conditions before it was slated for replacement by another strategy. This shortsighted policy creation is damaging in the long run. This research is clear evidence that policies as sweeping as a national energy initiative need to be constructed on long term trajectories, subject to the flexibility of an adaptive management regime to address shortcomings and redress early failures. In the case of the SNBP, the program should redirect its resources to rigorous data collection on the agronomy of Jatropha and the conditions that can generate appropriate yields across the country.

\subsection{Food Competition and Land Use Change}

This study did not substantiate concerns that biofuel programs would stimulate detrimental land use changes or result in a loss of arable land for food cultivation. Jatropha planted as a live fence was not in competition with alimentary crops, and commercial plantations were located on degraded land that had previously been used for large scale peanut or cotton cultivation. Furthermore, the threat of losing woodland and forest to Jatropha has not been observed in more than a few anecdotal cases when Jatropha prices were artificially high at the onset of the SNBP. In Senegal, planting Jatropha actually has the long term potential for improving soil quality and reducing erosion, contributing to the nutrient content of the top soil horizon, and slowing the movement of water, which stimulates nutrient penetration.

The food vs. fuel debate presents important questions and inspires useful debate, but may be a distraction from the core problem in Senegal, which is sustainable wealth creation. Most farmers surveyed for this study rely on their crops as their primary economic activity, and change their crops from year to year depending on price forecasts so that they can get the best return for their efforts. Food security can come in two ways: food is grown, harvested, and consumed locally; or food is imported from external suppliers. If Senegal can create sustainable development and generate economic prosperity, food production could, in part, be outsourced to other parts of the world with more suitable growing conditions for food crops. Therefore, the focus should be on maximizing the economic potential of Senegal's arable land, and if this can be achieved through a robust biofuel production chain, then this will lead to greater long term prosperity and growth than corn or millet production. A system of live fencing for biofuels which maintains prime land for food production is arguably the best approach. 


\subsection{Arguments for a Mixed-Method Interim}

Although Jatropha is not presently mature enough to be implemented as a viable feedstock for domestic biofuel production, this research suggests that under the right conditions, it could actually work quite well for local liquid fuel production at some point in the future. Until effective policy and conducive market conditions are established, committed project developers can continue moving forward to be strategically well positioned. The most compelling strategy observed in the field is the approach of Technologies for Human Development (THD) in Fatick, which aims to generate the encompassing working conditions required for Jatropha biofuel production until the plant achieves more systematic yield results.

Recognizing the fact that liquid fuel prices are likely to follow a steady upward trend, accompanied by year to year volatility, rural populations will be particularly vulnerable to price spikes, THD is building the long term capacity for biofuel production by capitalizing on a mix of alternative economic activities to subsidize their Jatropha activities and emphasizing the role of Jatropha as an integral part of a permaculture system of agriculture. THD is committed to building the resiliency of the communities they work within, and are using their operations in the Fatick region as a test platform while simultaneously evaluating other regions for their Jatropha growing capabilities. Their methodology includes:

- Plantations integrated into an existing farm structure: THD advises its partner farmers in live fencing and has supplied over 180,000 seedlings. It continues to expand plantings on an annual basis, and has doubled the number of farmers it works with.

- Adaptive Plant Management: THD acts as a knowledge sharing hub for the 200 farmers in their collective network, and advises on best practices to expand yield results, ensuring that all practitioners learn and improve their holdings.

- Relationship Building: This is a particularly important function, as farmers are often reluctant to work with outside interests until a basis of trust is established. THD has earned the respect and trust of local community members who feel involved in the process of building a local energy procurement system.

- Creating local Expertise: Technical staff and agronomic advisors are drawn from the local community, and live in the communities that they serve, ensuring that knowledge stays embedded even if THD is to falter and halt their operations.

- Infrastructure Development: THD has the only operational press in the country capable of processing Jatropha oil. Although seed supplies are not yet sufficient to make significant quantities of oil, they will be ready to bring product to market as soon as their Jatropha plantations start producing.

- Priming the Local Market: THD has established the only guaranteed seed purchase program in the country, and is offering the highest purchase price (100 FCFA $/ \mathrm{kg}$ ) across 
West Africa. At this price, their Jatropha oil is produced at an economic loss, but THD can subsidize their biofuel operation by the sale of other high-value oils sourced from the local community, which further strengthens their market position. Among farmers surveyed, the lack of a guaranteed seed market was the highest ranking reason for halting Jatropha growing activities, so this step is crucial for future development.

- Finding External Markets: By beginning seed pressing and oil production operations in advance of large Jatropha harvests, THD has been able to reach out to potential buyers and establish working relationships with entities in the cosmetics market that can offer higher prices for quality oils. Building these relationships allows them to find niche markets for Jatropha oil byproducts such as biochar and organic fertilizer from the seed press cake. As their production output increases, they have a readily available market.

\subsection{Arguments for Innovative Support Structures}

While commercial entities like THD can pursue their own strategies for a mixed-method interim before the Jatropha market matures, the national government and other institutional bodies could offer more incentives to spur the development of the industry and remove the burden from private enterprises. Subsidies, tax incentives, and other indirect support mechanisms such as a guaranteed national seed or oil buyback program were never incorporated into the implementation of the SNBP, and this has been a noticeable contribution to the program's stunted development. These and other national support structures, such as infrastructure improvements, are a necessary first step.

There are other approaches that should be playing a more active role in the development of this sector of the economy that are not necessarily in the domain of the national government. Biofuel production is certainly advantageous for the local population, but its wider implication is the reduction of carbon emissions and a pathway towards more environmentally sustainable fuel sources that international players should be helping to promote. The most obvious way to support these activities is through carbon sequestration and reforestation credits that would help finance Jatropha planation operations, but these have largely been too difficult for smallholder farmers to access due to their regulatory requirements. Carbon credits, if adequately valued, could offer a very tangible incentive for farmers to plant Jatropha and remunerate them during the 5-8 years that it takes for a plantation to mature and begin regularly producing seed. These and other innovative measures need to be an active part of the solution. 


\subsection{General Recommendations}

This research sought to understand the key points of success or failure in the Senegal National Biofuel Program and the use of Jatropha curcas as a biofuel feedstock. While unsuccessful in its current form, observations, interviews and surveys suggest that a domestic biofuel productions system could be successful under the right conditions. Recommendations are offered with contextually relevant points for Senegal, but can be generalized to domestic biofuel programs in similar socio-economic settings. This section offers several recommendations to guide policymakers and project promoters, as well as suggestions of further research interest.

\section{Short-term Action Points:}

(1) Cease promotion of Jatropha curcas cultivation as a full field or intercrop plant, and only promote live fencing as a secondary economic activity for smallholder farmers. This will avoid competition with food crops and lost economic potential from alternative cash crops.

(2) Commit any remaining funding from the SNBP to intensive data collection and research initiatives for Jatropha agronomy, with a focus on yield and resilience. Soil analyses and regional suitability for Jatropha cultivation must be assessed.

(3) Create a standard, guaranteed price for Jatropha seed in all regions, with designated market access points and transparent transactions. Farmers will only pursue Jatropha as an economic activity if there are government purchase assurances.

(4) Accelerate the extension of farm implements, fertilizers and pesticides to existing plantations, and disseminate information on best practices to smallholder farmers.

(5) Facilitate access to low cost project financing and loans to promote investment.

(6) Commit resources to build regional pressing facilities and byproduct processing plants to ensure that local communities can add value to their Jatropha feedstock and maximize economic gain at the point of production.

\section{Long-term Action Points:}

(7) Redraft the Senegal National Biofuel Program with reasonable and attainable goals, with clearly defined timelines and responsibilities for the appropriate government agencies involved in its implementation.

(8) Increase efforts to share information between existing Jatropha industry members and promote exchanges with neighboring West African nations. A strong sub-regional network of practitioners would be collectively better positioned to tackle the challenges of developing this nascent biofuel market, set contracts with external buyers, and develop norms for fuel purity, grading, labeling, etc. 
(9) Develop a fuel blending program with clear and realistic targets to integrate Jatropha biofuel production into the national fuel distribution system

(10) Legislate biofuel subsidies, loan guarantees, tax incentives and carbon credit schemes to bring the cost of domestic biofuel down to compete with imported fossil fuels.

(11) Ensure that domestically produced fuel stays in the domestic market, and regulate against export schemes .

(12) Evaluate other biofuel feedstocks, such as castor, sunflower and sugar cane, which have shown equal promise and could help diversify the biofuel market.

\subsection{Areas of Further Study}

This research uncovered several areas of further study that would contribute to our understanding of the field of Jatropha biofuel production and the valorization of domestic biofuels in general. As the culture of Jatropha for biofuel is still quite recent, there is a wide gap in both the technical and socio-political aspects of successful implementation that need to be filled. The following list includes what this research found to be the key areas of future research.

(1) First and foremost, agronomic research needs to focus on improved growth and field characteristics for Jatropha to deliver more consistency in performance and yield. No single factor will have a greater impact on the success of this field than improved feedstock performance.

(2) An in-depth analysis of Jatropha byproducts and their potential economic value would allow biofuel producers to improve the economies of fuel production.

(3) The carbon sequestration value of Jatropha plants is still quite uncertain and makes the carbon credit auditing process lengthy and costly. Generating a more practical standard could expand this credit access to many more farmers.

(4) The use of non-refined Jatropha oil in standard engines could have detrimental effects on the long term performance and shorten the lifetime of such motors. Early work suggests motors need to operate at close to full charge/power to avoid unwanted carbon buildup, but further research into this area could greatly facilitate commercial adoption.

(5) An analysis of the various commercial arrangements between Jatropha farmers and commercial operators on an international scale would allow new producers to evaluate the best business model to pursue in different socio-economic environments. 


\subsection{Final Remarks}

Creating a domestic biofuel production system that is environmentally sensitive, economically viable and fair to local communities is an immense challenge. The Senegal National Biofuel Program was a clear failure of policy creation and implementation, and has left many farmers skeptical of such initiatives. The clear message from this research is that policy realism, consistency and continuity are vital to the success of such programs, and they must be driven by long term projections with reasonable expectations rather than bold, short term goals motivated by political posturing.

The production of biologically based fuels cannot be the sole motivation for such programs, and taking into account the impact on local communities and environmental risks such as detrimental land use change must be factored into the initial cost-benefit analysis. Any future initiatives to promote biofuels in Senegal must be grounded in sound data collection, draw in relevant experience from neighboring countries, and involve a reasonable period of due diligence to avoid undue harm to vulnerable rural communities.

This study contributes to our understanding of the challenges facing liquid biofuel production programs, and answers critical questions pertaining specifically to the Senegal National Biofuel Program that had been left unanswered. This initial work can guide future researchers who seek to develop comprehensive energy networks that are well adapted to their respective environmental and socio-economic conditions. The findings from this study suggest that a solution to local energy production and consumption could still be a decade or more away, and the research community will need to play a large role in achieving this goal.

Although several policy recommendations are proposed in the previous sections, they are put forward subject to a more thorough understanding of the impacts of biofuel subsidies, fixed market prices and guaranteed financing structures and their cost implications for the state. These are matters that this study could not address, and should be examined carefully before any new policy measures are put into place. As indicated repeatedly in this thesis, consistency is of paramount importance, and therefore policy changes must be carefully weighed and measured to ensure that they can stand the test of time.

It was a great pleasure to preform this research, and I was inspired time and again by the resilience of the Senegalese people, whose drive and tenacity in the face of harsh environmental and economic conditions will eventually deliver them the prosperity envisioned by the SNBP. I hope that this work contributes meaningfully to the body of knowledge concerning biofuels, and helps bring the people of Senegal closer to their development goals. 


\section{References}

Achten WMJ, Verchot L, Franken YJ, Mathijs E, Singh VP, Aerts R, Muys B (2008). Jatropha bio-diesel production and use. Biomass and Bioenergy 32(12), 1063-1084

Achten, W.M.J., et al. (2009). Jatropha: From global hype to local opportunity, Journal of Arid Environments, doi:10.1016/j.jaridenv.2009.08.010

Ackerman, F., Stanton, E., DeCanio, S., \& others. (2009). The Economics of 350: The benefits and costs of climate stabilization. Portland: Economics for Equity and Environment

ADECIA, (2012). Rapport sur les politiques publiques en faveur des biocarburants a base de cultures paysannes de Jatropha au Mali et au Burkina Faso. Agence pour le développement de la cooperation internationale dans les domaines d l'agriculture, de l'alimentation et des espaces ruraux (ADECIA). 16 December, 2012

Akintayo, (2004). Characteristics and composition of Parkia biglobbossa and Jatropha curcas oils and cakes. Bioresource Technology, 92 (2004), pp. 307-310

Amatayakul, W., and G. Berndes. (2007). Fuel ethanol program in Thailand: energy, agricultural, and environmental trade-offs and prospects for $\mathrm{CO}_{2}$ abatement. Energy for Sustainable Development 11(3):51-66.

Antizar-Ladislao, B., \& Turrion-Gomez, J. L. (2008). Second-generation biofuels and local bioenergy systems. Biofuels, Bioproducts and Biorefining, 2(5), 455-469.

BAD, (2006). High oil prices and the African economy. Ouagadougou, Burkina Faso. From: Dia Djiby, Sakho-Jimbira, M.S., Fall, C.S., Ndour, A., and Dieye, P.N., (2010). "Energetic crisis and space reconstruction in Senegal: traditonal crops vs biofuels?" Sud, Sciences \& Technologies, Semestriel n ○19-20, December 2010

Banerji et al., (1985). R. Banerji, A.R. Chowdhury, G. Misra, G. Sudarsanam, S.C. Verma, G.S. Srivastava. Jatropha seed oils for energy. Biomass, 8 (1985), pp. 277-282

Baxter, P., \& Jack, S. (2008). Qualitative case study methodology: Study design and implementation for novice researchers. The Qualitative Report, 13(4), 544-559.

Berndes, G. (2002). Bioenergy and water--the implications of large-scale bioenergy production for water use and supply. Global Environmental Change, 12(4), pp. 253-271.

Berndes, G., M. Hoogwijk, and R. van den Broek (2003). The contribution of biomass in the future global energy supply: a review of 17 studies. Biomass and Bioenergy, 25(1), pp. 1-28.

Braun, V., \& Clarke, V. (2006). Using thematic analysis in psychology. Qualitative Research in Psychology, 3(2), 77-101. doi: 10.1191/1478088706qp063oa

Burkina Faso, (2009). Document Cadre de Politique de Développement des Biocarburants au Burkina Faso. Ministère des Mines des Carrières et de L'Energie. October 2009

Camblong, H., Sarr, J., Niang, A. T., Curea, O., Alzola, J. A., Sylla, E. H., \& Santos, M. (2009). Microgrids project, Part 1: Analysis of rural electrification with high content of renewable energy sources in Senegal. Renewable Energy, 34(10), 2141-2150.

Chamberlin, J. 2008. It's a small world after all: defining smallholder agricultural in Ghana. Discussion Paper 00823. International Food Policy Research Institute, Washington, D.C., USA. 
Christensen, J. M., Mackenzie, G. A., Pedersen, M. B., \& Campus, R. (2012). Enhancing access to electricity for clean and efficient energy services in Africa.

Chum, H., A. Faaij, J. Moreira, G. Berndes, P. Dhamija, H. Dong, B. Gabrielle, A. Goss Eng, W. Lucht, M. Mapako, O. Masera Cerutti, T. McIntyre, T. Minowa, K. Pingoud, (2011) Bioenergy. In IPCC Special Report on Renewable Energy Sources and Climate Change Mitigation [O. Edenhofer, R. Pichs-Madruga, Y. Sokona, K. Seyboth, P. Matschoss, S. Kadner, T. Zwickel, P. Eickemeier, G. Hansen, S. Schlömer, C. von Stechow (eds)], Cambridge University Press, Cambridge, United Kingdom and New York, NY, USA.

Chynoweth, D. P., Owens, J. M., \& Legrand, R. (2001). Renewable methane from anaerobic digestion of biomass. Renewable energy, 22(1), 1-8.

CIA, (2009). Senegal. The World Factbook.

Coulibaly, (2013) Le Jatropha curcas ou Pourghere : veille plants, nouvel usage; evolution des perceptions paysannes et insertion de la plante dans les systèmes de production paysannes a Mangodara. Masters Thesis final report. June 2013. 115p.

Creswell, J. W. (2012). Qualitative inquiry and research design: Choosing among five approaches. Sage.

De Fraiture, C., M. Giordano, and Y. Liao (2008). Biofuels and implications for agricultural water uses: blue impacts of green energy. Water Policy, 10(S1), pp. 67-81.

Delucchi, M. A. (2010) Impacts of biofuels on climate change, water use, and land use. Annals of the New York Academy of Sciences. Blackwell Publishing Inc., 1749-6632. pp 28-35

Dia Djiby, Sakho-Jimbira, M.S., Fall, C.S., Ndour, A., and Dieye, P.N., (2010). "Energetic crisis and space reconstruction in Senegal: traditonal crops vs biofuels?" Sud, Sciences \& Technologies, Semestriel n¹9-20, December 2010

Diedhiou, I. Dia, D., Fall, Cheickh (2010) From: La Grande Muraille Verte. Dia, A., \& Duponnois, R. (Eds.). (2010). Le projet majeur africain de la Grande Muraille Verte: concepts et mise en œuvre. IRD Editions.

Diouf, B., Pode, R., \& Osei, R. (2013). Initiative for 100\% rural electrification in developing countries: Case study of Senegal. Energy Policy, 59, 926-930.

Divakara, B. N., Upadhyaya, H. D., Wani, S. P., \& Gowda, C. L. (2010). Biology and genetic improvement of $<\mathrm{i}>$ Jatropha curcas $</ \mathrm{i}>$ L.: A review. Applied Energy, 87(3), 732-742.

Dong, L., Liu, H., \& Riffat, S. (2009). Development of small-scale and micro-scale biomass-fuelled CHP systems-A literature review. Applied thermal engineering, 29(11), 2119-2126.

EIA (2013). International Energy Outlook 2013. U.S. Energy Information Administration. July 2013.

Eisentraut, A. (2010). Sustainable production of second-generation biofuels: potential and perspectives in major economies and developing countries (No. 2010/1). OECD Publishing.

ENDA/Energie (2006), Rôle des énergies renouvelables sur le développement des activités productives en milieu rural ouest africain : le cas du Sénégal. Rapport final, mars 2005, 50 p.

ENDA, (2010). Rapport Final: Approvisionnement durable en Energie: Production et Importation de la biomasse et des carburants biogènes. Programme Energie Environnement Développement. Rapport Final, Avril 2010, 41p.

Enefebio (2007), Synthèse des enquêtes au sein des PME au Sénégal. Lettre d'information n¹, 4 p.

EU, (2011). Assessing the impact of biofuels production on developing countries from the point of view of Policy Coherence for Development. Contract Number 2012/299193- Final Report February 2013 
Ewing, M., \& Msangi, S. (2009). Biofuels production in developing countries: assessing tradeoffs in welfare and food security. Environmental Science \& Policy, 12(4), 520-528.

Faye I.M., Benkahla A., Touré O., Seck S.M., Ba C.O., (2011), Les acquisitions de terres à grande échelle au Sénégal : description d'un nouveau phénomène, Initiative Prospective Agricole et Rurale, 45 p.

Fereday, J., \& Muir-Cochrane, E. (2008). Demonstrating rigor using thematic analysis: A hybrid approach of inductive and deductive coding and theme development. International journal of qualitative methods, 5(1), 80-92.

Food and Agriculture Organization (FAO). 2008. The state of food and agriculture biofuels: prospects, risks and opportunities. FAO, Rome, Italy.

Fischer, G., E. Hizsnyik, M. Shah, and H. Velthuizen. 2009. Biofuels and food security: implications of an accelerated biofuels production. Summary of the OFID prepared by International Institute for Applied Systems Analysis. OFID Pamphlet Series. The OPEC Fund for International Development, Vienna, Austria.

Foidl, N., Eder, P., (1997). Agro-industrial exploitation of J. curcas. In: Gübitz, G.M., Mittelbach, M., Trabi, M. (Eds.), Biofuels and Industrial Products from Jatropha curcas. Dbv-Verlag, Graz, Austria.

Francis, G., Edinger, R., \& Becker, K. (2005). A concept for simultaneous wasteland reclamation, fuel production, and socio-economic development in degraded areas in India: Need, potential and perspectives of Jatropha plantations. In Natural Resources Forum (Vol. 29, No. 1, pp. 12-24). Blackwell Publishing, Ltd.

German, L., G. C. Schoneveld, and P. Pacheco 2011. The social and environmental impacts of biofuel feedstock cultivation: evidence from multi-site research in the forest frontier. Ecology and Society 16(3): 24.

Goldemberg, J., \& Teixeira Coelho, S. (2004). Renewable energy - traditional biomass vs. modern biomass. Energy Policy, 32(6), 711-714.

GTZ, (2009). Jatropha Reality Check: A field assessment of the agronomic and economic viability of Jatropha curcas and other oilseed crops in Kenya. German Technical Cooperation. Final Report. Nairobi, December 2009. 146p.

Gübitz, G. M., Mittelbach, M., \& Trabi, M. (Eds.). (1997). Biofuels and industrial products from Jatropha curcas (pp. 978-3704102423). Dbv-Verlag für die Technische Universität Graz.

Gübitz, G. M., Mittelbach, M., \& Trabi, M. (1999). Exploitation of the tropical oil seed plant< $>$ Jatropha curcas</i $>$ L. Bioresource Technology, 67(1), 73-82.

Guest, G., MacQueen, K. M., \& Namey, E. E. (2012). Applied thematic analysis. Los Angeles: Sage Publications.

Hagan, (2007). Biofuels Assessment Report, ECOWAS subregion. AU/Brasil/UNIDO Biofuels seminar in Africa. 30 July-1 August, 2007. Addis Ababa, Ethiopia.

Harvey, M., \& Pilgrim, S. (2011). The new competition for land: Food, energy, and climate change. Food Policy, 36, S40-S51.

Hathie, I. (2013) Energy and Food Security in Sub-Saharan Africa: Global Crisis, Local Impacts. Hathie, Ibrahima and Yiyugsah, Benedict. Woodrow Wilson International Center. January 2013. 21 p.

Havlík, P., Schneider, U. A., Schmid, E., Böttcher, H., Fritz, S., Skalský, R., ... \& Obersteiner, M. (2011). Global land-use implications of first and second generation biofuel targets. Energy Policy, 39(10), 5690-5702. 
Hay, I., and Rosamond, B. 2002. "Globalization, European Integration and the Discursive Construction of Economic Imperatives.” Journal of European Public Policy 9 (2): 147-167.

Heller, Joachim (1996). Physic nut. Jatropha curcas L. Promoting the conservation and use of underutilized and neglected crops. 1. Institute of Plant Genetics and Crop Plant Re- search, Gatersleben/ International Plant Genetic Resources Institute, Rome.

Hill, J., Nelson, E., Tilman, D., Polasky, S., \& Tiffany, D. (2006). Environmental, economic, and energetic costs and benefits of biodiesel and ethanol biofuels. Proceedings of the National Academy of Sciences, 103(30), 11206-11210.

Hunsberger, C. (2014). Jatropha as a biofuel crop and the economy of appearances: experiences from Kenya. Review of African Political Economy, 41(140), 216-231.

IATA (2009). Report on Alternative Fuels. International Air Transport Association, Montreal, Canada, 92 pp.

IEA-OECD, (2008). Deploying renewables: principles for effective policies. Executive summary; 2008.

IEA Bioenergy, (2009). Bioenergy: A Sustainable and Reliable Energy Source. Main Report. IEA Bioenergy: ExCo:2009:06, 108 pp.

IEA (2010). Key World Energy Statistics 2010. International Energy Agency, Paris, France, 82 pp.

IEA, (2011). International Energy Agency in World Energy Outlook 2011, 546-547

IEA (2013). World Energy Outlook 2013 Executive Summary. International Energy Agency, Paris, France. 8p.

IMF (2008). World Energy Outlook 2008. International Monetary Fund. October 2008.

Igoe, J. (2010). "The Spectacle of Nature in the Global Economy of Appearances: Anthropological Engagements with the Spectacular Mediations of Transnational Conservation." Critique of Anthropology 30 (4): 375-397.

IPAR, (2012). Impact des investissements agricoles italiens dans les biocarburants au Senegal. Rapport Final. Avril 2012.60p.

IPCC, (2011). IPCC Special Report on Renewable Energy Sources and Climate Change Mitigation. Prepared by Working Group III of the Intergovernmental Panel on Climate Change [O. Edenhofer, R. Pichs-Madruga, Y. Sokona, K. Seyboth, P. Matschoss, S. Kadner, T. Zwickel, P. Eickemeier, G. Hansen, S. Schlömer, C. von Stechow (eds)]. Cambridge University Press, Cambridge, United Kingdom and New York, NY, USA, 1075 pp.

IPCC, (2013): Climate Change 2013: The Physical Science Basis. Contribution of Working Group I to the Fifth Assessment Report of the Intergovernmental Panel on Climate Change [Stocker, T.F., D. Qin, G.-K. Plattner, M. Tignor, S.K. Allen, J. Boschung, A. Nauels, Y. Xia, V. Bex and P.M. Midgley (eds.)]. Cambridge University Press, Cambridge, United Kingdom and New York, NY, USA, 1535 pp.

IRENA, (2013). West Africa Power Pool: Planning and Prospects for Renewable Energy. The International Renewable Energy Agency. Final Report 2013. 96 p.

ISRA (2009), Programme spécial Biocarburants, Dakar, MAP, 16 p.

JatroREF, (2012). Le Tourteau de Jatropha, Quelles pistes sur sa Valorisation? December 2012.

JatroREF, (2012b). Pole D’Expertise “Production D’Huile. Etat des Lieux 2012. January, 2013.

JatroReF. (2012c). Elements sur l'organization de la production de Jatropha au Mali: Chemin parcouru et obstacles rencontres par les opérateurs. December 2012 
JatroREF, (2013). Atlas de la Production D’Huile de Jatropha; Benin, Burkina-Faso, Mali et Senegal. January 2013.

Jessop, B. (2004). "Critical Semiotic Analysis and Cultural Political Economy." Critical Discourse Studies 1 (2): 159-174.

Johnson, R. B., \& Christensen, L. B. (2004). Educational research: Quantitative, qualitative, and mixed approaches. Boston, MA: Allyn and Bacon.

Johnson, R. B., \& Turner, L. A. (2003). Data collection strategies in mixed methods research. In A.Tashakkori, and C. Teddlie (Eds.), Handbook of mixed methods in social and behavioral research (pp. 297-319). Thousand Oaks, CA: Sage.

Johnson, R. B., \& Onwuegbuzie, A. J. (2004). Mixed methods research: A research paradigm whose time has come. Educational researcher, 33(7), 14-26.

Jongschaap REE, (2007). Corre' WJ, Bindraban PS, Brandenburg WA. Claims and facts on Jatropha curcas L. Wageningen, The Netherlands: Plant Research International, 2007

Jumbe, C.B.L., Msiska, F.B.M., Madjera, M. (2009) Biofuels development in Sub-Saharan Africa: Are the policies conducive? Energy Policy, 37 (11), pp. 4980-4986.

Kandpal and Madan, (1995) Jatropha curcus: a renewable source of energy for meeting future energy needs. Renewable Energy, 6 (2) (1995), pp. 159-160

Keyzer, M. A., Merbis, M. D., \& Voortman, R. L. (2008). The biofuel controversy. De Economist, 156(4), 507-527.

Kojima, M., \& Johnson, T. (2005). Potential for biofuels for transport in developing countries. Energy Sector Management Assistance Programme, World Bank.

Kumar et al., (2003). M.S. Kumar, A. Ramesh, B. Nagalingam. An experimental comparison of methods to use methanol and Jatropha oil in a compression ignition engine. Biomass and Bioenergy, 25 (2003), pp. 309-318

Laser, M., E. Larson, B. Dale, M. Wang, N. Greene, and L.R. Lynd (2009). Comparative analysis of efficiency, environmental impact, and process economics for mature biomass refining scenarios. Biofuels, Bioproducts and Biorefining, 3(2), pp. 247-270.

LPDSE, (1997). Republique de Senegal. Lettre de Politique de Developpement du Secteur de L'Energie.

LPDSE, (2003). Republique de Senegal. Lettre de Politique de Developpement du Secteur de L'Energie.

LPDSE, (2008). Republique de Senegal. Lettre de Politique de Developpement du Secteur de L'Energie.

Mali Biocarburant, (2014). Sustainable Production of Biofuels in West Africa. Carbon Credits. Online at: http://www.malibiocarburant.com/malibioen/carbon-credits

MMEE, 2012. http://www.mmee.gov.ml

Molden, D. (ed.) (2007). Water for Food, Water for Life: A Comprehensive Assessment of Water Management in Agriculture. Earthscan, London, UK.

MSLGROUP (2012). Image: European Commission classification of first and second generation biofuels. From: The new regulatory framework on promotion and use of biofuels in the EU. MSLGROUP Brussels. Final Report. October 2012.

Naik, S. N., Goud, V. V., Rout, P. K., \& Dalai, A. K. (2010). Production of first and second generation biofuels: a comprehensive review. Renewable and Sustainable Energy Reviews, 14(2), 578-597.

Nordel (2008). Annual Report. Nordel, Helsinki, Finland, 23 pp 
Openshaw, K. (2000). A review of $<\mathrm{i}>$ Jatropha curcas $</ \mathrm{i}>$ : an oil plant of unfulfilled promise. Biomass and Bioenergy, 19(1), 1-15.

Parliament of Australia, (2013). Emissions Trading Schemes Around the World. 6 June 2013. Online at: http://www.aph.gov.au/About_Parliament/Parliamentary_Departments/Parliamentary_Library/pubs/ BN/2012-2013/EmissionsTradingSchemes

PANGEA, (2012) Annual Report. Partners for Euro-African Green Energy. Brussels, Belgium 2012

Ramanik, (2003). Properties and use of Jatropha curcas oil and diesel fuel blends in compression ignition engine. Renewable Energy, 28 (2003), pp. 239-248

Rahmstorf, Stefan (2008). "Anthropogenic Climate Change: Revisiting the Facts". In Zedillo, E. (PDF). Global Warming: Looking Beyond Kyoto. Brookings Institution Press. pp. 34-53.

République du Sénégal, (2007). Programme spécial Bio- carburants. Dakar, MDRA, 24 p.

République du Mali, (2008). Strategie National Pour le Developpement des Biocarburants. Direction Natinoal de L'Energie. January 2008

Schoneveld, G. C. (2010). Potential land-use competition from first generation biofuel expansion in developing countries. Occasional Paper 58, Center for International Forestry Research, Bogor, Indonesia.

Schoneveld , G. C., L. A. German, and E. Nutakor. 2011. Land-based investments for rural development? A grounded analysis of the local impacts of biofuel feedstock plantations in Ghana. Ecology and Society 16(4): 10.

Shanahan, T. M., Overpeck, J. T., Anchukaitis, K. J., Beck, J. W., Cole, J. E., Dettman, D. L., ... \& King, J. W. (2009). Atlantic forcing of persistent drought in West Africa. Science, 324(5925), 377-380.

Sharma, S.D., Gupta, S.N., Khabiruddin, M., (1997). Cultivation of Jatropha curcas as a future source of hydrocarbon and other industrial products. In: Gübitz, G.M., Mittelbach, M., Trabi, M. (Eds.), Biofuels and Industrial Products from Jatropha curcas. Dbv-Verlag, Graz, Austria.

Shah et al., (2004). S. Shah, A. Sharma, M.N. Gupta. Extraction of oil from Jatropha curcas L. seed kernels by enzyme assisted three phase partitioning. Industrial Crops and Products, 20 (2004), pp. 275-279

SIE-Sénégal (2007), Système d’Information Énergétique du Sénégal. Rapport annuel.

Simpson, B. (2009). Mission report regarding the potential use of Jatropha curcas as an additional source of fuel and income for farmers in the Senegal River Delta. On request of USAID. October 2009, $35 \mathrm{p}$.

Sims, R., P. Mercado, W. Krewitt, G. Bhuyan, D. Flynn, H. Holttinen, G. Jannuzzi, S. Khennas, Y. Liu, M. O’Malley, L. J. Nilsson, J. Ogden, K. Ogimoto, H. Outhred, Ø. Ulleberg, F. van Hulle, (2011). Integration of Renewable Energy into Present and Future Energy Systems. In IPCC Special Report on Renewable Energy Sources and Climate Change Mitigation [O. Edenhofer, R. Pichs-Madruga, Y. Sokona, K. Seyboth, P. Matschoss, S. Kadner, T. Zwickel, P. Eickemeier, G. Hansen, S. Schlömer, C. von Stechow (eds)], Cambridge University Press, Cambridge, United Kingdom and New York, NY, USA.

Sorda, G., Banse, M., \& Kemfert, C. (2010). An overview of biofuel policies across the world. Energy policy, 38(11), 6977-6988. 
Strauss, P. (2009). Einfluss des Frequenzverhaltens kleiner Generatoren und las- ten auf Stromnetze unter besonderer Berücksichtigung großer Netzstörungen. Dissertation, University of Kassel, Kassel, Germany, 128 pp.

Szabo, S., Bodis, K., Huld, T., \& Moner-Girona, M. (2011). Energy solutions in rural Africa: mapping electrification costs of distributed solar and diesel generation versus grid extension. Environmental Research Letters, 6(3), 034002.

Tashakkori, A., \& Teddlie, C. (1998). Mixed methodology: Combining qualitative and quantitative approaches. Applied Social Research Meth- ods Series (Vol. 46). Thousand Oaks, CA: Sage.

Terren, M., Jacquet de Haveskercke, P., Winandy, S., \& Mergeai, G. (2012). Attempted cultivation of Jatropha curcas L. in the lower Senegal river valley: story of a failure. Tropicultura, 30(4).

Tsai, W. T., \& Chou, Y. H. (2006). An overview of renewable energy utilization from municipal solid waste (MSW) incineration in Taiwan. Renewable and Sustainable Energy Reviews, 10(5), 491-502.

Tsing, A. (2000). "Inside the Economy of Appearances. Review of July 5, 2010." Public Culture 12 (1): 115-144.

UNDP and WHO, (2009) Energy Access Situation in Developing Countries: A Review Focusing on the Least Developed Countries and Sub-Saharan Africa. United Nations Development Programme \& World Health Organization, New York (2009)

UN-Water (2007). Coping with Water Scarcity: Challenge of the Twenty-First Century. Prepared for World Water Day 2007, United Nations, New York, NY, USA, 29 pp.

Vermeulen, S. and Cotula, L., (2010), Making the most of agricultural investment: a survey of business models that provide opportunities for smallholders, IIED/FAO/IFAD/SDC; London/Rome/Bern.

WEC (2013). 2013 World Energy Issues Monitor. World Energy Council. London 2013.

Weitzman, M. (2011). Fat-Tailed Uncertainty in the Economics of Catastrophic Climate Change. Harvard University.

Wen, Y., Tang, M., Sun, D., Zhu, H., Wei, J., Chen, F., \& Tang, L. (2012). Influence of climatic factors and soil types on seed weight and oil content of Jatropha curcas in Guangxi, China. Procedia Environmental Sciences, 12, 439-444.

WIESENHÜTTER, J., (2003). Use of the physic nut (Jatropha curcas 1.) to combat desertification and reduce poverty. GTZ, Germany.

Wiesenthal, T., Schade, B., Chritidis, P., Leduc, G., \& Pelkmans, L. (2007). Analysis of biofuel support policies. In Proceedings of the 15th Biomass Conference and Exhibition (pp. 7-11).

Wiesenthal, T., Leduc, G., Christidis, P., Schade, B., Pelkmans, L., Govaerts, L., \& Georgopoulos, P. (2009). Biofuel support policies in Europe: lessons learnt for the long way ahead. Renewable and Sustainable Energy Reviews, 13(4), 789-800.

Wolfram, C., Shelef, O., \& Gertler, P. J. (2012). How will energy demand develop in the developing world? (No. w17747). National Bureau of Economic Research.

World Bank. 2010. World development indicators. World Bank, Washington, D.C., USA.

Yin, R. K. (2003). Case study research: Design and methods (3rd ed.). Thousand Oaks CA: Sage. d

Youm, I., Sarr, J., Sall, M., \& Kane, M. M. (2000). Renewable energy activities in Senegal: a review.

Renewable and Sustainable Energy Reviews, 4(1), 75-89. 


\section{Appendices}

\section{A. Senegal National Biofuel Program}

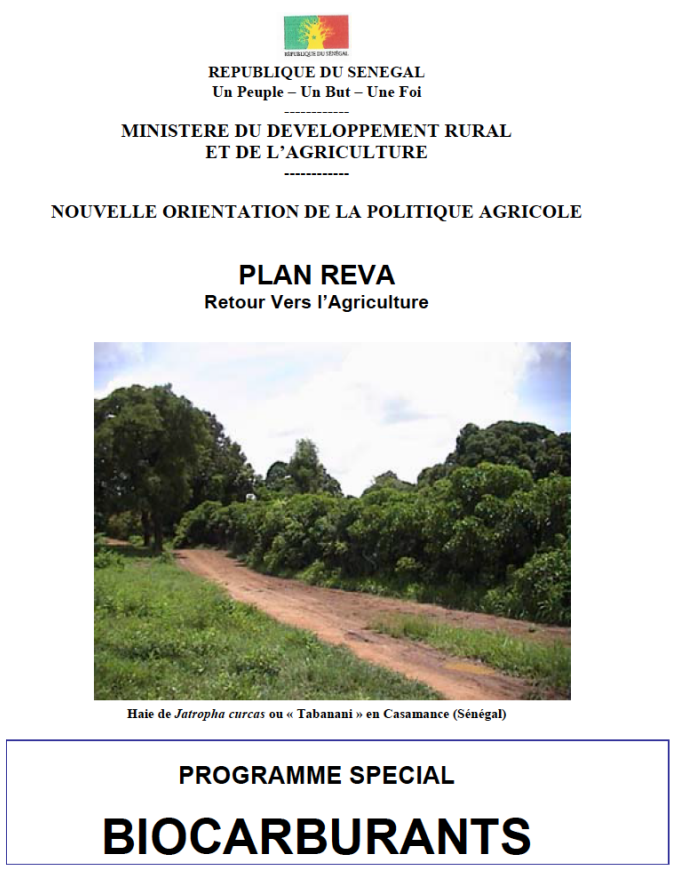

M. Hamath $S A L L$
Le Ministre

Le Ministre

Juillet 2007

PROGRAMME SPECIAL JATROPHA CURCAS

Production de graines attendue : 3210000 tonnes par an à partir de 2012

Production d'huile brute : 1190000000 litres

Production d'huile raffinée ou biodiésel : 1134000000 litres

Surface à emblaver : 321000 hectares

Besoins énergétiques actuels de type diésel du Sénégal

1. GASOIL : 462000 tonnes $=550000 \mathrm{~m}^{3}$

$=550000000$ litres

2. GAZ BUTANE : 150000 tonnes $=300000 \mathrm{~m}^{3}$

$=300000000$ litres

3. PETROLE LAMPANT : 8300 tonnes $=10500 \mathrm{~m}^{3}$

$=10500000$ litres

4. DIESEL OIL : 200000 tonnes $=235000 \mathrm{~m}^{3}$

$=235000000$ litres

TOTAL 1095500000 litres

Coût du programme : 647800300000 FCFA (129560060 dollars US)

Localisation : 321 Communautés Rurales.

Objectifs : Autosuffisance énergétique du Sénégal.

\section{Pour la periode juin 2007 - decembre 2007}

Surface à emblaver : 5000 hectares

Coût du programme : 1,5 milliards FCFA ( 3 millions de dollars US)

\section{PROJET BIOCARBURANT 2007/2012}

\section{RESUME DU PROGRAMME}

Objectifs du Programme : Production de un milliard cent quatre vingt dix millions (1 190000 000) de litres d'huile brute de Jatropha curcas.

Option: Espèce Jatropha curcas, Pourghère en français et "Tabanani » en Oulof.

Espèce peu exigeante en eau et présente au Sénégal à l'état naturel, utilisée dans le monde rural comme haies vives et en pharmacopée.

Durée de vie du Jatropha curcas : Cinquante (50) années environ

Type de plantations: Plantations massives, haies vives, bordures des maisons et des routes, délimitation des parcelles de cultures dans les zones du Centre, de l'Est et du Sud du pays.

I. PREMIERE PHASE DU PROGRAMME : la production de graines de Jatropha curcas 2007/2012.

1. Objectif de production de graines de Jatropha curcas : $3210000 \mathrm{~T}$ par an à partir de 2012 .

2. Superficie à emblaver : $321000 \mathrm{Ha}$ à raison de $1000 \mathrm{Ha}$ par Communauté Rurale en moyenne

3. Origine des semences : Sénégal, Mali, Inde.

4. Méthodes de multiplication: semis direct, pépinières, cultures in vitro (clonage), repiquage de plants et plantation de boutures.

5. Objectifs de production de plants : 802500000

5.1 Objectifs de pépinières : 1000000000 de plants (cultures in vitro).

5.2 Repiquage de boutures locales : 1000000 de boutures

6. Forme de diffusion du matériel végétal : Distribution aux producteurs et aux porteurs de projet selon les superficies demandées par le comité technique

national dirigé par un Coordonnateur du programme et supervisé par le Président de l'Association National des Conseillers Ruraux (ANCR) du Sénégal. 7. Densité de plantation à l'hectare : 2500 plants

8. Géométrie de plantation : interligne $2 \mathrm{~m} \times 2 \mathrm{~m}$

9. Rendement moven à l'ha: rendement progressif $0,5 \mathrm{~T}$ à la première année, $5 \mathrm{~T}$ à la troisième année, 8 à $9 \mathrm{~T}$ à la quatrième année et 10 à $12 \mathrm{~T}$ à la cinquième année, il est retenu un rendement moyen de $10 \mathrm{~T}$ à 1 'ha à partir de la cinquième année

10. Rendement en huile de la plante : $37 \%$

$10 \mathrm{~T}$ de graines pressées donnent 3700 litres d'huile brute de Jatropha, biodiesel équivalent au gasoil conventionnel, 1050 litres d'huile brute donnent 1000 litres d'huile raffinée.

11. Caractéristiques du biodiesel de Jatropha :

Comparaison de l'huile brute de Jatropha curcas ou « Tabanani » à d'autres combustibles à base d'huile

L'huile de Tabanani est un biodiesel très performant, contrairement aux autres biodiesels, elle peut être utilisée sans mélange et sans modification des moteurs.

Les autres biodiesels issus des plantes oléagineuses telles que le tournesol, le soja, le colza, le ricin et le coton, par exemple, sont mélangés au diesel conventionnel jusqu'à une proportion de $30 \%$ maximum; ce qui fait que les perspectives qu'offre le Jatropha sont incomparables aux autres dans le domaine du diesel ou de la substitution au gasoil conventionnel.

En ce qui concerne les alcools, comme l'éthanol, extraits des cultures qui renferment des sucres ou de l'amidon telles que la canne à sucre, la betterave à sucre ou les plantes à tubercules (manioc, pomme de terre), la proportion de mélange avec l'essence classique est d'environ de $17 \%$. Toutefois, le Brésil qui est en avance sur tout le monde a un objectif de $25 \%$.

Il convient de faire remarquer que tous les mélanges requièrent des moteurs spéciaux. C'est pourquoi le Tabanani offre, de par ses caractéristiques, les perspectives les plus avantageuses pour les pays producteurs que tous les autres biodiesels et alcools. 
D'ailleurs, le tableau suivant donne une idée claire des avantages que présente l'huile de Jatropha curcas par rapport aux autres huiles.

\begin{tabular}{|c|c|c|c|}
\hline & $\begin{array}{c}\text { Densité à } 20^{\circ} \mathrm{C} \\
\text { (g/cm3) }\end{array}$ & $\begin{array}{c}\text { Viscosité à } 20^{\circ} \mathrm{C} \\
\text { (cSt) }\end{array}$ & $\begin{array}{c}\text { Point de } \\
\text { combustion } \\
\left({ }^{\circ} \mathrm{C}\right)\end{array}$ \\
\hline Gasoil & 0,830 & 6 & 70 \\
\hline Huile brute de Jatropha curcas & 0,920 & 77 & 236 \\
\hline Huile raffinée de Jatropha curcas & 0,907 & Faible viscosité & 205 \\
\hline Biodiesel produit à partir du soja & 0,920 & 61 & 330 \\
\hline Biodiesel produit à partir du & 0,925 & 58 & 316 \\
\hline Tournesol & & & \\
\hline $\begin{array}{l}\text { Biodiesel produit à partir de } \\
\text { l'Huile de palme }\end{array}$ & 0,915 & 60 & 230 \\
\hline $\begin{array}{l}\text { Biodiesel produit à partir du } \\
\text { Coton }\end{array}$ & 0,921 & 73 & 243 \\
\hline $\begin{array}{l}\text { Biodiesel produit à partir de } \\
\text { Arachide }\end{array}$ & 0,914 & 85 & 258 \\
\hline
\end{tabular}

Arachide

Biodiesel : utilisable directement dans les moteurs diesel sans mélange et sans modification

Biofuel : utilisable comme biofuel dans les centrales pour la production de la bioélectricité (expérience au Mali).

\section{Coût de la première phase de production de graines de Jatropha :}

64780030000 F CFA

II. DEUXIEME PHASE : transformation des graines de Jatropha en huile

1. Les presses oul unités légères de trituration

Il existe des presses pour la trituration des graines de Jatropha dont certain types sont utilises au Mali et dont le cout est equivalent à celui des moulins a mil, environ $1500000 \mathrm{~F}$ CFA. Elles sont généralement d' origine indienne ou d fabrication locale sous l'encadrement d'ONG dans les pays où elles existent. 1 Ha produisant $10 \mathrm{~T}$ equivalent de 3700 litres de biocarburant pour un coût endre le litre d'huile Jatropha à $100 \mathrm{~F} \mathrm{CFA}$ avec un bénéfice de $50 \%$.

2. Centrales de production de biodiese
PROJET BIOCARBURANT 2007/2012

\section{CONTEXTE ET JUSTIFICATION}

En hausse continue, les cours du pétrole ont franchi, en juillet 2006, la barre des 75 dollars le baril (13 dollars en 1998) et dans le même temps, les prévisions révélaient une tendance à la hausse jusqu'en fin 2006. Les conséquences de ces hausses intempestives qui sont le fait de la spéculation influent de manière négative sur les économies des Pays Africains Non Producteurs de Pétrole (PANNP) et hypothèquent leur développement.

La facture pétrolière des PANNP est très élevée et le Sénégal ne fait pas exception. Entre 2000 et 2005 , elle est passée de 184 à 370 milliards de FCFA. Les subventions pétrolières du Sénégal qui se chiffraient à 23 milliards en 2002 devraient atteindre 117 milliards de FCFA en 2006.

En plus de l'allègement de cette facture pétrolière, les perspectives d'épuisement des réserves fossiles dans un horizon prévisible, les défis environnementaux (réchauffement climatique, protection de l'environnement) et le respect des conventions internationales (Protocole de Kyoto sur les émissions de gaz à effet de serre, ratifié par le Sénégal) constituent des enjeux importants.

Tel est le contexte général qui a poussé le Président de la République Maître, Abdoulaye WADE, à convoquer à Dakar une conférence internationale des Pays Non Producteurs de Pétrole en vue de définir une stratégie commune face à la flambée des prix de l'or noire et de ses conséquences négatives sur leurs économies. Le Président de la République ne s'est pas d'ailleurs arrêté là, il a inventé la formule WADE qui préconise le partage équitable des surplus provenant de la vente du pétrole par les multinationales.

Par ailleurs, les autorités nationales des pays de $1^{\prime}$ UEMOA $^{1}$ se sont engagés à promouvoir les bioénergies/biocarburants dont le biodiesel qui est fabriqué à partir de l'huile végétale. Ainsi ces pays s'orientent vers la tansformation de la production locale de graines oléagineuses en biodiesel et l'importation d'huile alimentaire.

Convaincu que la maîtrise de l'énergie constitue un vecteur essentiel pour

${ }^{1}$ Union Économique et Monétaire Ouest Africaine
Il n'existe pas pour le moment de données précises pour évaluer le coût d'opportunité d'une centrale de production de biodiesel.

Toutes les compagnies qui s'intéressent au Jatropha, faute de données réelles, mènent des études de faisabilité à partir de recoupement en référence, à d'autres filières similaires.

\section{TROISIEME PHASE : Distribution}

\section{Création de nouvelles stations de vente du biodiesel:}

Il peut être envisagé la création de stations spécialisées dans la vente du biodiesel au Sénégal.

\section{Utilisation des stations d'essence traditionnelles}

Les stations traditionnelles pourront également être utilisées pour la distribution des biocarburants. atteindre un des Objectifs du Millénaire pour le Développement (OMD), à savoir l'élimination de la pauvreté, le Chef de l'Etat sénégalais, Son Excellence Maître Abdoulaye Wade a également préconisé le développement, à l'échelle continentale des énergies renouvelables en s'inspirant de l'expérience brésilienne. A cet effet, une conférence des ministres des pays non producteurs de pétrole (PANPP) s'est tenue à Dakar en juillet 2006 avec la création d'une association et la mise en place d'un comité pluridisciplinaire chargé de la promotion des biocarburants.

En novembre 2006, cette volonté politique s'est traduite par la création d'un Ministère chargé des Biocarburants. Cette substitution au pétrole devrait permettre de booster le développement économique et social des PANPP grâce à la mise en place d'une vraie fillière.

En conséquence, le Sénégal s'est lancé dans la production de Biocarburants.

Le Sénégal a ainsi décidé de mettre l'accent prioritairement, sur la promotion du Jatropha Curcars (nom scientifique), Pourghère (en Français) ou "Tabanani » (en Wolof) qui est une espèce forestière semi ligneuse, non alimentaire qui pousse naturellement au Sénégal. Il n'a pas également occulté la nécessité de prospecter d'autres filières telles que le palmier à huile (projet avec les malaisiens), la canne à sucre qui donne un alcool (l'éthanol), le ricin ou Xexam, malaisiens), la carnesol.

La Compagnie Sucrière du Sénégal (CSS), quant à elle envisage de transformer la bagasse issue de la canne à sucre en éthanol.

Le biocarburant est devenu une réalitê.

Son utilisation réduit les émissions de gaz à effet de serre.

Aussi, la quantité de gaz carbonique émise par les biocarburants est-elle compensée par la captation du carbone lors de la croissance des plantes.

A cet effet, il est en voie de devenir le " carburant écologique " de choix de certains pays d'Amérique du Sud, d'Asie et d'Europe.

Le biocarburant est une chance pour l'avenir des pays non producteurs de pétrole.

Le développement de ce type d'énergie en Afrique est d'autant plus pertinent qu'il profite à la disponibilité d'immenses terres cultivables, ce qui constitue un avantage comparatif certain. L'Afrique pourrait ainsi devenir le premier 
fournisseur mondial de biocarburants

Toutefois, l'avantage le plus palpable est la réduction de la facture pétrolière pour les Etats et pour les ménages.

Cette énergie renouvelable est aussi intéressante du point de vue de l'emploi car locales. Elle fait appel à une main d'oeuvre de proximité et à des professions préexistantes.

Son apparition dans des pays comme le Sénégal contribuera à freiner l'exode rural et l'émigration clandestine.

En définitive, les biocarburants représente une énergie à bon marché et un atout pour l'indépendance énergétique et pour l'environnement notamment, l'amélioration de la qualité des sols.

\section{OBJECTIFS}

Il s'agit de produire 1190000000 de litres d'huile brute de Jatropha curcas, soit 1134000000 de litres d'huile raffinée utilisable comme biodiesel.

L'objectif fondamental est ainsi de réaliser l'autosuffisance énergétique nationale par la production de bioénergie de substitution en augmentant et en

Le développement des biocarburants entre dans le cadre des orientations définies par la Stratégie de Croissance Accéléré (SCA), le Document de Stratégie de Sylvo Pastorale et les Objectifs du Millénaire pour le Développement (OMD).

Les objectifs visés sont les suivants :

$>$ Diversification des cultures

> Baisse de la facture pétrolière des ménages et de l'Etat.

$>$ Indépendance énergétique

- Autosuffisance en diesel à partir de 2012 par la satisfaction des besoins. à partir du biodiesel issu du Jatropha curcas et d'autres espèces.

> Production d'éthanol à partir de cultures comme la canne à sucre.

> Production de bioélectricité à partir de centrales qui fonctionnent à l'huile brute de Jatropha. elle constitue un moyen de production décentralisé et adapté aux ressources diversifiant significativement la production agricole. Réduction de la Pauvreté (DRSP), le Plan REVA, la Loi d'Orientation Agro

$20 \%$ et un objectif de $75 \%-25 \%$ en 2007 ). Il faut toutefois signaler que l'écobilan de bioéthanol n'est pas très bon à cause du faible rendement de la fermentation alcoolique qui produit beaucoup de dioxyde de carbone.

\section{Biodiesel}

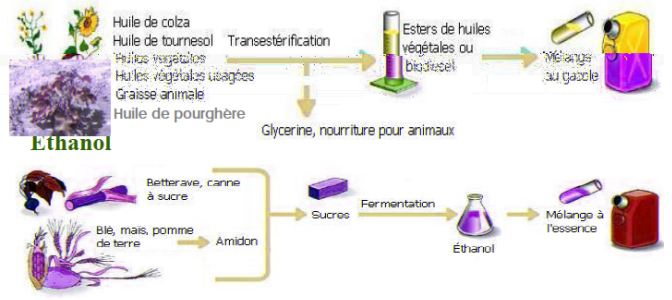

2. La filière des huiles végétales ou du biodiesel pour les moteurs diesel

Le biodiesel est de l'huile végétale pure (HVP) produit à partir de ressources renouvelables telles que les huiles de grains oléagineux. les graisses de cuisson recyclées et les déchets de graisses animales. Le biodiesel est un carburant à combustion propre destiné au remplacement du diesel issu du pétrole. Le biodiesel est jusqu'à plus de $70 \%$ moins polluant que le gasoil et ne rejette pas de produits dangereux dans l'atmosphère.

L'huile de Tabanani, contrairement aux autres biodiesels, peut être utilisée sans mélange et sans modification des moteurs tandis que les autres biodiesels issus des plantes oléagineuses telles que le toumesol, le soja, le colza, le ricin et le coton par exemple sont mélangés au diesel classique jusqu'à une proportion de $30 \%$ maximum. Le Jatropha est ainsi pour le moment le seul biodiesel capable de se substituer au gasoil classique.

Le procédé classique de fabrication de biodiesel en général est appelé transestérification et consiste à faire réagir un alcool (méthanol ou éthanol) sur de l'huile végétale pré-traitée en présence d'un catalyseur (soude) : voir Figure ci-cessus. Cette technologie permet de produire à partir d'une tonne d'huile $110 \mathrm{~kg}$ de méthanol. $970 \mathrm{~kg}$ de biodiesel et $108 \mathrm{~kg}$ de glycérine.

En général, les moteurs fonctionnant au gasoil doivent être modifiés dans la

plupart des cas pour fonctionner au biodiesel.

> L'expérience est en cours au Mali avec l'électrification de villages à partir de cette plante.

$>$ Création des métiers agricoles et d'emplois suffisamment

rémunérateurs environ 100000 emplois directs.

$>$ Accélération de la modernisation du secteur agricole

$>$ Création d'un environnement du monde rural attractif et attrayant.

> Amélioration de la balance commerciale et celle des paiements.

$>$ Amélioration de l'environnement

> Réduction de la pauvreté et de la disparité entre le monde rural et le monde urbain.

\section{LA FILIERE DES BIOCARBURANTS}

Les biocarburants sont des carburants issus de la biomasse. Ils peuvent se substituer partiellement (ou totalement) aux carburants pétroliers fossiles. Les biocarburants obtenus à partir de plantes terrestres résultent principalement de trois (3) filières: la filière huile (colza, palmier à huile, tournesol, Jatropha, ricin etc.), la filière alcool (betterave, blé, canne à sucre, pomme de terre, maïs etc.) et la filière biogaz dont les produits sont issus de la transformation des déchets végétaux et organiques.

\section{La filière éthanol ou filière alcool pour les moteurs à essence}

Produit à partir de matières agricoles riches en sucre (canne à sucre, betterave) ou en amidon (maïs, manioc, pomme de terre, blé, etc.) ou de déchets de bois par le procédé de fermentation, l'éthanol est une alternative à l'essence (voir Figure ci-après). Son utilisation requiert des modifications sur les moteurs à essence classique. Grand producteur de canne à sucre, le Brésil est leader mondial dans la production d'éthanol.

L'éthanol est un alcool qui peut être utilisé comme carburant pour les voitures à essence. Il peut aussi être obtenu à partir d'hydrocarbures, mais dans ce cas on parle d'éthanol et non de bioéthanol.

Le bioéthanol est produit et utilisé à grande échelle au Brésil à partir de la canne à sucre. Les voitures pourraient être conçues pour rouler à l'éthanol pur. Cependant, à l'état actuel, elles roulent avec un mélange essence-éthanol (80\%-
En effet, le gasoil est issu d'une huile minérale appelée pétrole. Pour passer à $100 \%$ de l'huile minérale à l'huile végétale, il suffit d'ajuster le moteur pour l'adapter à la viscosité du biocarburant utilisé. En dehors de ca, il n' y a pas de différence majeure, si ce n'est que l'huile végétale est meilleure pour les moteurs car elle contient de l'oxygène. Elle est même recommandée pour les vieilles mécaniques et pour l'environnement dans les grandes villes.

3. la filière biogaz (méthane) pour les centrales électriques : Produit sous forme gazeuse, par fermentation sans oxygène, à partir de matières organiques (traitement de déchets alimentaires, déchets végétaux, résidus de cultures...).

IV. LE JATROPHA CURCAS OU JATROPHA = POURGHERE (nom français) et TABANANI (nom Oulolof)

\section{Le Jatropha Curcas une plante adaptée au Sénégal}

Le Jatropha curcas est toutefois une plante d'origine latino-américaine, répandue en zones tropicales arides et semi-arides, bien adapté aux conditions édapho-climatiques (sols filtrants : sableux ou à dominante sableuse, isohyètes $300-400$ à plus de $1000 \mathrm{~mm}$ par an, fortes températures,...)

Le genre Jatropha comprend des plantes dicotylédones de la famille des Euphorbiaceae. Comme pour la plupart des Euphorbiaceae, les fruits (baies) et la sève sont toxiques. On dénombre environ 160 espèces de Jatropha à travers le monde, les plus connues étant :

- Jatropha curcas dont la graine fournit une huile à usage industriel qui peut être utilisée comme biocarburant ;

- Jatropha gossypifolia dont l'huile est purgative et la racine utilisée contre la lèpre ;

Jatropha integerrima à la floraison rouge décorative :

- Jatropha multifida (arbre corail) dont les feuilles sont consommées au Mexique ;

- Jatropha phyllacantha, plante du Brésil aussi appelée favela ;

En conséquence, les caractéristiques de l'huile de Jatropha curcas justifient le choix de l'espèce pour le programme spécial Biocarburants du Sénégal.
- Jatropha podagrica, plante ornementale très prisée 
En outre, il est bien connu au Sénégal. Il y pousse à l'état naturel, principalement dans les régions du centre, Diourbel, Kaolack, Fatick et du Sud Est, Tambacounda, Kolda et Casamance. On le trouve sous forme de fortes concentrations dans des zones du Sud-Est ou sous forme de haies vives le long des bordures des routes et des pourtours de maisons.

Les haies vives de Jatropha servent à clôturer les maisons rurales, à délimiter les périmètres des champs, à empêcher l'accès des animaux en divagation, à servir de brise vent et à lutter contre l'érosion hydrique et éolienne des sols.

Les racines de la plante se développent tout près de la surface du sol arrêtant ou ralentissant l'eau de ruissellement comme des digues, augmentant le rendement des récoltes.

Sa sève est utilisée pour soigner des blessures, ses feuilles comme tisane contre certaines infections.

Les animaux ne mangent pas les feuilles de cet arbre.

L'huile de Jatropha est aussi utilisée comme lubrifiant, savon et les tourteaux comme fertilisants (expérience très rentable au Mali)

Le tourteau issu des graines de Jatropha pressées est un engrais organique de haute valeur comparable au fumier des poules.

\section{L'huile de Jatropha curcas:}

L'huile brute de Tabanani extraite des graines est filtrée et utilisée directement comme carburant dans les moteurs diesel sans aucune transformation.

Cependant, une légère modification au niveau du moteur est requise pour permettre l'alternance entre l'huile de Tabanani et le gasoil.

La consommation d'huile de Tabanani est pareille à celle du gasoil et elle donne la même force. L'huile de Tabanani utilisée comme carburant peut faire fonctionner les moulins motorisés, les moteurs, les motopompes, les groupes électrogènes et les véhicules diesel, sans la mélanger avec le gasoil.

Elle n'exige pas de traitement chimique. En effet 1050 litres d'huile brute donnent 1000 litres d'huile raffinée comme biocarburant de meilleure qualité que le gasoil qui est polluant.
- 1999 à 2000, essais d'extraction et d'utilisation de l'huile de Jatropha par l'ONG Enterprise Works ex ATI International : fabrication de presses locales, fonctionnement de moulins à mil.

- 2003, plantations de Jatropha par le PROGEDE dans ses zones d'intervention : haies vives autour des périmètres maraîchers, plantations massives.

- 2006, Primé par le «Development Market Place» le PROGEDE va acquérir des véhicules multiservices fonctionnant avec l'huile de Jatropha.

- 2005-2006: Capitalisation d'expériences au Brésil (mission d'experts brésiliens au Sénégal : octobre 2006, programme conjoint de partenariat sur le Jatropha en cours de finalisation, textes brésiliens attendus comme référence pour l'élaboration d'un cadre réglementaire pour le Sénégal,...) et au Mali (visite d'échanges effectuée par les technicien du Ministère).

- Utilisation de presse de graines de Tabanani par le PROGEDE.

- Invention au Sénégal d'un réchaud à huile de Jatropha pour la cuisson des aliments.

\section{Initiatives pour la mise en cuvre du Programme spécial de} production de Jatropha

- Recherches effectuées pour la connaissance du matériel végétal existant au Sénégal et la maîtrise des techniques de multiplication de plants :

onformément à la volonté du Chef de l'Etat, l'Institut Sénégalais de Recherche gricole (ISRA) qui a mené des recherches sur le Jatropha curcas a mis en ace un programme de recherches sur les biocarburants pour contribuer à la ise en œuvre de ce programme pilote de production d'un (1) milliard de plants. z programme permettra d'assurer un niveau de production de biomasse tisfaisant et la base de l'implantation d'une filière "Biocarburants" au snégal.

¿s activités ont notamment porté sur :

- L'élaboration d'une synthèse bibliographique sur le Jatropha

Or, les autres cultures biodiesel annuelles telles que, la canne à sucre sont des alcools comme l'éthanol et sont mélangées à l'essence à un pourcentage faible, 17 à $20 \%$ à l'heure actuelle.

En Inde et dans plusieurs pays l'huile de Tabanani fait fonctionner des véhicules, des trains et des groupes électrogènes.

La découverte du Tabanani est récente et tous les pays dont le Sénégal sont au même point de départ, toutefois avec une légère avance du Brésil, de l'Inde et de l'Indonésie qui ont déjà fait des avancées en matière de recherche.

\section{Avantages du Jatropha}

Le Jatropha curcas est une espèce très rustique et très plastique, résistant à des climats semi-arides et pouvant facilement pousser sur des sols relativement pauvres. Sa culture pourrait permettre de protéger les sols de l'érosion (fixation des sols) et de retenir l'eau (amélioration du bilan hydrique) aidant, ainsi, à lutter contre la désertification.

Le Jatropha curcas est une espèce peu exigeante en eau, en fertilisants et en entretien pouvant pousser presque partout au Sénégal, même sur des sols gravillonnaires, sableux ou salés (terres marginales), en zones semi-aride et/ou humide. Elle peut se développer là où il n'existe guère d'autres activités agricoles. Elle peut donc, sans entrer en compétition avec l'agriculture destinée à l'alimentation, constituer un nouvel outil de développement comme nouvelle filière agricole.

Le Jatropha curcas peut produire des graines dès la deuxième année de plantation et cette production peut durer environ 50 ans. Les graines deviennent mûres lorsque la couleur de la capsule vire au jaune. La production de graines varie de $0,5 \mathrm{~T}$ à l'hectare durant la première année à plus de $15 \mathrm{~T}$ l'hectare à la cinquième année.

L'espèce est généralement plantée en plein ou en lignes sous forme de haies vives. En plein, la densité optimale de plantation recommandée en Inde est de 1'ordre de 2500 plants par hectare (écartement de $2 \mathrm{~m} \times 2 \mathrm{~m}$ ) mais des densités plus faibles (1 666 plants par hectare) ont également été adoptées dans des systèmes pluviaux localisés dans des sites où les sols étaient plus pauvres.

Des initiatives probantes peuvent également être notées au Sénégal : documentation des connaissances sur la plante. conservation de matériel végétal de Jatropha et de ricin sous diverses formes: différentes provenances de semences du Sénégal en chambre froide, boutures jaugées, plants issus de semis plantés, vitroplants.

- La Mise au point de protocoles de multiplication de plants.

- Tests de culture in vitro effectués et concluants : test de germination in vitro, choix du type d'explants à utiliser, mode de désinfection des explants, milieux de culture à utiliser, temps nécessaire pour assurer une bonne acclimatation des vitroplants..

- Tests de multiplication en pépinière/serre : test de germination des graines, semis direct de Jatropha, bouturage avec différentes tailles de d'hormones de croissance, ...

Tests et validation de l'effet améliorateur de la mycorhization sur la croissance des jeunes plants de Jatropha en plantation ; ce qui permettra d'améliorer l'installation des plantes en milieu réel (sites de production).

- Plantation test d'1 hectare de Jatropha avec des plants issus de pépinières et de boutures.

- Création d'un comité technique national par arrêté ministériel pour la mise en œuvre du programme spécial Jatropha.

- Nomination d'un Coordonnateur national du Programme.

- Désignation du superviseur du programme en la personne du Président de l'Association Nationale des Conseillers Ruraux du Sénégal.

- Elaboration de la carte nationale du Jatropha.

- Recensement des périmètres de cultures du Jatropha dans chaque Communauté Rurale.
La Constitution d'une collection d'écotypes locaux et la boutures (différents nombres de nœuds), utilisation de différentes doses 


\section{BESOINS ENERGETIQUES DU SENEGAL}

Les besoins énergétiques du Sénégal sont assez importants et pèsent très lourdement sur le budget annuel de l'Etat. Ils sont estimés à 370 milliards de $\mathrm{F}$ CFA en 2005 alors que les subventions pétrolières du Sénégal qui se sont chiffrées à 23 milliards de F CFA en 2002 sont passées à 117 milliards de F CFA en 2006. Il est très facile de mesurer le déséquilibre budgétaire produit au Sénégal par la hausse vertigineuse du pétrole dont le baril est passé de 13 dollars en 1998 à 75 dollars en juillet 2006 .

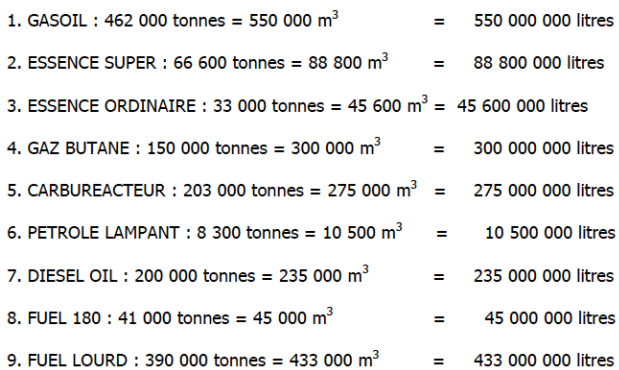

4682900000 litres

Source : Ministère de l'Energie, des Mines, et de l'Industrie du Sénégal \begin{tabular}{|c|c|c|c|}
\hline TOTAL(FCFA) & $\mathbf{6 4 7 8 0 0 3 0 0 0 0}$ & 201 807 F CFA/Ha \\
\hline $\begin{array}{l}\text { NB : Si l'Etat investit pour le compte des paysans } 201807 \text { F / Ha il assure l'implantation } \\
\text { définitive de la filière Biocarburant an Sénégall }\end{array}$
\end{tabular}

VII. EVALUATION DU COUT D'EXPLOITATION POUR LE PAYSAN A PARTIR DE LA $1{ }^{\text {ere }}$ ANNEE DE PRODUCTION

Le coût annuel de l'engrais à l'Ha : 10000 F CFA

Le coût du matériel agricole à l'Ha : $20000 \mathrm{~F} \mathrm{CFA}$; amortissement : 4 000F/Ha Coûts de production pour un hectare de Jatropha curcas à partir de la lère année de production
2ème 3ème 4ème 5ème 6ème

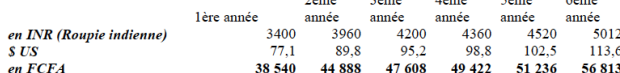

$\begin{array}{lrrrrrr}\text { SUS } & 77,1 & 89,8 & 95,2 & 98,8 & 102,5 & 113,6 \\ \text { en FCFA } & 38540 & \mathbf{4 4 8 8 8} & 47608 & \mathbf{4 9 4 2 2} & \mathbf{5 1 2 3 6} & \mathbf{5 6 8 1 3}\end{array}$

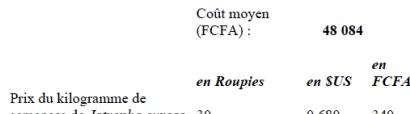

$0,680 \quad 340$

La moyemne annuelle des frais d'exploitation de la $1^{\text {c̀rc }}$ année à la $5^{\text {cmc }}$ année de production : $50000 \mathrm{~F} \mathrm{CFA}$

Coût de production moven pourr un hectare de Jatropha curcas
VI. EVALUATION DU COÛT DU PROJET

Superficie emblavée : $321000 \mathrm{Ha}$

\begin{tabular}{|c|c|c|c|}
\hline & Désignation & Montant $F C F A)$ & Observations \\
\hline Sous total 1 & $\begin{array}{l}\text { Construction et équipement du } \\
\text { laboratoire de culture in vitro }\end{array}$ & 458500000 & \\
\hline \multirow{4}{*}{$\begin{array}{l}\text { Production de } \\
1000000000 \text { de } \\
\text { plants pour } 321000 \\
\text { Ha avec un taux de } \\
\text { perte de 20\% }\end{array}$} & Acquisition des semences & 218280000 & \multirow{4}{*}{$\begin{array}{c}\text { Coût d'un plant à la } \\
\text { sortie du laboratoire } \\
\text { est d'environ } 54 \mathrm{~F} \\
\text { CFA }\end{array}$} \\
\hline & 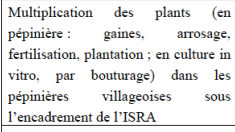 & 52172250000 & \\
\hline & \begin{tabular}{|l} 
Serres d'acclimatation \\
\end{tabular} & 524000000 & \\
\hline & Serres d'endurcissement & 524000000 & \\
\hline \multirow[t]{7}{*}{$\begin{array}{l}5 \text { Sous total } 2 \\
\end{array}$} & & 53441530000 & \\
\hline & $\begin{array}{lll}\text { Appui institutionnel au } & \text { au } \\
\text { fonctionnement des laboratoires de } & \text { de } \\
\text { culture in vitro et stations de } \\
\text { démonstration des plantations de } \\
\text { l'ISRA }\end{array}$ & 200000000 & \\
\hline & $\begin{array}{l}\text { Formation des producteurs pour la } \\
\text { réalisation de pépinières villageoises }\end{array}$ & 50000000 & \\
\hline & $\begin{array}{c}\text { Subvention de l'Etat pour } \\
\text { l'acquisition des engrais et des } \\
\text { produits phytosanitaires } \\
\end{array}$ & 3210000000 & $\begin{array}{c}\text { Subvention }=100000 \\
\quad F \text { la tonne } \\
\text { Dose }=100 \mathrm{Kg} / \mathrm{Ha}\end{array}$ \\
\hline & $\begin{array}{l}\text { Subvention du matéricl agricole } \\
\text { tracteur }\end{array}$ & 6420000000 & $\begin{array}{c}-2 \text { tracteurs/CR } \\
\text { - Coût d'un tracteur }+ \\
\text { equipement }= \\
20000000 \text { F CFA } \\
\text { - Subvention } 50 \%\end{array}$ \\
\hline & Encadrement des paysans & 1000000000 & 5 ans \\
\hline & & 10880000000 & \\
\hline
\end{tabular}

en Inde

Le coût de revient annuel de l'exploitation du paysan à l'Ha : 64000 F CFA Rendement moyen en graines à l'Ha des 5 premières années $=5$ tonnes Recettes à l'Ha $60 \mathrm{~F}$ x $5000 \mathrm{Kg}=300000 \mathrm{~F} \mathrm{CFA} / \mathrm{Ha}$

Le coût d'exploitation total d'un Ha sans subvention mais cela suppose que le paysan dispose de tous les moyens, ce qui n'est pas le cas $=78000 \mathrm{~F} \mathrm{CFA}$

Dans tous les cas le projet est rentable pour le paysan même s'il vend les graines à l'état brut.

Au Mali l'expérience montre que $12 \mathrm{~T}$ de graines transformées peuvent générer 3630 dollars (environ $1996500 \mathrm{~F} \mathrm{CFA}$ ) de revenus pour un bénéfice de 1430 dollars (environ $850000 \mathrm{~F} \mathrm{CFA}$ ), lorsque l'huile est extraite et les produits vendus.

\section{RESULTATS ATTENDUS}

> Un milliard (1 000000$)$ de plants de Jatropha curcas produits par culture in vitro, pépinière et bouturage.

> 321000 ha plantés (1 000 ha par Communauté Rurale)

$>$ Organisations de producteurs et représentants de collectivités locales formés à la production de plants par pépinière, aux techniques de plantation et à l'entretien des plants jusqu'à la première production (18 mois après plantation).

> Un milliard cent quatre vingt dix millions (1 190000000$)$ de litres d'huile de Jatropha produits pour la satisfaction totale des besoins nationaux en gasoil qui s'élèvent à 550 millions de litres en 2007.

> Production de bioélectricité et d'électricité lancées à partir d'unités locales de transformation.

$>$ Facture pétrolière du Sénégal allégée.

> Facture des ménages baissée significativement avec la réduction des coûts; le biocarburant étant à bon marché

$>100000$ emplois directs créés.

> Capacités techniques des organisations de producteurs et des collectivités locales renforcées.

> Pôles agro-industriels créés dans chaque région du Sénégal. 
- Revenus agricoles accrus et diversifiés par l'exploitation des opportunités offertes par les filières bioénergétiques émergentes.

> Conditions de vie des populations rurales améliorées grâce à l'accroissement du niveau de satisfaction de leurs besoins économiques et sociaux à travers l'utilisation de technologies avancées et adaptées, baisse significative de la pauvreté

$>$ Equilibre de la balance des paiements améliorés.

\section{STRATEGIES DE MISE EN GEUVRE DU PROGRAMME}

\section{a. Comité technique national}

Il est créé un comité technique national chargé de la mise en œuvre du programme spécial biocarburants sous l'autorité du Ministre, dirigé par un coordonnateur national et supervisé par le Président de l'Association Nationale des Conseillers Ruraux (ANCR)

Le comité technique comprend en outre, les techniciens du Ministère, les Organisations Paysannes, les Organisations Professionnelles Agricoles, les Elus locaux, les Gouverneurs Adjoints chargés du développement, les représentants des associations villageoises de jeunes et de femmes, les partenaires au développement $(\mathrm{ONG})$, projets et programmes de développement

Des superviseurs sont désignés par les organisations paysannes au niveau départemental et local.

\section{b. Multiplication des plants}

En tant qu'obtenteur des semences (prébases, bases), l'ISRA assurera, avec la participation des différents acteurs nationaux et des partenaires au développement, la production de plants nécessaires pour la mise en œuvre du programme spécial Biocarburants. La multiplication de plants se fera essentiellement par culture in vitro et par pépinières à partir des $25 \mathrm{~T}$ de semences dont une partie est déjà collectée au Sénégal par le Commissariat à la Sécurité Alimentaire.

Cette activité de multiplication de plants de Jatropha curcas, avec un objectif de 1 milliard de plants, sera conduite à travers l'implantation à l'ISRA d'un laboratoire de culture in vitro à grande capacité, suivant le modèle de

CULTESA (Centre de recherches en Biotechnologies), à Santa Cruz (Ténériffe, Espagne). Ce laboratoire qui sera financé par le Président de l'île de Ténériffe pourra également travailler sur d'autres espèces (pomme de terre, oignon...). .

Elle fera également l'objet d'une collaboration scientifique entre le CULTESA et l'Institut Sénégalais de Recherches Agricoles/Unité de Recherches en Culture in vitro (URCI) pour la mise au point de protocoles de multiplication in vitro de plants de Jatropha curcas des échanges d'expériences, la formation des techniciens...

Une mission de la Directrice du CULTESA au Sénégal sera très prochainement organisée pour l'identification et la collecte de graines des variétés locales de Jatropha curcas destinées à la multiplication de plants d'une part, et pour des échanges scientifiques avec les chercheurs de l'ISRA, d'autre part.

Après cette multiplication, les plants seront distribués aux producteurs et aux porteurs de projet selon les superficies demandées ; ces derniers étant chargés de la mise en place des plantations. Les services techniques (ISRA, ANCAR, DRDR, Inspections des Eaux et Forêts,...) seront chargés de la formation, de l'encadrement des producteurs et du suivi des plantations.

Quant à l'implantation des unités d'extraction et de transformation de l'huile de Jatropha en biodiésel et de production d'électricité, elle fera l'objet d'un partenariat entre l'Etat du Sénégal et les opérateurs étrangers qui souhaitent s'investir dans la filière dans notre pays.

\section{c. Mise en place de pépinières de production de plants et} responsabilisation des producteurs

A l'échelle nationale, des pépinières de plants de Jatropha seront implantées dans des zones favorable à la multiplication (Niayes, Vallée du Fleuve Sénégal et Anambé).

Les paysans seront propriétaires des pépinières et bénéficieront de la formation de l'ISRA et de l'encadrement des services techniques de l'Etat (ISRA, Direction de 1'Horticulture, SAED, ANCAR, Directions Régionales de Développement Rural, etc.)

\section{d. Collecte de boutures}

A la demande du Ministre de l'Agriculture, les Gouverneurs, Préfets et Sous Préfets ainsi que les commissions locales chargées du développement rural ont identifié à travers le pays les zones naturelles de concentration du Jatropha curcas. Ce recensement a permis d'organiser une opération de collecte des graines par le Commissariat à la Sécurité Alimentaire.

De même, il sera organisé la collecte des écotypes locaux (boutures et semences) du Jatropha dans les différentes zones agro-écologiques du Sénégal à partir de la première semaine du mois de juillet pour leur plantation dans les communautés rurales.

Il est proposé à cet effet à Monsieur le Président de la République d'ériger le Jatropha curcas en arbre parrain pour la campagne nationale de reboisement 2007 et la généralisation de la délimitation des champs par le Jatropha curcas par anticipation du cadastre rural.

\section{ANNEXE}

Conditions de Partenariat pour l'exploitation des cultures innovantes de type Biocarburant

1. Constitution d'une Société Anonyme d'exploitation de la filière biocarburant : $51 \%$ du capital au moins pour les Sénégalais.

2. Prix au producteur garanti et suffisamment rémunérateur pour susciter l'intérêt des paysans.

3. Prix de cession du biodiesel à l'Etat ou aux Organismes habilités, arrêté par une convention Etat- Partenaires.

4. Encadrement et assistance en intrants agricoles et techniques garantis aux agriculteurs par les promoteurs.

5. Les terres appartiennent à la collectivité et ne font pas l'objet de cession ou de bail.

6. Prix de vente public des produits finis conseillé, afin d'accroître les retombées positives sur les ménages.

7. Transformation sur place, au Sénégal, de la matière première. 


\title{
B. Participant Information Sheet
}

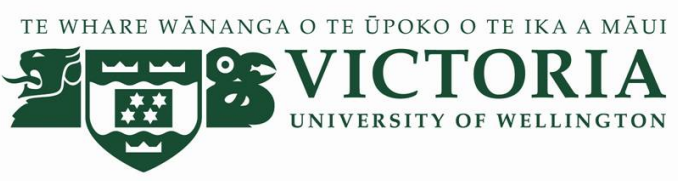

\section{Hope or Hype: A Socio-economic Assessment of Jatropha Curcas for Biofuel Production in Senegal}

\begin{abstract}
Information Sheet for Interview Participants
Thank you for your participation in this research. Please read this information sheet before your interview.

Researcher: David Campbell, School of Geography, Environment and Earth Sciences

I am a Masters student in Environmental Studies at Victoria University of Wellington. In fulfillment of this degree I am undertaking research to produce a published thesis.

This research is being conducted to gain an understanding of the domestic biofuel industry in Senegal, and particularly whether it can be sustainably developed independent of government intervention. This research aims to explore the policies and economic activities related to the Senegalese biofuel industry, especially concerning the plant feedstock Jatropha Curcas. I will be interviewing a range of people involved in decision-making and planning of the biofuel market as well as policymakers, academics, entrepreneurs, business owners and government officials.
\end{abstract}

\section{Interview Format:}

This interview will take approximately $30-60$ minutes of your time. It is based on a semistructured format so the exact nature of the questions have not been determined in advance but will depend on the way that the interview develops. Should the line of questioning progress in a way that makes you uncomfortable you can decline to answer any question(s) at any stage. You may, at any time, request statements to be off the record.

\section{Participation:}

Your participation is completely voluntary and you can leave the interview at any time and may withdraw from the study by 31 June, 2014. Although every effort will be made to keep participant identity confidential, this cannot be guaranteed as some participants may be identifiable to close acquaintances due to the nature of their comments.

\section{Data Use and Storage:}

The data collected will be securely stored in such a way that only the researcher and the researcher's university supervisor will be able to gain access to it. At the end of the project any 
personal information will be destroyed immediately, except that on which published results rely. These data will be stored securely for a period of five years.

One or more articles may be submitted to scholarly journals and the research may form the basis of conference presentations or further funding applications. You may receive a final report with the findings if you wish. You may also receive a copy of any interview transcript if you wish.

The opinions, views and statements recorded during the interviews will only be used for the purposes of this research project, plus any scholarly journal articles or further research funding applications that may result. All opinions, views and statements made by you will be attributed in the final report to a pseudonym. The pseudonym will represent the position you hold in relation to the Senegalese biofuel industry (e.g., Policymaker, Academic researcher, Business Professional).

This research has been approved by the Human Ethics Committee at Victoria University of Wellington.

If you have any further questions at any time, please contact David Campbell (details below). Thank you for your participation.

David Campbell

campbedavi1@myvuw.ac.nz

(221) 781716851
Ralph Chapman (Supervisor)

ralph.chapman@vuw.ac.nz

(64) 044636153 


\title{
C. Participant Consent Form
}

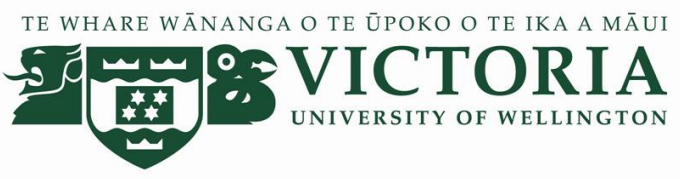

\section{Hope or Hype: A Socio-economic Assessment of Jatropha Curcas for Biofuel Production in Senegal}

\begin{abstract}
Consent Form
I have read and understood the information sheet and I understand that I can request more information at any stage. I understand that every effort will be made by the researcher to protect my identity; however some participants may be identifiable to close acquaintances due to the nature of their comments. I am aware that a pseudonym will be used to represent my opinions in the final write up of this information and consent to this.
\end{abstract}

\section{Yes / No}

I am aware that participation is purely voluntary and I can withdraw at any time, refuse to answer any questions, or retract any statements before 31 June 2014.

I am aware that I can request statements to be off the record at any time during the interview. I understand that the information I give will not be used for any purpose other than those listed below and outlined in the information sheet without my consent. I understand I will have the chance to check the transcripts prior to publication and make any comments.

I understand that data collected will be securely stored in such a way that only the researcher and the researcher's supervisor will be able to gain access to it. At the end of the project any personal information will be destroyed immediately, except that on which published results rely, which will be stored securely for a period of five years.

I would like to receive a copy of the interview after it has been transcribed: $\quad$ Yes I No I would like to receive a report of the findings at the conclusion of the research: Yes / No If yes, my postal address is: $\quad$ My email address is:

I, consent to being interviewed by David Campbell for the purposes of the research project and producing one or more journal articles, and presentations at conferences or further funding applications.

Signed:

Date: 


\section{Semi Structures Interviews}

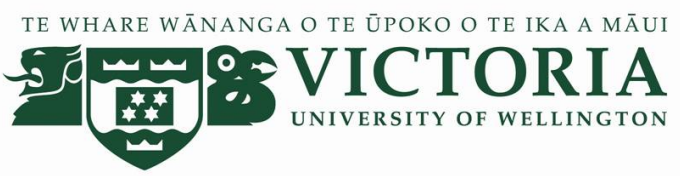

\section{Semi-Structured Interview Question Bank:}

The following questions will be used in a series of personal interviews with professionals with experience related to he Senegalese Biofuel Industry. There are questions related to financing, project development, agronomic characteristics of the plants being used, and policies relevant to these initiatives at the national and local level. Not all questions will be used in each interview. Only topics directly related to the interviewee's expertise will be addressed.

\section{Generalized Questions related to the Biofuel Industry:}

Can you describe your role in the Senegalese Biofuel Sector, whether it be academic, political, business oriented or otherwise?

What are the main barriers to implementing a sustainable biofuel industry in Senegal? Is it important?

Do you think the public is aware of these initiatives?

How was the Senegalese Biofuel Initiative created? What were the processes that were followed?

How much does legislation and policy guide the creation of such plans? Is it necessary?

How was Jatropha Curcas selected as the target feedstock for this program? Are there alternatives? What are the advantages of Jatropha?

What types of research are currently being conducted, and who is doing the research?

Where does the funding for the research come from, and what are the intended outcomes?

What type of support, be it financial/political does the government offer for biofuels?

What are the current organizations and professional networks relating to biofuel in Senegal?

How is information and knowledge shared about biofuels through these networks?

What factors are considered when developing those plans/communications? 
What are the country's future plans for biofuel development? What factors determine or influence those future plans?

What are your expectations for biofuels in Senegal now and in the future?

How are these expectations communicated to relevant interest groups?

How could these expectations be communicated more effectively to relevant interest groups?

What current policies impact the uptake of biofuel use, production, and sale?

\section{Market-Related Questions:}

How has Jatropha Curcas been used in NZ historically, and who were the original suppliers and markets?

What is the current level of demand for Jatropha, and who are the suppliers?

What forces work in favor of the Jatropha market and what work against it?

Who are the most likely users of Jatropha?

Where is Jatropha cultivated? Where is it processed for biofuel?

\section{Resource Mobilization:}

How is funding secured for research and experimental projects for Jatropha in Senegal?

What type of financial environment exists for purchasing/using Jatropha biofuel?

What other types of biofuel are available in Senegal? Are there other renewable energy forms available or being considered?

\section{International Indicators and Comparisons:}

Where does most biofuel production in West Africa come from?

What are the typical associated costs (seed stock/processing/tariffs/shipping/etc)?

Do experiences with Jatropha in other countries influence your views of biofuels in Senegal?

Do governmental policies for biofuels in other countries influence prices in Senegal?

Do prices of biofuel in other countries influence prices in Senegal? 


\section{E. Farmer Survey and Questionnaire}

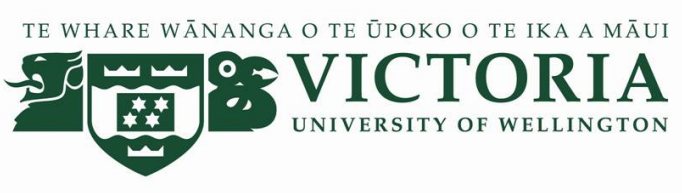

\section{Farmer Survey}

\section{TIME AND LOCATION}

Date:

Survey Number:

Region:

Kaolack

Tambacounda

Kedougou

Town/Village:

\section{FARMER IMFORMATION}

\section{Name}

Nearest Town

Are you part of a Farmer's Collective?

Do you have a regular water source?

How many working age members of your

family participate in farming tasks?

Do you have any of the following items? Circle all that apply.

Car / Motorcycle / Generator / Radio / Cell Phone /

How many wells are in your village?

Do you have a well in your fields?

Do you have cattle?

Do you have sheep?

Do you have goats? Bicycle / Donkey Cart / Tractor / Water Tank

\begin{tabular}{|ll} 
Yes $/$ & No \\
Yes $/$ & No
\end{tabular}

\begin{tabular}{cccc} 
Yes & $/$ & No & \\
\hline Yes & $/$ & No & How Many? \\
\hline Yes & $/$ & No & How Many? \\
Yes & $/$ & No & How Many?
\end{tabular}

\section{LAND USE AND AGRONOMY}

\begin{tabular}{|c|c|c|c|c|}
\hline $\begin{array}{l}\text { Current Land } \\
\text { Use }\end{array}$ & Agroforestry & Farming & Forest & Grazing \\
\hline
\end{tabular}




\section{LAND USE AND AGRONOMY}

\section{How many}

Acres?

\section{TRADITIONAL AGRICULTURAL ACTIVITY}

\begin{tabular}{|c|c|c|c|c|c|c|}
\hline $\begin{array}{l}\text { What crops } \\
\text { to you } \\
\text { grow? }\end{array}$ & Corn & Millet & Rice & Peanuts & Cotton & Other (list) \\
\hline \multicolumn{7}{|l|}{$\begin{array}{l}\text { Acres } \\
\text { planted }\end{array}$} \\
\hline \multicolumn{7}{|l|}{$\begin{array}{l}\text { Harvest kg/ } \\
\text { yr }\end{array}$} \\
\hline \multicolumn{7}{|l|}{$\begin{array}{l}\text { Cost of } \\
\text { Production }\end{array}$} \\
\hline $\begin{array}{l}\text { Price (CFA } \\
\text { kg) }\end{array}$ & & & & & & \\
\hline
\end{tabular}

\section{BIOFUELS ACTIVITY}

How many Jatropha plants are you growing?

Do you grow it in a field or as a hedge?

Field / Hedge / Intercropped

When did you first plant Jatropha?

Are there other uses for Jatropha than biofuel?

Yes / No

What are these uses?

What was the propagation method?

Seed / seedlings / cuttings / other:

Where did your seeds come from?

What types of pests affect your crops?

termites / millipedes / locusts / other:

Do you irrigate your crops?

Yes / No

If so, how often?

Do you apply fertilizer to your crops?

Yes / No

If so, how often?

Do you apply pesticide to your crops?

Yes I No

If so, how often? 


\begin{tabular}{|c|c|}
\hline \multicolumn{2}{|l|}{ BIOFUELS ACTIVITY } \\
\hline Do you weed or maintain the land? & Yes I \\
\hline \multicolumn{2}{|l|}{ If so, how often? } \\
\hline Do you prune your Jatropha bushes? & Yes I \\
\hline \multicolumn{2}{|l|}{ If so, how often? } \\
\hline Have you harvested from your crops yet? & Yes I \\
\hline In what year did your crops begin to produce & 1st / 2nd / 3rd / 4th / 5th / still no production \\
\hline \multicolumn{2}{|l|}{ Did you sell your seeds this year? } \\
\hline If yes, to whom? & $\begin{array}{l}\text { Other farmers / Merchants / Oil Processor / } \\
\text { Export Entity }\end{array}$ \\
\hline \multicolumn{2}{|l|}{$\begin{array}{l}\text { How much were you offered for your seeds per } \\
\mathrm{Kg} \text { ? }\end{array}$} \\
\hline \multicolumn{2}{|l|}{ If not sold, how did you use your seed stock? } \\
\hline $\begin{array}{l}\text { Do you grow anything else to produce } \\
\text { biofuels? If so, what plants? }\end{array}$ & Castor / Croton / Sunflower / Other: \\
\hline
\end{tabular}

\section{Farmer Questionnaire}

How did you get the idea to grow Jatropha? Have you grown it in the past?

Are there other uses for Jatropha other than for biofuel?

Did you receive government support to plant Jatropha?

Did you have to buy all of your seeds or were they given to you?

Do you receive a fair price for your seeds compared to other crops you grow?

Have you been satisfied with growing Jatropha? Has it been a good investment?

Do you feel you are better off since you started growing Jatropha?

Do you think it is important to grow crops for biofuel?

What have been your greatest challenges in cultivating Jatropha?

What kind of support do you need to continue growing Jatropha?

Before planting Jatropha in partnership with SOPREEF, did you know you could use it as a biofuel?

Have you considered abandoning your Jatropha crops for an alternative? If so, why?

Are there any other concerns regarding Jatropha that you would like to express? 


\section{F. Human Ethics Committee Clearance}

TE WHARE WĀNANGA O TE DPOKO O TE IKA A MĀUI

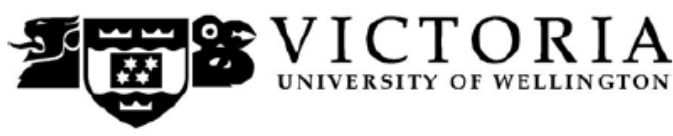

\section{MEMORANDUM}

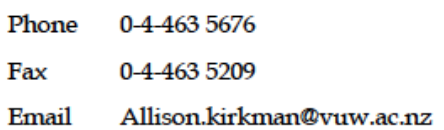

\begin{tabular}{l|l}
\hline TO & David Campbell \\
\hline COPY TO & Ralph Chapman \\
\hline FROM & Dr Allison Kirkman, Convener, Human Ethics Committee \\
\hline
\end{tabular}

\begin{tabular}{l|l}
\hline DATE & 13 March 2014 \\
\hline PAGES & 1 \\
\hline
\end{tabular}

\begin{tabular}{l|l}
\hline SUBJECT & $\begin{array}{l}\text { Ethics Approval: } 20624 \\
\text { Hope or Hype: A Socioeconomic Assessment of Jatropha Curcas } \\
\text { for Biofuel Production in Senegal }\end{array}$ \\
\hline
\end{tabular}

Thank you for your application for ethical approval, which has now been considered by the Standing Committee of the Human Ethics Committee.

Your application has been approved from the above date and this approval continues until 30 September 2014. If your data collection is not completed by this date you should apply to the Human Ethics Committee for an extension to this approval.

Best wishes with the research.

Allison Kirkman

Human Ethics Committee

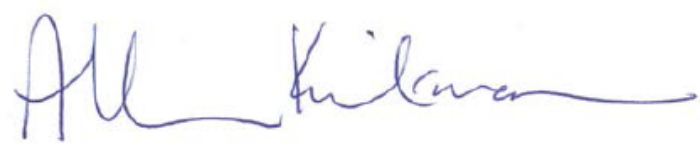

